\title{
Contests for public goods
}

Citation for published version (APA):

Heine, F. A. (2017). Contests for public goods. [Doctoral Thesis, Maastricht University]. Tilburg University. https://doi.org/10.26481/dis.20170419fh

Document status and date:

Published: 01/01/2017

DOI:

10.26481/dis.20170419fh

Document Version:

Publisher's PDF, also known as Version of record

\section{Please check the document version of this publication:}

- A submitted manuscript is the version of the article upon submission and before peer-review. There can be important differences between the submitted version and the official published version of record.

People interested in the research are advised to contact the author for the final version of the publication, or visit the DOI to the publisher's website.

- The final author version and the galley proof are versions of the publication after peer review.

- The final published version features the final layout of the paper including the volume, issue and page numbers.

Link to publication

\footnotetext{
General rights rights.

- You may freely distribute the URL identifying the publication in the public portal. please follow below link for the End User Agreement:

www.umlib.nl/taverne-license

Take down policy

If you believe that this document breaches copyright please contact us at:

repository@maastrichtuniversity.nl

providing details and we will investigate your claim.
}

Copyright and moral rights for the publications made accessible in the public portal are retained by the authors and/or other copyright owners and it is a condition of accessing publications that users recognise and abide by the legal requirements associated with these

- Users may download and print one copy of any publication from the public portal for the purpose of private study or research.

- You may not further distribute the material or use it for any profit-making activity or commercial gain

If the publication is distributed under the terms of Article $25 \mathrm{fa}$ of the Dutch Copyright Act, indicated by the "Taverne" license above, 
Contests for Public Goods 
Contests for Public Goods

(C) Florian Heine, Tilburg 2017

All rights reserved. No part of this publication may be reproduced, stored in a retrieval system, or transmitted, in any form, or by any means, electronic, mechanical, photocopying, recording or otherwise, without the prior permission in writing from the author.

This book was typeset by the author using $\mathrm{IAT}_{\mathrm{E}} \mathrm{X}$

Vector images adapted from Vector Open Stock and Photoroyalty / Freepik

Cover Font uses "Linowrite" by Lennard Glitter

Cover design by Vera Bossel

Published by Tilburg University

ISBN 978-94-6167-306-0

Printed in the Netherlands by PrismaPrint 


\title{
Contests for Public Goods
}

\author{
DISSERTATION
}

to obtain the degree of Doctor at Maastricht University, on the authority of Rector Magnificus,

Prof. Dr. Rianne M. Letschert,

in accordance with the decision of the Board of Deans,

to be defended in public on

Wednesday 19 April 2017, at 14:00 hrs.

by

Florian Andreas Heine 


\section{Supervisor:}

Prof. Dr. Arno Riedl

\section{Co-Supervisor:}

Dr. Martin Strobel

\section{Assessment Committee:}

Prof. Dr. Frank Moers (chairman)

Prof. Dr. Christine Harbring (RWTH Aachen University)

Dr. Andrzej Baranski Madrigal

Prof. Dr. Adriaan Soetevent (University of Groningen) 
To Elisabeth 



\section{Acknowledgements}

First and foremost I would like to thank my supervisors Arno Riedl and Martin Strobel, who have been the co-architects of this piece. Arno's rigorous orientation towards delivering excellent research has shaped the way I want to approach science. Your comments have been critical and insightful. I got to know Martin already during the first semester of my Master's programme at Maastricht University School of Business and Economics (SBE). Your open and amiable character has always been a catalyst for new ideas.

I extend my appreciation towards the AE1 section of SBE. The Department's generous contribution to my professional education has been nothing short of vital. Without the support and guidance that I have enjoyed, I would not feel ready to embark upon the next step in my career. My experience at Maastricht University is one for which I am extremely grateful. It has been a challenge of the best kind and I consider it an honour to have been part of this team and to have had the opportunity to learn from some of the best scholars in the profession. Christian Seel, I am grateful for the marvellous cooperation in all the courses that I have been teaching with you. Elke and Nicole, the department is clearly blessed with your excellent work and lovely spirit. Sylvia, you have my deep appreciation for all that you have done for me.

A special thank you goes out to my paranymphs, Aline and Vera who have been incredibly supportive both during the final phase and throughout the whole process of my $\mathrm{PhD}$. Aline has not only been one of the first persons I met upon my arrival in Maastricht, we became besties and I always cherish your hospitality and warm-heartedness. Vera, you have the unique talent to brighten up the grimmest day with your positive spirit. Maastricht would not have been half as pleasant without the dear Honey Badgers, most of whom I got to know during my Research Master. Anne, you are such a rich lode for advice on so many aspects of life and I admire how you can just get things done. Nadine, you can be a lot of fun to hang out with and enjoy sports. You truly are a maverick in motivation and discipline. Lennart, I miss all those nice little events we shared every week: Arkham Horror, sushi, cinema, Pizza Hut etc. Your creativity in coming up with fun social events have held our little group together. Christine, we shared the fate of being a PhD student at AE1, which created a lot of room for "casual unconstrained conversations" about our daily working life and the main actors therein. Judith, thank you for being a wonderful host for our group's get-togethers at your place and for your frolic energy.

The group of friends I made during my time in Maastricht extends beyond the Honey Badgers, of course. Henrik, Anika, Marleen, Tom, Ile, Martina, Gabri, Oana, Diogo, thank you for so many precious moments and hopefully plenty more to come. Most of this work has been written in one of the few different offices I had during my time at SBE, which 
I had the pleasure to share with Sjoerd, Aidas, Fortuna, Kutay, Pierfrancesco, Mehmet, Seher, Norman and Christine.

A significant chunk of this dissertation was created at the University of Nottingham School of Economics (UoN). I am very thankful to Martin Sefton, who has been a marvellous host at UoN and is an inspiring co-author. I will constrain the potentially endless list of great colleagues I met to my dear office mates Despoina, Georgina, Hanna, Alejandro and Sabrina, and to Valeria whose support was nothing short of pivotal. My dear 87 family has a special place in my heart. I will always dearly remember having tea with Samantha before hitting the hay, enjoying the food that our mum Jenny cooked for us, listening to the newest gossip from Jou or extinguishing Rita's fire in the kitchen.

Every now and then I have gathered the courage to leave the University environment and face the outside world. Jan and Leo, I am happy that we manage to keep in good contact despite the distance. Our intermittent reunions constitute a steady highlight in my agenda. Xander, I marvel at your creative ideas both in birthday presents or other event surprises. Quincy, I enjoy receiving and sharing the latest gossip with you. Rayyan, I will always remember our good times - blblblblblbl. Jaime, you have shared the last couple of steps of this enterprise with me and I hope that I will keep having you by my side for all other challenges ahead along the way.

I could not have put up with life in academia without the regular distraction of playing handball with some of the finest squads I could have wished for: Stolberger SV, Nottingham Handball Club and HV BFC. The atmosphere and open-heartedness of BFC's club members cannot easily be paralleled. I wish my past clubs continued success in the future!

My family has played a huge role in making me the person that I am today. Britta and Julia, I always enjoy spending time with you. Unfortunately we do not see each other that much, but the few times together are filled with joy and love. Uwe, I am thankful that you are there for them. Armin, I am glad that I can always count on you. Ursula, your achievements have set an inspirational example for me. Elisabeth, you are dearly missed. 


\section{Contents}

1 Introduction $\quad 1$

2 To Tender or not to Tender? Deliberate and Exogenous Sunk Costs in a Public Good Game 5

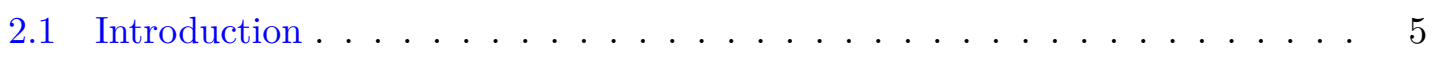

2.2 Background .......................... 7

2.2.1 Endogenous prize contests . . . . . . . . . . . . . . 7

2.2.2 Public good games with entry option . . . . . . . . . 8

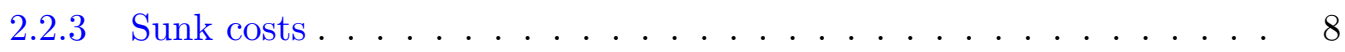

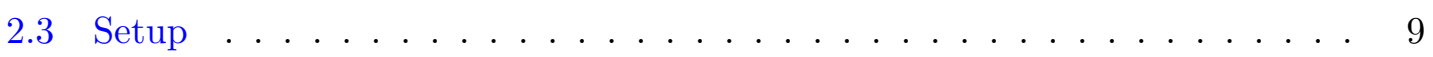

2.3 .1 Procedures . . . . . . . . . . . . . . . . 10

2.4 Equilibrium Strategies . . . . . . . . . . . . . . . . . . . . 11

2.4.1 Behavioural Hypotheses . . . . . . . . . . . . . . . . . . . 11

2.5 Results. . . . . . . . . . . . . . . . . . . . 13

2.5.1 Team Contest. . . . . . . . . . . . . . . . . 13

2.5.2 Second Stage contribution . . . . . . . . . . . . . 15

2.5.3 Relation between first and second stage contribution . . . . . . . 17

2.5.4 Regression to the mean . . . . . . . . . . . . . 22

2.6 Conclusion . . . . . . . . . . . . . . . . . . . . 23

Appendix 2.A Social Value Orientation-Measure . . . . . . . . . . . . . 24

Appendix 2.B Instructions . . . . . . . . . . . . . . . . . 25

Appendix 2.C Risk Neutral Equilibrium _. . . . . . . . . . . . . . 28 
Appendix 2.D Contest Expenditures - The Role of Beliefs . . . . . . . . . . . 29

Appendix 2.E Control Variables and OLS regression _ . . . . . . . . . . . 29

3 Reward and Punishment in a Team Contest 33

3.1 Introduction . . . . . . . . . . . . . . . . . 33

3.2 Reward and Punishment in Economic Games . . . . . . . . . . . . . . . 35

3.3 Experimental Design . . . . . . . . . . . . . . . . . . . . . . . 36

3.3.1 Equilibrium Strategies . . . . . . . . . . . . . . . . . . 39

3.3.2 Realisation of the Experiment . . . . . . . . . . . . . . 40

3.4 Results. . . . . . . . . . . . . . . . . . . . . . 41

3.4.1 Statistical Methodology . . . . . . . . . . . . . . . . . . 41

3.4.2 Contributions to the Group Account . . . . . . . . . . . . . . . 41

3.4.3 Response giving . . . . . . . . . . . . . . . . . . . 42

3.4.4 Rent dissipation . . . . . . . . . . . . . . . . 4 46

3.4.5 Individual Level Analysis . . . . . . . . . . . . . . . . . . . . 47

3.4 .6 Dynamics in Decision Making . . . . . . . . . . . . . . . . 48

3.4.7 Who receives Response? . . . . . . . . . . . . . . . . . . 49

3.5 Concluding Comments . . . . . . . . . . . . . . . . . 51

Appendix 3.A Instructions . . . . . . . . . . . . . . . . 54

Appendix $3 . B$ Stages $\ldots \ldots \ldots \ldots \ldots \ldots$

Appendix 3.C Mathematical Appendix ................ 58

Appendix 3.D Group wise Analysis of Contribution . . . . . . . . . . . . 58

Appendix 3.E Personal attributes . . . . . . . . . . . . . . . . . . 63

Appendix 3.F Response received, dyadic analysis . . . . . . . . . . . 65

4 Let's (not) escalate this! Intergroup leadership in a team contest $\quad 67$

4.1 Introduction . . . . . . . . . . . . . . . . . 67

4.2 Leadership in Economic Games . . . . . . . . . . . . . . . . . . . . 69

4.3 Setup ................................. 70 
4.3.1 Realisation of the Experiment . . . . . . . . . . . . . 72

4.4 Equilibrium Strategies ....................... 73

4.4.1 Alternative Hypotheses .................. 75

4.5 Results.............................776

4.5.1 Contest expenditures . . . . . . . . . . . . . . . . . 77

4.5.2 The Effect of Leaders' Contribution . . . . . . . . . . . . . . . 78

4.5.3 Transactional Leadership: Prize Allocation and Followers' Reaction . 80

4.5.4 Intergroup Leadership: The chat contents . . . . . . . . . . . . 83

4.5.5 Risk Aversion and Social Value Orientation . . . . . . . . . . . . 86

4.6 Conclusion ........................... 89

Appendix 4.A Measuring Risk Aversion . . . . . . . . . . . . . . . . 89

Appendix 4.B Measuring Social Value Orientation . . . . . . . . . . . . 90

Appendix 4.C Instructions ........................ 90

Appendix 4.D Risk Neutral Equilibrium . . . . . . . . . . . . . . . . 94

Appendix 4.E Risk Aversion ........................ 95

Appendix 4.F Regression Tables . . . . . . . . . . . . . . . . . . 97

$\begin{array}{llr}5 & \text { Conclusion } & 99\end{array}$

$\begin{array}{ll}\text { Valorization } & 111\end{array}$

$\begin{array}{lr}\text { Biography } & 115\end{array}$ 



\section{List of Figures}

2.1 Contribution to the Team Contest. . . . . . . . . . . . . . . . 14

2.2 Individual contribution to the team project $\ldots \ldots \ldots \ldots$

2.3 Contribution to the team project in relation to individual lottery tickets purchased . . . . . . . . . . . . . . 19

2.4 Relationship between first stage and second stage contribution and fitted regression line . . . . . . . . . . . . . . 21

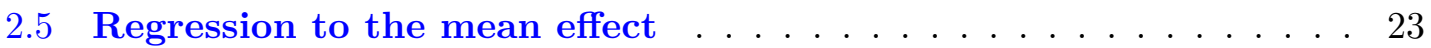

2.6 Slider questions as seen by the subjects to measure Social Value

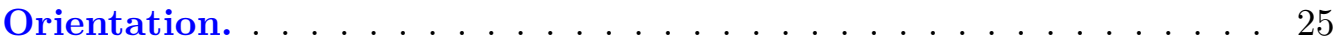

3.1 Individual contribution to the group account per treatment. Contest environment on the left, non-contest environment on the right. 42

3.2 Average contribution to the group account per treatment. Contest environment on the left, non-contest environment on the right. . . 43

3.3 Response given per treatment . . . . . . . . . . . . . . . 44

3.4 Response given per treatment f . . . . . . . . . . . . . 45

3.5 Response received in relation to deviation from average group contribution with $5 \%$ confidence interval. . . . . . . . . . . 51

3.6 Response received in relation to deviation from average group contribution with $5 \%$ confidence interval. . . . . . . . . . . . 52

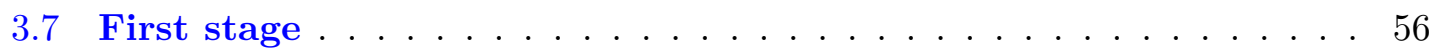

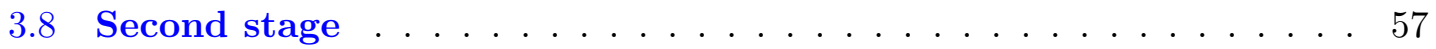

3.9 Third stage $\ldots \ldots \ldots \ldots \ldots \ldots \ldots \ldots \ldots$

3.10 Average contribution per group, reward treatment, contest environment. Paired groups are displayed together. . . . . . . . . . . 59 
3.11 Average contribution per group, punishment treatment, contest environment. Paired groups are displayed together. . . . . . . . . . 59

3.12 Average contribution per group, baseline treatment, contest environment. Paired groups are displayed together. Session for groups 3 \& 4 did not take place due to no-shows. . . . . . . . . . . . . . . 60

3.13 Average contribution per group, R\&P treatment, contest environment. Paired groups are displayed together. . . . . . . . . . . . . 60

3.14 Average contribution per group, reward treatment, non-contest environment. ........................ 61

3.15 Average contribution per group, punishment treatment, non-contest environment. . . . . . . . . . . . . . . . . . . . 61

3.16 Average contribution per group, baseline treatment, non-contest environment. Session for group 6 did not take place due to no-shows. 62

3.17 Average contribution per group, R\&P treatment, non-contest environment. . . . . . . . . . . . . . . . . . . 62

3.18 Response received in relation to deviation from sender's contribution with $5 \%$ confidence interval. . . . . . . . . . . . . . . . . 65

3.19 Response received in relation to deviation from sender's contribution with $5 \%$ confidence interval. . . . . . . . . . . . . . . 65

4.1 Contribution to the Contest .................. . 78

4.2 Contribution to the Contest over the Periods . . . . . . . . . . 79

4.3 Contribution to the Contest First Round . . . . . . . . . . . . 80

4.4 Influence of Leader's Contribution on Followers . . . . . . . . . . . . 81

4.5 Reallocation of Prize by Transactional Leaders . . . . . . . . . . . 82

4.6 Followers' Relative Contribution in Relation to the Prize they Received from the Leader in the Previous Period . . . . . . . . . . . 83

4.7 Prevalence of Chat Messages per Treatment . . . . . . . . . . . . 86

4.8 Examples for the slider questions as seen by the subjects to measure Social Value Orientation. . . . . . . . . . . . . . . . . 91

4.9 Equilibrium Contributions per contest group under CARA . . . . 96

4.10 Equilibrium Contributions per contest group under CRRA . . . . 96 


\section{List of Tables}

2.1 Determinants of stage 1 contribution . . . . . . . . . . . 15

2.2 Average individual contribution . . . . . . . . . . . . . . 16

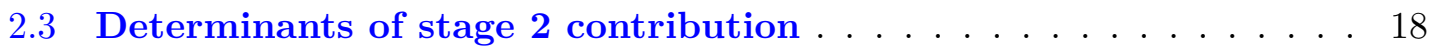

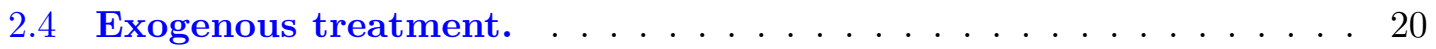

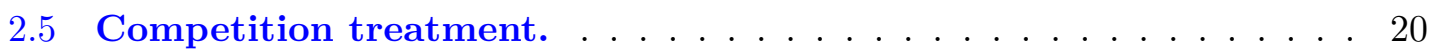

2.6 Comparing Slopes and Intercepts . . . . . . . . . . . . . . 22

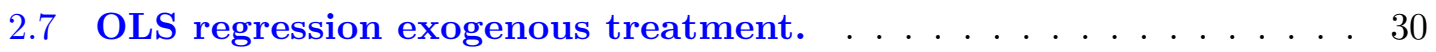

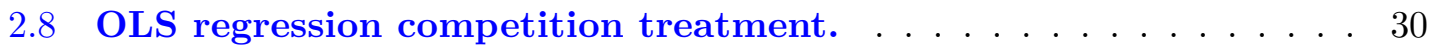

2.9 Effect of first stage contribution and dummies on cooperation level in the team project. . . . . . . . . . . . . . . 31

3.1 Share of response cases, contest environment (in percentages) . . . 45

3.2 Share of response cases, non-contest environment (in percentages) 45

3.3 Individual overspending compared to the Nash equilibrium benchmark . . . . . . . . . . . . . . . . 46

3.4 Individual level analysis $\ldots \ldots \ldots \ldots$. . . . . . . . . . . . 47

3.5 Dynamic analysis . . . . . . . . . . . . . . . . . . . . 48

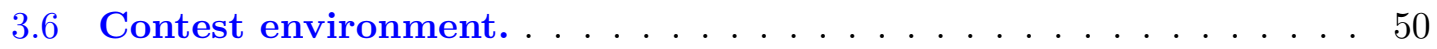

3.7 Non-contest environment. . . . . . . . . . . . . . . . . . 50

3.8 Individual level analysis f . . . . . . . . . . . . . . . . 64

4.1 Treatment overview . . . . . . . . . . . . . . . . . . 72

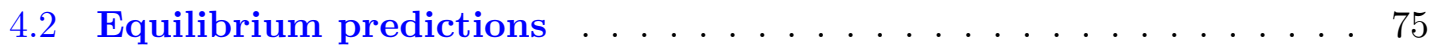


4.3 Leader Contribution as Function of Chat Contents . . . . . . . . . . 84

4.4 Risk Aversion and Social Value Orientation Components . . . . . . 87

4.5 Gamble choices . . . . . . . . . . . . . . . . . . . 90

4.6 Comparing Slopes and Intercepts . . . . . . . . . . . . . . 97

4.7 Analysis of Chat Contents using Interaction Terms . . . . . . . . . 98 


\section{Chapter 1}

\section{Introduction}

Being a social species, humans have a long history of living in tribal clans. The complex character of communal society has shaped psychological mechanisms and heuristics to cope with this environment (cf. Vugt, Cremer, and Janssen, 2007; Tooby and Cosmides, 1988). Put simply: Be nice towards members of your own group and treat them favourably at a cost to oneself (altruism), and respond to representatives from outside the own group with fear and aggression (parochialism). Choi and Bowles (2007) identify the intersection of these as parochial altruism and demonstrate that "under conditions (...) experienced by late Pleistocene and early Holocene humans, neither parochialism nor altruism would have been viable singly, but by promoting group conflict, they could have evolved jointly." As a matter of fact, a history of hostile demeanour between (ethnic) clans is universal across all human societies and is likely to have shaped human psychology since prehistory (Bowles, 2009). ${ }^{1}$

At first, the antiquated image of skirmishing primeval hordes might seem far fetched when describing present day societal challenges and phenomena. Especially in a time of mass media and long distance communication, our networks and social identification have grown so much more complex. The strict dichotomous relationship of feeling akin to the people in our direct vicinity and alienated from those who do not share our territory has long seized to apply and has been replaced with an alternative categorisation instead. The ingroup has become the social group to which a person identifies as being a member of and the outgroup is everything beyond. In this sense, people can feel close to others according to gender, race, age or religion, for example, and ingroup / outgroup categorisation can happen within a matter of minutes.

Henri Tajfel has been one of the pivotal patrons of social identity theory. His work on the minimal group paradigm has shown that smallest conditions can suffice for discrimination to occur against groups. Experimental studies have shown that even essentially meaningless and arbitrary distinctions - like preferences for a type of painting (Tajfel, Billig, Bundy, and Flament, 1971) or a coin flip (Tajfel and Turner, 1979) - can create the tendency to single out the perceived outgroup.

\footnotetext{
${ }^{1}$ Many aspects of human intergroup aggression can also be observed in other social primates (eg. Manson, Wrangham, Boone, Chapais, Dunbar, Ember, Irons, Marchant, McGrew, Nishida, Paterson, Smith, Stanford, and Worthman, 1991).
} 
The work of Sherif (1961) constitutes a compelling illustration of how factions can be implemented exogenously, but also showcasing ways to overcome such stratification. His seminal field study employed 11 year old boys in a summer camp, who were not aware of the fact that they were subject to an experiment. The children were sorted into two groups and engaged in a number of competitive games like tug of war, for example. They were housed separately for the first phase, so prior to starting the competitive games, they did not know about the existence of the other group. This first phase was dedicated to setting up personal bonds within the group. In the second phase, the aforementioned competitive games took place, upon which a firm rivalry between the groups emerged. The boys even ended up refusing to eat in the same room together. Subsequently, in the final phase of the experiment, however, the students were to perform a number of coordination games across groups and peace broke out again. In the end the groups decided to travel home together in the same bus. The author concludes that groups naturally develop own dynamics and values. The key for cooperation, is a common goal across participants. If the goal differs between some participants, conflict breaks out, possibly even resulting in harming of the opponent party without deriving any advantage for the contest in question.

The study of Goette, Huffman, Meier, and Sutter (2012) takes advantage of the fact that Swiss Army officers are randomly assigned to platoons, creating a natural manipulation with respect to group membership. The officers play a one-shot prisoners' dilemma game, randomly with either a member of their own platoon or from another one. Also, one of the two economic environments apply: In the non-competitive (neutral group) environment they play exclusively with one partner, while in the competitive group environment, a bonus is offered to the platoon with the highest average payoff. Goette et al. (2012) find higher levels of favouritism toward the in-group in presence of competition (cooperation rates increase by 36 percentage points), but also no decrease in out-group cooperation. ${ }^{2}$ This study shows that a competitive between-group situation does not only go along with antagonism against outsiders, but also with an increase in ingroup favouritism.

These group dynamics have a vital relevance in our daily life and in modern day business, where a myriad of cases exist, in which resources need to be allotted to a subset of the population. Typically, individuals agglomerate to bundle their resources or complement their competences. Consider for example a company or a syndicate participating in a public procurement tender for a construction project. Here, each department or subunit delivers some jigsaw piece for constituting the whole picture of a complete and possibly successful project proposal. The more effort delivered per subunit, the higher is the chance of winning the tender. Other applications are electoral campaigns in politics, R\&D competition or lobbying. These situations can be modelled using a lottery game by Tullock (1980) and Katz, Nitzan, and Rosenberg (1990), where (members of) contest parties spend resources in order to influence the winning probability.

The implications of the underlying strand of research lends instructive insights into another field of interest. In the political decision making process, like for example in the context of international socio-economic conflicts or the so-called war on terror, very similar patterns can be identified. Considering the development of the Islamic State of Iraq and the Levant (ISIL) or Al-Qaeda, as well as the current multitude of terrorist attacks in Europe, one act of violence leads to another, creating a web of violent attacks. Violence in the Middle East leads to people attacking France, France responds in stepping up their attacks

\footnotetext{
${ }^{2}$ In another treatment design, which included a punishment mechanism, participants do display a taste for harming the out-group through their punishment behaviour.
} 
in the Middle East which possibly evokes the creation of new terrorist groups. In point of fact, ISIL is a comparably young organisation, developed as response to (a perception of) domination, perpetuated by western coalitions throughout the Middle East. It would be preposterous to expect intensified bomb strikes in those areas to cause a peaceful response this time. ${ }^{3}$

Absent of any religious or ethnic catalyst, my research contributes at describing this vicious loop of between-group struggles. The results of my studies portray leaders pushing followers to chip in resources beyond a financially prudent scale and groups distributing rewarding tokens to high contributors and punishing conciliating play.

In the following chapters, I present results from computerised laboratory experiments which model various forms of corresponding between group competition for a public good of predetermined or endogenous size. An encompassing result of my studies is that subjects are willing to accept a financially suboptimal outcome for the prospect of coming out ahead of the opponent party. This complements prevailing experimental literature on (group) contest games, where subjects invest considerably more resources than would be predicted by (subgame perfect) Nash equilibria under standard assumptions (Sheremeta, 2015; Dechenaux, Kovenock, and Sheremeta, 2012). Moreover, spending patterns are established at a level which is socially inefficient to a substantial degree.

First, in Chapter 2, we model a tendering market for a cooperative project, in which we investigate what effect the contest parties' engagement in the tendering process has in the contribution decision of the final team project. Moreover, while subjects in one treatment make a conscious decision on how much to invest in the contest, this decision is exogenously imposed on subjects in the control treatment. As such, they incur sunk costs and enter the public goods game with different wealth levels. To date, most existing evidence on this topic is based on data where sunk costs have either been exogenously defined by the experimenter or endogenously accrued by the subjects. Our design adds to the literature by comparing sunk costs that have been incurred exogenously and sunk costs that have been accrued deliberately by the subject herself. Our results show that subjects in the deliberate treatment have a slightly lower tendency to contribute to the public good, when their team has lost. An equivalent higher contribution level for winning groups, however, cannot be observed. The implications of our results can be applied to the tendering process of public works contracts and vindicate a rather sceptical view. If both candidates dispose of comparable productivity levels, the harm to the losing party is not met by an analogous positive burst of the winning party. From an overall social welfare perspective, devising a method of arbitration which avoids a between group contest would be favourable.

A team contest entails both public good situations within the teams as well as a contest across teams. In Chapter 3, we analyse behaviour in such a team contest when allowing to punish or to reward other group members. Moreover, we compare two types of contest environment: One in which two groups compete for a prize and another one in which we switch off the between-group element of the team contest. Unlike what experimental studies in isolated public goods games indicate, we find that reward giving, as opposed to punishing, induces higher contributions to the group project. Furthermore, expenditures

\footnotetext{
${ }^{3}$ I understand that a prominent motive for an increased engagement in the Middle East would be "to fix the problem" created by alleged western influence. However, the history of attempting to fix the situation does not deliver evidence that a solution can be brought about by alien intervention.
} 
on rewarding other co-players are significantly higher than those for punishing. This is particularly pronounced for the between-group contest.

In Chapter 4 we present an experiment designed to examine whether the existence of a leader can curtail over-contribution and improve group welfare in a team contest. Furthermore, we compare different levels of leader authority and the effect of communication between leaders of competing groups with respect to conflict potential and social welfare. Our results indicate that contest expenditures in treatments with a leader are higher, unless there is communication. Moreover, leaders with authority fan the flames of between group competition by allocating a relatively larger share of the prize to subjects that have delivered more input to the competition. When allowing for communication between leaders of competing groups, those who manage to agree on taking turns for delivering input to the contest, exert a mitigating effect on spending levels. 


\section{Chapter 2}

\section{To Tender or not to Tender? Deliberate and Exogenous Sunk Costs in a Public Good Game ${ }^{1}$}

\section{$2.1 \quad$ Introduction}

In economics and in society in general, many situations are of a competitive kind. For example in public tenders, (cellular telephone) license lotteries or struggles for resources, considerable funds are spent to outperform a competitor. One of the most widely used models for (team) competition is the contest game (Tullock, 1980; Katz et al., 1990), where agents invest resources in order to influence the probability to win a prize.

In the field, however, the factual rents derived from the prize at stake are often not fully defined ex ante and depend on what the winning party makes of it. Baye and Hoppe (2003) present a model for an endogenous contest prize, in which players' contributions determine both the probability of winning and the value of the prize. By contributing to the contest, players create a positive externality to all other competitors by increasing the prize at stake. At the same time, contributing generates negative externalities, as it reduces other players' probability to win. As economic application, consider a situation where R\&D efforts affect realised profits from having the best idea.

However, contributions to winning the contest often do not directly influence the variable prize at stake. This is determined separately from the contest instead. Imagine a procurement tender for a construction project involving two corporations - each consisting of several subdivisions - running for the contest. After the decision on which one has been awarded with the project, the subdivisions of the winning corporation can deliver input to construct the project of which the benefits are shared equally within the winning corporation.

\footnotetext{
${ }^{1}$ Based on an article by Florian Heine and Martin Sefton. We would like to thank Valeria Burdea for invaluable help in the realisation of the experiment. Financial support from the Gesellschaft für experimentelle Wirtschaftsforschung e.V. (GfeW) through the "Heinz Sauermann-Förderpreis zur experimentellen Wirtschaftsforschung" grant is gratefully acknowledged.
} 
A related example of this kind of contest is the recent competition between Boeing and Airbus for a major deal with El Al Airlines. ${ }^{2}$ We depart from the standard conceptualisation of this market situation as duopoly of unitary players towards a more complex (and probably more realistic) one. As such, each competitor consists of different segments (for the aviation example e.g. production of fuselage, wings, turbines) and eventual rents depend on success or failure in the competition and the subsequent behaviour of each firm's segments, under incomplete contracts. Our model also applies to situations in which the group's payoff depends on their relative performance within an organisation (i.e. R\&D units, independent profit centres).

There are two stages: First, on the corporation level, each group spends resources in order to secure the project. In the second stage, subdivisions invest resources for a project, whose benefits are shared equally within the firm. Both firms produce after the contest, but we assume that the successful group managed to gain access to a more attractive project, delivering higher returns on capital. ${ }^{3}$ Theoretically, contribution decisions to the group project - which constitutes a public good - should be independent of the amount of money spent in the first stage, as it represents a sunk cost. Literature suggests though, that agents' decisions are in fact influenced by sunk costs (Arkes and Blumer, 1985). More specifically, individuals seem to be more willing to invest into an ongoing project, if more money has been spent on it before (e.g. Whyte, 1993; Arkes and Blumer, 1985).

Subdivision managers in charge could as well be subject to the inverse effect, though. Contributing to the tender could be perceived as the first stage of a reciprocal or gift exchanging process. As such, having invested a lot of resources in the first stage could make individuals feel entitled to cut back for the public good. Another argument for this behaviour would be inequity averse preferences (cf. Fehr and Schmidt, 1999), as those who contributed more to the first stage of the game are relatively poorer. So far, research on sunk cost has mainly focussed on investment or consumption decisions. However, the dynamics of a public good game with a prior investment decision are different, because social preferences (as for example, reciprocity) have a bearing on decision making as well.

In this paper we present an experimental study to investigate the effect of a firststage investment on agents' willingness to contribute to a public good. Furthermore, the experimental design allows to disentangle the effect of unintentional exogenous sunk costs from sunk costs emanating from deliberate investments into a between-group contest. Executing this study in a controlled laboratory setting allows isolating aforementioned factors and to draw more robust conclusions.

The article is structured as follows: In the next section we discuss the conceptual background of our study; then we explain the setup of the experiment in Section 2.3; in Section 2.4 we formulate hypotheses; before presenting results in Section 2.5; Section 2.6 provides concluding comments and suggestions for future research.

\footnotetext{
${ }^{2}$ See Bornstein and Gneezy (2002) or Stub (2012); Egozie (2015) in press.

${ }^{3}$ Public procurement procedures for legal aid providers in the UK illustrate a related application: Legal firms enter a tendering process for duty provider contracts. While this represents an attractive business for legal enterprises, there is a considerable amount of firms operating without duty work. In 2015, around 200 firms won no contract and currently operate without duty work (Fouzder, 2015, in press).
} 


\subsection{Background}

This chapter draws from three different strands of literature: 1) Endogenous prize contests, 2) Public good games with entry option and 3) Sunk costs. In this section we review some of the relevant literature.

\subsubsection{Endogenous prize contests}

An important component of contests is the prize at stake (cf. Dechenaux et al., 2012; Konrad, 2009). Not only does it represent the motivational cue for engaging in a contest from a behavioural perspective, but it also determines the equilibrium prediction in pure strategies (cf. Abbink, Brandts, Herrmann, and Orzen, 2010; Konrad, 2009). In the field, there exists a number of contest situations with an exogenous prize, like a money prize in sports tournaments or known rents from patents in $R \& D$ races. However, often the contestants themselves can influence the prize to take away from a successful competition. So far research on endogenous contest prizes has focused on scenarios where the prize is influenced by players' contribution to the contest (Baye and Hoppe, 2003) or by the price demanded in a Bertrand competition game (Bornstein and Gneezy, 2002; Bornstein, Kugler, Budescu, and Selten, 2008).

In Morgan, Orzen, Sefton, and Sisak (forthcoming), subjects were able to make a realtime decision on entering a contest, while observing the number of co-players currently in the market. They find a substantial excess entry into the market, as compared to the risk neutral benchmark prediction. This was especially the case when the outside option underlay a stochastic risk. The symmetric equilibrium investment level in the subsequent contest negatively depends on the number of entrants into the market. While Morgan et al. (forthcoming) join the ranks of articles that find considerable overspending into the contest, they also observe a large fraction of subjects exhibiting a rather passive investment strategy after having decided to enter the contest. Morgan et al. (forthcoming) offer two explanations for the behaviour of this latter group: 1) Escape the outside option for treatments where it is risky. 2) Risk or loss averse subjects entering the market early, under the expectation that only few other players would enter, refrain from placing a high bid upon observing that there were in fact unexpectedly many entrants to the market.

Huyck, Battalio, and Beil (1993) conduct an experiment where players auction for the right to participate in a coordination game. The price for the right to play reduces strategic uncertainty and works as a tacit communication device. While subjects consistently fail to coordinate on a payoff-dominant equilibrium when endowed with the right to play, subjects who went through a pre-play auction, achieve the efficient outcome in the coordination game.

In the context of a weak link game, Cooper, Ioannou, and Qi (2015) compare a market mechanism with random sorting with regards to subjects' productivity. While there exists an efficiency gain from the market mechanism for high performance workers, this effect is almost completely offset by a negative effect on subjects with low performance pay.

We present an endogenous contest prize where the contributions for outperforming the competitor do in fact not influence the size of the prize. Instead, these expenses are 
dedicated solely to the contest. Public tenders, for example, are widely used for determining the granting of funds for projects or for (public) facilities. Success or failure of the project depend on the winning party's behaviour in the post-contest phase.

\subsubsection{Public good games with entry option}

There exists an established theoretical literature on public goods games with entry option. Frank (1987) and Amann and Yang (1998) argue that when subjects can opt between setting up a partnership with another player or an outside option, entering conveys a message about the players' types. This helps coordination towards more efficient, cooperative strategies. Other authors refer to a false consensus bias as the reason for the matching of types. If this is the case, cooperators are relatively more likely to enter the cooperative game, as they tend to be more optimistic about the level of cooperation, than free riders are (Orbell and Dawes, 1991).

Orbell and Dawes (1993) and Nosenzo and Tufano (2015) examine the effect of voluntary entry to a public goods game experimentally. Orbell and Dawes (1993) find a positive effect on cooperation and efficiency in the presence of voluntary entry to a one-shot public goods game. Nosenzo and Tufano (2015) compare the effectiveness of an entry option with an exit option in a one-shot public goods game experiment. Although the possibility to exit increases subjects' ability to coordinate towards the cooperative strategy, the entry option does not deliver a significant effect.

\subsubsection{Sunk costs}

Classical examples of elicitation of sunk cost fallacies or escalating commitment, demonstrate cases where agents are more willing to invest (additional) resources with higher previous investments (Garland, 1990; Arkes and Blumer, 1985). One field study reported in Arkes and Blumer (1985), for example, demonstrates that subjects who paid the full price for a theatre season ticket attend more performances than subjects that have randomly benefited from a reduced price. Amongst the most prominent psychological explanations for the sunk cost fallacy is prospect theory (Kahneman and Tversky, 1979): People do not update their reference point which makes them accept too much risk. Staw (1981) offers a self-justification bias as alternative explanation: Subjects tend to invest more resources into a losing asset in order to rationalise or justify their previous strategy.

One prominent aspect of our design is the fact that we can contrast sunk costs incurred exogenously and those having been accrued deliberately by the subject herself. So far, most existing evidence on this topic is based on data where the sunk costs have either been exogenously defined by the experimenter (i.e. Garland, 1990) or endogenously accrued by the subjects (i.e. Friedman, Pommerenke, Lukose, Milam, and Huberman, 2007).

An example that considers this issue is presented by Offerman and Potters (2006). In an experimental study they examine the effect of auctioning entry rights to a market on subsequent prices. In one treatment, agents do not issue bids themselves, but entry rights are given randomly and the same cost as in the auctioning treatment is induced exogenously. Most notably, prices do not differ between the auction and the exogenous 
treatment. At the same time, the effect size of the sunk cost fallacy seems to depend on the market situation. While there is a significant positive effect on average prices in an oligopolistic market, they are unaffected in the monopoly treatment. Offerman and Potters (2006) argue that while the entry fee encourages players to risk engaging in a collusive strategy, this was - by design - much less of an issue in the monopoly market because collusion is not possible by definition.

\subsection{Setup}

Before the main part of the experiment, we took a measure of individual social value orientation (SVO), using techniques introduced by Murphy, Ackermann, and Handgraaf (2011). ${ }^{4}$ Using this data we test if more socially oriented participants recognise the overall welfare reducing character of the between group contest, which should negatively influence first stage expenditures. Furthermore, we would expect players with a higher SVO score to exhibit a greater willingness to contribute to the group project, as second stage contribution is socially beneficial.

This study incorporates two experimental treatments: A competition treatment and an exogenous treatment. While subjects in the former treatment compete for the right to play a public good game with a relatively more attractive Marginal Per Capita Return (MPCR), players in the latter treatment incur an exogenous cost, before being sorted into an either high or low MPCR game. Details are described in what follows.

[Competition treatment:] Players are sorted in groups of three and compete against another group of the same size. This composition keeps unchanged and players' identities are never associated with their decisions. The game consists of two stages and it includes investment decisions as explained in the following.

First stage Each player receives an endowment of $T=200$ tokens. For a price of 1 token per ticket, they can purchase up to 100 tickets for the contest. Spendings of subject $k$ in group $K$ and $m$ in group $M$ are labelled $v_{k}$ and $v_{m}$, respectively. Tokens that are not spent for the contest will be added to the player's private account. With $p_{K}$ being the probability for group $K$ to win over group $M$, the contest success function (CSF) (similar to Tullock, 1980; Katz et al., 1990) is

$$
p_{K}\left(\left(v_{k}\right)_{k \in K},\left(v_{m}\right)_{m \in M}\right)= \begin{cases}\frac{\sum_{k \in K} v_{k}}{\sum_{k \in K} v_{k}+\sum_{m \in M} v_{m}} & \text { if } \max _{i \in K \cup M}\left\{v_{i}\right\}>0 \\ 1 / 2 & \text { otherwise }\end{cases}
$$

Second stage Players learn if their group has won or lost, other group's first stage spending level, the corresponding winning probability and their group mates' wealth level $T-v_{i}$. Then, each group plays a public good game with $w_{i}$ being individual $i$ 's investment into the public good. ${ }^{5}$ For this, subjects can invest a maximum of 100 tokens. ${ }^{6}$

\footnotetext{
${ }^{4}$ Details are described in Appendix 2.A.

${ }^{5}$ This was called team project in the instructions.

${ }^{6}$ Each player receives 200 tokens in the beginning, of which she can spend 100 tokens for the contest
} 
The winning group will enjoy a high MPCR of $H i=0.8$. The losing group will be facing a low MPCR of $L o=0.4 .^{7}$ Individual payoff for player is then determined by:

$$
\pi_{i}\left(w_{i}\right)= \begin{cases}200-v_{i}-w_{i}+0.8 \cdot \sum_{i \in I} w_{i} & \text { Winning group } \\ 200-v_{i}-w_{i}+0.4 \cdot \sum_{i \in I} w_{i} & \text { Losing group }\end{cases}
$$

[Exogenous treatment:] Players are sorted in groups of three and are connected with another group of three, analogous to the competition treatment. Their first stage behaviour will be matched with a pair of groups in the competition treatment. This means, for each pair of groups with voluntary first stage spending, there will be a pair of groups in the exogenous treatment, that gets the same amount of tokens deducted by the computer. ${ }^{8}$ Participants pass the following two stages:

First stage Each player receives an endowment of $T=200$ tokens. Individual factors $v_{i}$ are induced, matching another group's behaviour in the competition treatment and deducted from $T$.

Second stage Groups play a public good game. Players see the current wealth level of their group mates (being $T-v_{i}$ ) and the wealth level of the other group they are connected with. Keeping in line with the matched groups from the competition treatment, the MPCR will be $H i=0.8$ or $L o=0.4$. Individual payoff is determined by:

$$
\pi_{i}\left(w_{i}\right)= \begin{cases}200-v_{i}-w_{i}+0.8 \cdot \sum_{i \in I} w_{i} & \text { Winning group } \\ 200-v_{i}-w_{i}+0.4 \cdot \sum_{i \in I} w_{i} & \text { Losing group }\end{cases}
$$

\subsubsection{Procedures}

Using ORSEE by Greiner (2004) we recruited 186 participants for the experiment, which was conducted in the CeDEx lab at the University of Nottingham between May 2015 and March 2016. During this computerised laboratory experiment, ${ }^{9}$ each participant sat in a cubicle, visually separated from each other. Participants were randomly seated at one of 24 computers and found the instructions for the SVO measure at their place. After the SVO measure was taken, instructions for the main part were distributed. All instructions were read aloud both in order to enhance the understanding and to make it credible to the participants that everyone shares the same information. Find a copy of the instructions in Appendix 2.B.

and 100 tokens for the subsequent public good game. We choose this setup with an overall endowment and two separate spending ceilings to put emphasis on the overall wealth effects of the first stage decisions and the fact that the two stages are linked as one game. Furthermore, there exist two separate ceilings, to keep constant the decision space across all players. So although players frequently enter the second stage with different momentary wealth levels, there are no constraints for the individual decision space emanating from the wealth levels.

${ }^{7} 1>H i>L o>1 / 3$. The first and the last inequality define the public good game, in which subjects face a trade-off between individual monetary interest and social efficiency. The second inequality makes sure that the winning group encounters a more attractive game.

${ }^{8}$ There has been one session less in the exogenous treatment because of no-shows. Hence, there is in fact one pair of groups from the competition treatment which is not mirrored in a exogenous treatment session.

${ }^{9}$ The software was programmed with "z-Tree" (Fischbacher, 2007). 
The main part of the experiment started with a trial period, including comprehension questions, in order to make participants familiar with the interface and to ensure a thorough understanding. After the main part, participants answered a short questionnaire about personal attributes (i.e. age, gender) and preferences (political convictions, risk attitudes...).

The experiment took one hour, which included reading instructions, taking an SVO measure, a trial period, the main part of the experiment, a questionnaire and payment. Average earnings were $£ 12.00$, which was paid out privately and in cash at the end of the session. ${ }^{10}$

\section{$2.4 \quad$ Equilibrium Strategies}

Under risk-neutrality and individualistic preferences, each player $i$ in group $K$ maximises her expected earnings, which is

$$
E\left(\pi_{i}\left(v_{i}, w_{k \in K}\right)\right)=T-v_{i}-w_{i}+p_{K} \cdot H i \sum_{k \in K} w_{k}+\left(1-p_{K}\right) L o \sum_{k \in K} w_{k}
$$

As $1>H i>L o>1 / 3$, investment into the public good is socially desirable but individually costly for risk-neutral individualistic agents, who are only concerned with their own earnings. The second-stage Nash equilibrium therefore is $w_{i}=0 \forall i \in K \cup M$, which renders both public good games indifferent in expected values, i.e. zero. In the competition treatment, no resources will be spent in the first stage, so $v_{i}=0 \forall i \in K \cup M$. Find a more formal approach in Appendix 2.C.

\subsubsection{Behavioural Hypotheses}

Next to the subgame perfect equilibrium as benchmark we formalise alternative hypotheses to capture other regarding preferences. Inequality 2.4.1 describes a hypothesis concerning the relation between the different mean contribution rates for each possible second stage outcome.

$$
\overline{w_{i}} \mid \text { win, comp } \quad>\quad \overline{w_{i}} \mid \text { win, ex } \quad>\quad \overline{w_{i}} \mid \text { lose, ex } \quad>\quad \overline{w_{i}} \mid \text { lose, comp }
$$

$\overline{w_{i}} \mid A, B$ represents average contribution levels given a particular group has won or lost (i.e. $A \in\{$ win, lose $\}$, respectively) and given the group is in either the competition or the exogenous treatment (i.e. $B \in\{$ comp, ex $\}$, respectively).

The second inequality (between winning and losing groups) is in line with established empirical results on public good games, that contributions increase with higher MPCR (eg. Gunnthorsdottir, Houser, and McCabe, 2007; Isaac and Walker, 1988). For the first and the last inequality, we expect this tendency to be more pronounced for the competition treatment because of sorting and signalling effects. Using first stage contribution, players can signal their other regarding preferences.

\footnotetext{
${ }^{10}$ About $€ 16.00$ or $\$ 18.00$ at the time of the experiment.
} 
Applying a forward looking argumentation (as in Capraro, 2013), the size of first stage contributions conveys a signal about future play. In order to make an investment of $\epsilon$ in the first stage of the competition treatment, a subject expects her profits in stage two to be at least $\epsilon$ higher than without this prior investment. This reduces strategic uncertainty, as players can eliminate from consideration the set of strategies, that are payoff dominated in this sense. Capraro (2013) offers an alternative argument for why first stage contribution could trigger higher cooperation to the team project. In their theoretical model, "players forecast how the game would be played if they formed coalitions and then they play according to their most optimistic forecast" (Capraro, 2013). If first stage spending is interpreted as signal towards the level of cooperativeness, this can make the "most optimistic forecast" more viable, increasing the likelihood of it being played. This reasoning does not apply when subjects incur sunk costs randomly. First stage sunk costs in the exogenous treatment do not convey a tacit signal about players' types.

As discussed in Subsection 2.2.2, voluntary contribution to the first stage contest in our setup can be interpreted as an implicit signal about whether or not an agent intends to engage in the second stage public good game. Relating to the argument above, if cooperators are more optimistic about the level of cooperation, they estimate higher expected profits from the second stage public good game. Therefore we hypothesise that agents, exhibiting cooperative behaviour in the second stage tend to spend more resources in the contest.

From this we derive a hypothesis concerning the relationship of second stage $\left(w_{i}\right)$ and first stage contribution $\left(v_{i}\right)$, formalised in inequality 2.4 .2 below:

$$
\frac{\Delta w_{i}}{\Delta v_{i}}>0
$$

Furthermore, by the nature of this game's structure, subjects might very well enter the public goods game with different wealth levels. Agents that have spent more resources in the contest are relatively poor and vice versa. At the same time, contributions to the second stage public good are restricted to 100 tokens, irrespective of players' first stage behaviour. Reuben and Riedl (2013) study the emergence of contribution norms in a public good game with heterogeneous agents. Without punishment opportunities, there is no significant difference in contribution to the public good between agents with different money endowment. This is the case despite (uninvolved) individuals' stated normative preferences "that high types should contribute more".

If subjects are indeed motivated by inequality concerns in the sense of Bolton and Ockenfels (2000) and Fehr and Schmidt (1999), more wealthy agents (those with lower first stage spendings) would contribute relatively more in the second stage. Accordingly, we would be able to observe a positive relationship between second stage contribution $w_{i}$ and first stage spending level of player $i$ 's teammates $v_{-i}$, warranting the second inequality of hypothesis 2.4.3 below. Moreover, our setup allows to disentangle inequality concerns from actions motivated by reciprocity. It is only in the competition treatment that first stage contributions are determined by a conscious decision from the respective player. Accordingly, the positive relationship between teammates' first stage contribution and own second stage spending in the competition treatment would be stronger than the one in the exogenous treatment, if contributions to the team project are motivated by reciprocity. This establishes the first inequality of Hypothesis 2.4.3, which is akin to the opposite of Hypothesis 2.4.2, enabling us to draw a distinction between inequality aversion / reciprocity and costly signalling of cooperativeness. 


$$
\frac{\Delta w_{i}}{\Delta v_{-i}}\left|\operatorname{comp}>\frac{\Delta w_{i}}{\Delta v_{-i}}\right| \text { ex }>0
$$

$\frac{\Delta w_{i}}{\Delta v_{-i}} \mid B$ represents the slope of contribution to the team project in relation to the teammates' first stage contribution level, given the group is in either the competition or the exogenous treatment (i.e. $B \in\{c o m p, e x\}$, respectively).

\section{$2.5 \quad$ Results}

This section consists of three parts. First (Subsection 2.5.1) we describe subjects' contest spending behaviour in the competition treatment. We analyse, which individual factors determine the willingness to spend resources to the between group contest. In the second part (Subsection 2.5.2) we study how much subjects contribute to the team project and discuss structural differences comparing winning and losing groups for the two treatments. Afterwards, we investigate the relationship of first and second stage contribution (Subsections 2.5.3 and 2.5.4).

As this is a one-shot game, individual data can be tested as independent observations. For hypothesis testing, we use non-parametric methods, as the data is not normally distributed (Shapiro-Wilk test for normality. $\mathrm{N}=186, \mathrm{P}=0.00$. Same result for first stage and second stage contribution.): Wilcoxon signed-rank test (Wilcoxon test) for paired data (Wilcoxon, 1945) and Mann-Whitney U test (MWU) for independent sample data (Mann and Whitney, 1947). We test for trends using Spearman's rank correlation (Spearman test) (Spearman, 1904; Conover, 1999). For regression analyses we employ robust OLS, as well as a Tobit model with limits at 0 and 100, as this is where the subjects' action space is limited.

\subsubsection{Team Contest}

Subjects spend on average about 29 points on first stage tickets, which is substantially higher than the benchmark prediction of zero contribution. Figure 2.1 depicts the distribution of team contest contributions, indicating 0 as the modal contribution level. See Appendix 2.D for a discussion of the role of beliefs for contest expenditures in this game.

We use both Tobit regression with limits at 0 and 100, as well as ordinary least squares (OLS), respectively, to analyse determinants of individual contribution to the between group contest; results are summarised in Table 2.1. First of all, the individual measure of subjects' social value orientation $(S V O)^{11}$ has a negative effect on subjects' first stage contribution behaviour. ${ }^{12}$ This means that participants with a relatively more social orientation might recognise the overall-welfare reducing nature of first-stage contributions. Furthermore, the self-reported risk tolerance measure (risk parameter) has only weak explanatory power for how many lottery tickets are bought. In Abbink et al. (2010) and Katz et al. (1990),

\footnotetext{
${ }^{11}$ For details see Appendix 2.A

${ }^{12}$ Only with some degree of variation, all subjects display preferences that fall into the pro-social category.
} 


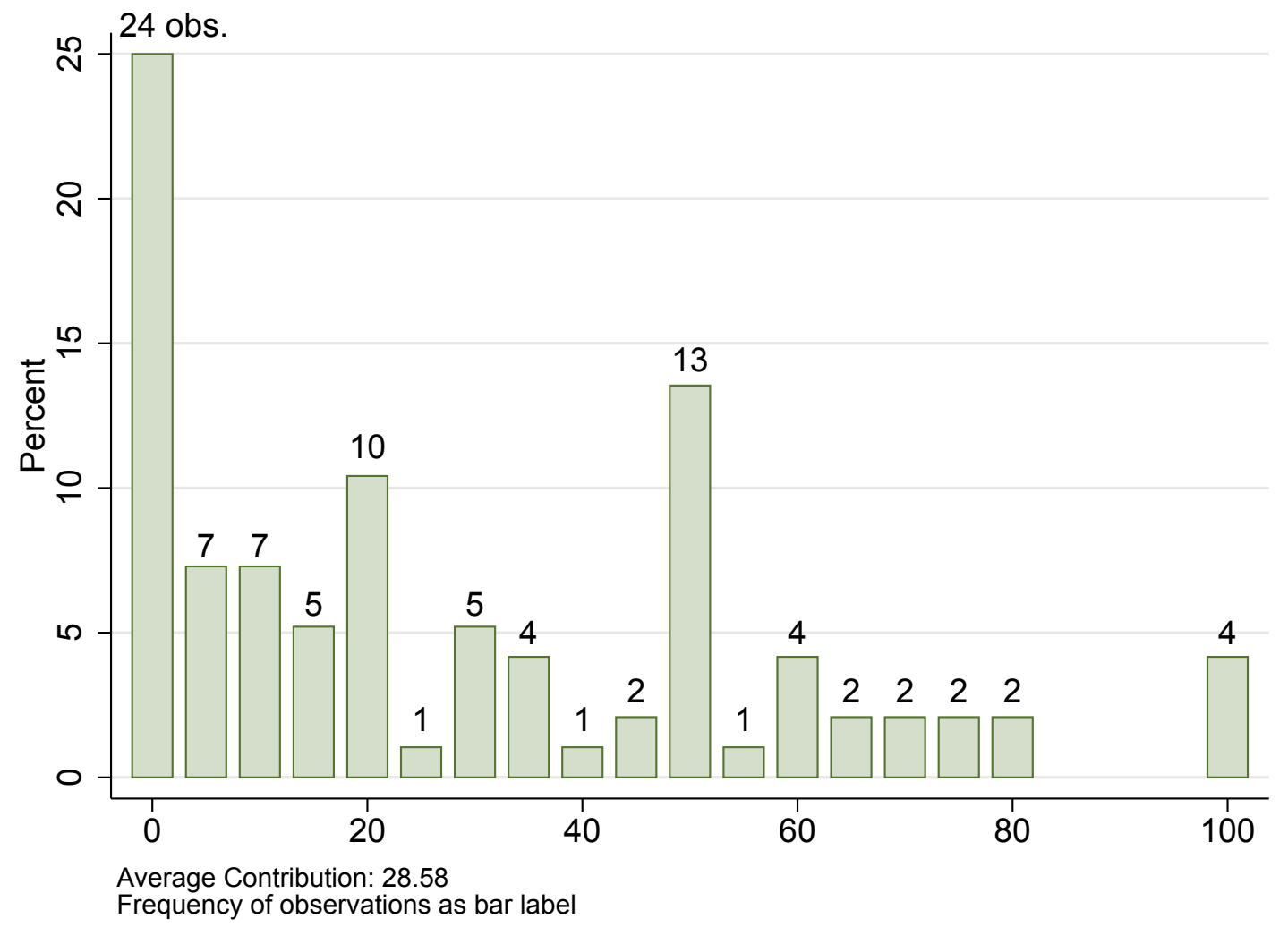

Figure 2.1: Contribution to the Team Contest.

equilibrium contributions diminish with higher levels of both constant absolute risk aversion and constant relative risk aversion.

We discover a strong gender effect, such that female participants purchase significantly more lottery tickets. The magnitude of this factor is substantial, given that the entire decision space only ranges from $v_{i} \in[0,100]$. The strong positive magnitude of this factor comes somewhat surprisingly, given an established literature on women's lower level of competitiveness (eg. McDonald, Navarrete, and Van Vugt, 2012; Vugt et al., 2007). To our knowledge, this puzzling result is not paralleled by other studies on (group) contest games. However, first stage contribution can be interpreted as "a task that each member prefers that another member of the group undertakes" (Vesterlund, Babcock, and Weingart, 2014). The authors find that in mixed groups, women volunteer twice as often as men to take over such tasks.

Players' age is positively related to first stage contributions only in Regressions (2) and (4) when control variables are included. These controls are comprised of questionnaire items which have been answered on a multiple point scale subsequent to the main part of the experiment. Politics important has been generated through the questionnaire using a scale from $1-4$, where subjects were asked how important they find politics in their life.

Another strong positive effect is displayed by Trust in others, ${ }^{13}$ such that subjects

\footnotetext{
${ }^{13}$ For this term, subjects answer the following question from the World Values Survey (Inglehart and Archivo de Estudios Sociales, 2000): "Generally speaking, would you say that most people can be trusted or that you need to be very careful in dealing with people?" They pick one of the following two answers:
} 


\begin{tabular}{|c|c|c|c|c|}
\hline \multirow{2}{*}{\multicolumn{5}{|c|}{$\begin{array}{c}(1) \\
\text { First stage Contribute }\end{array}$}} \\
\hline & & & & \\
\hline VARIABLES & Tobit & Tobit & OLS & OLS \\
\hline $\begin{array}{l}\text { Social value } \\
\text { orientation (SVO) }\end{array}$ & $\begin{array}{l}-2.961^{* *} \\
(1.38)\end{array}$ & $\begin{array}{c}-2.209^{*} \\
(1.25)\end{array}$ & $\begin{array}{l}-2.384^{* *} \\
(1.05)\end{array}$ & $\begin{array}{c}-1.823^{*} \\
(1.03)\end{array}$ \\
\hline Risk parameter & $\begin{array}{c}3.245 \\
(2.73)\end{array}$ & $\begin{array}{r}3.458 \\
(2.34)\end{array}$ & $\begin{array}{c}2.479 \\
(2.10)\end{array}$ & $\begin{array}{r}2.567 \\
(1.97)\end{array}$ \\
\hline Female & $\begin{array}{l}14.074^{*} \\
(8.04)\end{array}$ & $\begin{array}{l}20.993^{* * *} \\
(7.49)\end{array}$ & $\begin{array}{r}9.866 \\
(6.14)\end{array}$ & $\begin{array}{l}14.702^{* *} \\
(6.19)\end{array}$ \\
\hline Age & $\begin{array}{c}2.656 \\
(1.78)\end{array}$ & $\begin{array}{l}4.783^{* * *} \\
(1.74)\end{array}$ & $\begin{array}{r}2.251 \\
(1.39)\end{array}$ & $\begin{array}{l}3.503^{* *} \\
(1.45)\end{array}$ \\
\hline Politics important & & $\begin{array}{c}-3.214 \\
(4.04)\end{array}$ & & $\begin{array}{c}-3.605 \\
(3.48)\end{array}$ \\
\hline Trust in others & & $\begin{array}{l}16.506^{* *} \\
(6.67)\end{array}$ & & $\begin{array}{l}13.068^{* *} \\
(5.68)\end{array}$ \\
\hline Income Equality & & $\begin{array}{c}-4.884^{* *} \\
(2.05)\end{array}$ & & $\begin{array}{r}-2.595 \\
(1.67)\end{array}$ \\
\hline Constant & $\begin{array}{r}97.148 \\
(83.90)\end{array}$ & $\begin{array}{r}11.600 \\
(80.22)\end{array}$ & $\begin{array}{r}86.402 \\
(64.29)\end{array}$ & $\begin{array}{r}22.997 \\
(66.41)\end{array}$ \\
\hline $\mathrm{N}$ & 93 & 93 & 93 & 93 \\
\hline (Pseudo) R-squared & 0.015 & 0.069 & 0.122 & 0.426 \\
\hline
\end{tabular}

Table 2.1: Determinants of stage 1 contribution

who express a higher level of trust contribute more to the contest. In this sense, contest expenditures could be seen as sacrifice for the group's benefit, which can repay if a high level of cooperation will be realised in the subsequent second stage.

The factor income equality only displays a negative coefficient in Regression (2). Individuals stated their proximity to which of the two following statements they feel closer on a scale from one to seven: "We need larger income differences as incentives for individual effort." - "Incomes should be made more equal." Accordingly, this factor aims at capturing individual preferences for either a steep or flat income curve. There is some indication as to that more equality-oriented participants exert less resources for the between group contest.

\subsubsection{Second Stage contribution}

Table 2.2 lists average contributions for both treatments and winning and losing groups. Across all treatments and first stage outcomes, subjects invest on average about 27 points into the team project. Also notice that for each the exogenous and the competition treatment, both average contribution levels are virtually identical overall. In hypothesis 2.4.1 we formulate three inequalities, reflecting differences in sorting and MPCR. Consider Fig-

"Need to be very careful." or "Most people can be trusted." 
ure 2.2 for an overview of individual contributions to the team project. As for the second inequality of our hypothesis, we observe a stark difference between average contribution levels comparing winning and losing teams, respectively (Wilcoxon test on team level: $\mathrm{N}$ $=62, \mathrm{P}=0.001$. Higher rank sum than expected for winning teams). Members of the winning teams spend about twice as much on the team project, as compared to subjects in the losing teams. This is true for both the competition and the exogenous treatments.

\begin{tabular}{lcc|c}
\hline & Win & Lose & Overall \\
\hline Exogenous & 34.3 & 19.5 & 26.9 \\
Competition & 37.2 & 16.3 & 26.8 \\
\hline Overall & 35.8 & 17.8 & 26.8
\end{tabular}

Table 2.2: Average individual contribution

The third inequality in our hypothesis postulates that subjects in a losing group in the competition treatment contribute less to the team project than a member of a losing group in the exogenous treatment. The reason for this are sorting effects and signalling. Although the average second stage contributions point in the right direction (19.5 for exogenous and 16.3 for competition treatment), nonparametric tests on the group level fail to back this hypothesis (Wilcoxon test on team level: $\mathrm{N}=31, \mathrm{P}=0.566$ ). At the same time, for losing groups complete free riding occurs much more frequently in the competition treatment $(28$ times) than in the exogenous treatment (19 times).

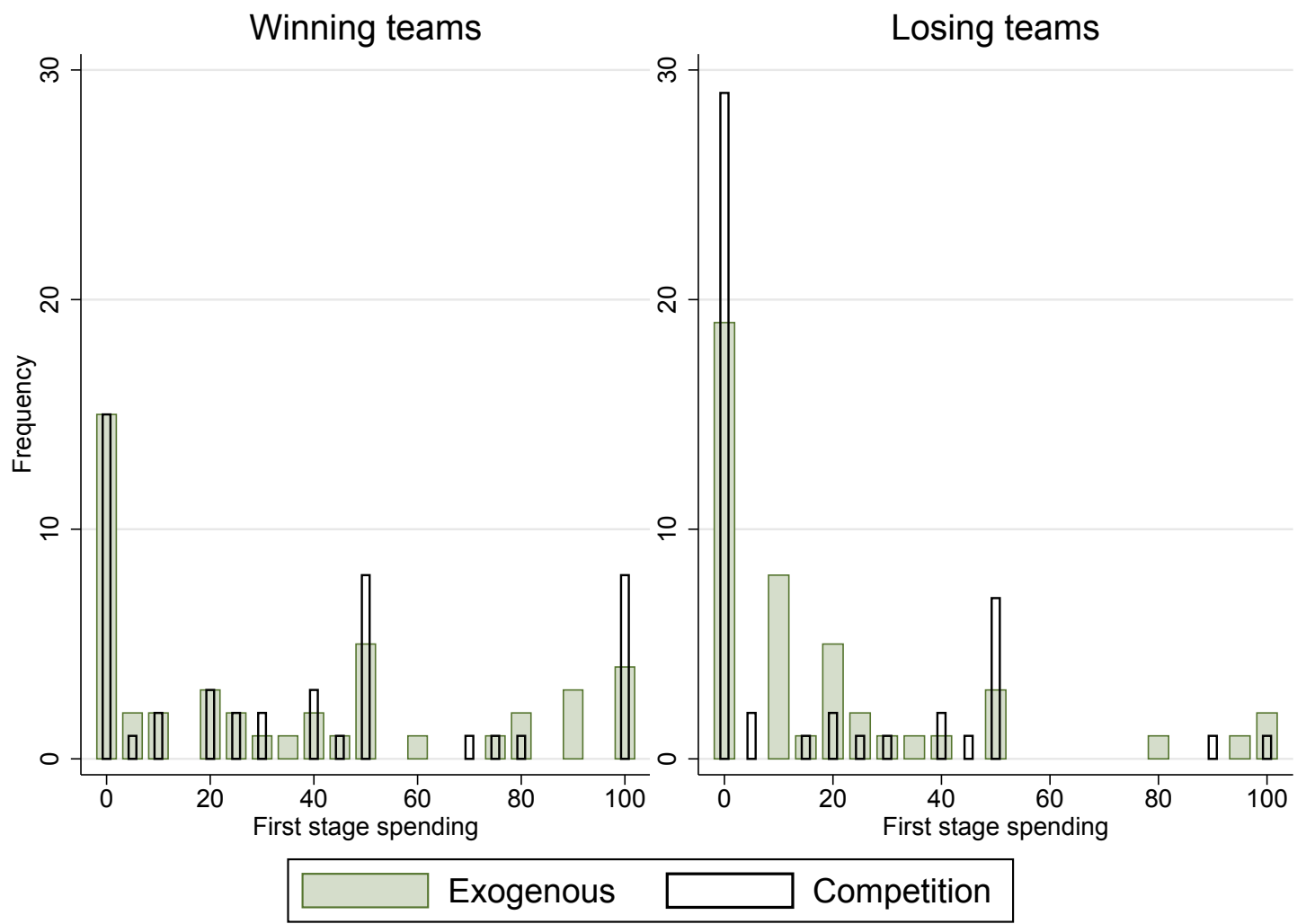

Figure 2.2: Individual contribution to the team project 
The results concerning the first inequality of Hypothesis 2.4.1 pan out similarly: The hypothesis states that subjects in a winning team contribute more in the competition treatment, as compared to winning teams in the exogenous treatment. Again this difference emanates from sorting and signalling effects. While the average second stage contributions slightly tend towards this direction (34.3 for exogenous and 37.2 for competition treatment), this indifference is far from being significant (Wilcoxon test on team level: $\mathrm{N}=31, \mathrm{P}=$ 0.566). Hence, subjects seem to not perceive contributions to the contest as a strong signal for second-stage cooperativeness in the winning groups.

\subsubsection{Relation between first and second stage contribution}

Based on the argument that first stage contribution is used as costly device to signal the willingness to cooperate in the team project, we formulate hypothesis 2.4.2 (Subsection 2.2.3 adds to this, applying a sunk costs argumentation), which postulates a positive relationship between individual contest expenditures and the subsequent investment into the team project. Concurrently, we discuss an antithetic perspective on this matter by devising hypothesis 2.4.3. Here, both inequality aversion and reciprocity actually warrant a negative relationship between first and second stage contribution. Our setup allows us to analyse which of the above arguments prevail.

In Table 2.3 we present results for a Tobit model with limits at 0 and 100 (Regressions (5) and (6)) and OLS (Regressions (7) and (8)) both with robust standard errors for intragroup correlation. We regress contributions to the team project on first stage expenses and a number of controls. Overall results for models (5) through (8) deliver evidence to support hypothesis 2.4.2, displaying a positive interrelation between the two factors. This means that subjects who tend to spend more in the contest phase of the game, are also those who chip in relatively more resources to the subsequent team project.

Interestingly, the degree of social value orientation ( $S V O$ ) negatively influences the willingness to cooperate in the team project. This seems considerably unintuitive, as one would expect more socially oriented individuals to invest more into the group account. ${ }^{14}$ By contrast, the positive coefficient for the risk parameter is more in line with intuitive expectations. Subjects who report to accept more risk are also ready to spend more resources for the team project. Unlike for first stage expenditures, there is no gender effect when it comes to contributions towards the public good.

Next to the parameter age - which is again significantly positive - we include the same controls as in Regressions (2) and (4), as well as a dummy variable for each of the four situations a subject could end up in:

Exogenous lose Subject in the exogenous treatment in a group that lost in the first stage.

Exogenous win Subject in the exogenous treatment in a group that won in the first stage.

\footnotetext{
${ }^{14}$ While the results of Regressions (1) - (4) suggest a potential multicollinearity problem, this should only increase the standard errors of the coefficients if they are collinear. Even given that this should not influence the coefficients, the models' variance inflation factors (VIF's), reject the possibility of a potential multicollinearity problem here in the first place.
} 


\begin{tabular}{|c|c|c|c|c|}
\hline & (5) & $(6)$ & (7) & (8) \\
\hline \multicolumn{5}{|c|}{ Second stage Contribute } \\
\hline VARIABLES & Tobit & Tobit & OLS & OLS \\
\hline \multirow{2}{*}{$\begin{array}{l}\text { First stage } \\
\text { Contribute }\end{array}$} & $0.450^{* * *}$ & $0.357^{* *}$ & $0.237^{* *}$ & $0.204^{* *}$ \\
\hline & $(0.16)$ & $(0.17)$ & $(0.09)$ & $(0.10)$ \\
\hline \multirow{2}{*}{$\begin{array}{l}\text { Social value } \\
\text { orientation }(\mathrm{SVO})\end{array}$} & $-4.236^{* *}$ & $-3.651^{* *}$ & $-1.932^{* *}$ & $-1.558^{*}$ \\
\hline & $(1.64)$ & $(1.63)$ & $(0.90)$ & $(0.93)$ \\
\hline \multirow[t]{2}{*}{ Risk parameter } & $7.373^{* *}$ & $8.286^{* *}$ & $3.943^{* *}$ & $4.450^{* *}$ \\
\hline & $(3.47)$ & $(3.27)$ & $(1.94)$ & $(1.89)$ \\
\hline \multirow[t]{2}{*}{ Female } & 12.473 & 13.703 & 1.760 & 1.975 \\
\hline & $(8.85)$ & $(9.15)$ & $(4.73)$ & $(5.21)$ \\
\hline \multirow[t]{2}{*}{ Age } & $4.765^{* *}$ & $3.581^{*}$ & $2.448^{*}$ & 1.806 \\
\hline & $(2.17)$ & $(1.93)$ & $(1.23)$ & $(1.18)$ \\
\hline \multirow[t]{2}{*}{ Exogenous lose } & 10.133 & 15.906 & 2.001 & 5.370 \\
\hline & $(11.71)$ & $(11.90)$ & $(5.48)$ & $(6.09)$ \\
\hline \multirow[t]{2}{*}{ Exogenous win } & $25.783^{* *}$ & $26.397^{* *}$ & $12.650^{*}$ & $12.959^{*}$ \\
\hline & $(12.54)$ & $(12.70)$ & $(6.36)$ & $(6.78)$ \\
\hline \multirow[t]{2}{*}{ Competition win } & $31.806^{* * *}$ & $33.932^{* * *}$ & $14.593^{* * *}$ & $16.219^{* *}$ \\
\hline & $(10.73)$ & $(12.21)$ & $(5.19)$ & $(6.25)$ \\
\hline \multirow[t]{2}{*}{ Politics important } & & $-14.516^{* *}$ & & $-7.570^{* *}$ \\
\hline & & $(6.44)$ & & $(3.50)$ \\
\hline \multirow[t]{2}{*}{ Trust in others } & & 10.791 & & 5.402 \\
\hline & & $(7.38)$ & & $(4.58)$ \\
\hline \multirow[t]{2}{*}{ Income Equality } & & 2.001 & & 1.274 \\
\hline & & $(2.80)$ & & $(1.49)$ \\
\hline \multirow[t]{2}{*}{ Constant } & 58.386 & 64.972 & 41.763 & 41.404 \\
\hline & $(96.01)$ & (103.90) & $(55.26)$ & $(62.00)$ \\
\hline $\mathrm{N}$ & 181 & 181 & 181 & 181 \\
\hline (Pseudo) R-squared & 0.041 & 0.057 & 0.205 & 0.279 \\
\hline
\end{tabular}

\section{Table 2.3: Determinants of stage 2 contribution}

Competition lose Subject in the competition treatment in a group that lost in the first stage. This is the default in regressions (5) through (8).

Competition win Subject in the competition treatment in a group that won in the first stage.

In consonance with the hypothesis tests above, both Exogenous win and Competition win are significantly positive, confirming that winning in the first stage leads to higher contributions to the team project.

Figure 2.3 adds to the observation that there exists a somewhat heterogeneous relationship between treatments and winning and losing groups, respectively. The graph depicts the 
relationship between individual lottery tickets purchased (stage 1 contribution) and input into the team project. It appears that for both winning and losing teams in the competition treatment, it is the subjects that contributed more to the between group contest before, who also chip in for the team project subsequently. For the exogenous treatment this seems considerably less clear cut. This conjecture is confirmed by the results of a Spearman test, where for the competition treatment, both individuals from winning (Spearman test: $\mathrm{N}$ $=48$, Spearman's rho $=0.415, \mathrm{P}=0.003$ ) and losing teams (Spearman test: $\mathrm{N}=48$, Spearman's rho $=0.429, \mathrm{P}=0.002$ ) display a significant positive correlation between stage 1 and stage 2 contributions. For the exogenous treatment, neither individuals from the winning (Spearman test: $\mathrm{N}=48$, Spearman's rho $=0.100, \mathrm{P}=0.512$ ) nor the losing teams (Spearman test: $\mathrm{N}=48$, Spearman's rho $=-0.186, \mathrm{P}=0.222$ ) display a significant correlation in this regard.

Using a Tobit model with robust standard errors for intragroup correlation and limits at 0 and 100, we regress contribution to the team project on first stage contribution and a few controls. ${ }^{15}$ Consider Tables 2.4 and 2.5, where each of the four situations are analysed separately: Losing / winning groups of the exogenous and losing / winning groups of the competition treatment, each with and without control variables. ${ }^{16}$

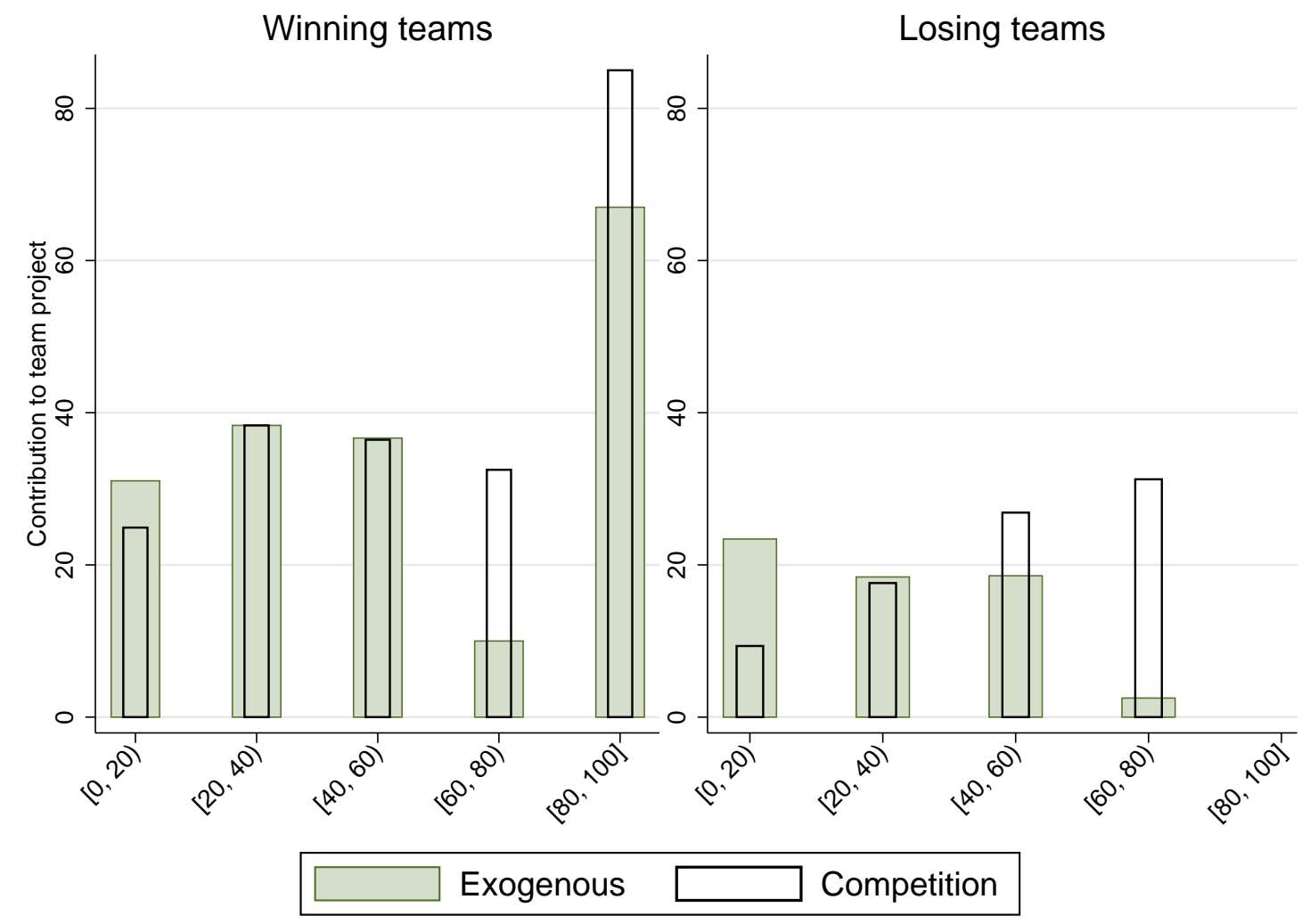

\section{Figure 2.3: Contribution to the team project in relation to individual lottery tickets purchased}

\footnotetext{
${ }^{15}$ Results for corresponding models using OLS regression stay qualitatively identical. They are presented in Appendix 2.E.

${ }^{16}$ In Appendix 2.E we discuss these in a more detail in an explorative analysis.
} 
For the competition treatment there mostly exists a clear positive relationship between contribution to the lottery game and to the team project. This means that relatively poorer subjects spend more to the team project. This is not the case, however, for the exogenous treatment: Here only Regression (9) displays a significant negative coefficient.

On what concerns the aforementioned opposing effect for the losing teams, the data analysis indicates a definite trend towards opposite directions for the two situations in question: While the factor "First stage Contribute" has a slightly negative coefficient in Regression (9), it is positive in Regressions (13) and (14).

Also, the unintuitive negative effect of social value orientation (SVO) reappears for the competition treatment in all regressions (13) - (16). This relationship does not exist,

\begin{tabular}{lcc|cc}
\hline & \multicolumn{3}{c}{ Contribution to the team project } \\
\cline { 2 - 5 } VARIABLES & \multicolumn{2}{c}{$(9)$} & $(10)$ & \multicolumn{2}{c}{$(11)$} & $(12)$ \\
\hline First stage & $-0.787^{*}$ & -0.507 & -0.239 & 0.340 \\
Contribute & $(0.44)$ & $(0.31)$ & $(0.40)$ & $(0.24)$ \\
Social value & -3.760 & -0.364 & -4.063 & -1.082 \\
orientation (SVO) & $(2.53)$ & $(1.57)$ & $(3.49)$ & $(3.75)$ \\
Constant & 299.156 & 36.099 & 89.393 & 68.190 \\
& $(197.29)$ & $(76.27)$ & $(198.21)$ & $(190.44)$ \\
\hline Controls & $Y e s$ & $N o$ & $Y e s$ & No \\
$\mathrm{N}$ & 43 & 45 & 44 & 45 \\
Pseudo R-squared & 0.162 & 0.008 & 0.166 & 0.005 \\
\hline$* \mathrm{p}<0.10, * * \mathrm{p}<0.05, * * * \mathrm{p}<0.01$ & & &
\end{tabular}

Robust standard errors in parentheses.

Table 2.4: Exogenous treatment.

\begin{tabular}{lcc|cc}
\hline & \multicolumn{4}{c}{ Contribution to the team project } \\
\cline { 2 - 5 } VARIABLES & \multicolumn{2}{c}{ Competition lose } & Competition win \\
\hline First stage & $0.516^{*}$ & $1.020^{* *}$ & 0.292 & $0.659^{* *}$ \\
Contribute & $(0.29)$ & $(0.42)$ & $(0.20)$ & $(0.29)$ \\
Social value & $-7.092^{* * *}$ & $-6.295^{*}$ & $-5.044^{*}$ & $-8.776^{* *}$ \\
orientation (SVO) & $(2.20)$ & $(3.46)$ & $(2.54)$ & $(3.85)$ \\
Constant & $839.238^{* * *}$ & 288.492 & -22.327 & $458.028^{* *}$ \\
& $(188.87)$ & $(178.36)$ & $(169.36)$ & $(202.28)$ \\
\hline Controls & $Y e s$ & No & $Y e s$ & $N o$ \\
$\mathrm{~N}$ & 46 & 48 & 47 & 48 \\
Pseudo R-squared & 0.255 & 0.051 & 0.213 & 0.061 \\
\hline$*$ p $<0.10, * * \mathrm{p}<0.05, * * * \mathrm{p}<0.01$ & & \\
Robust standard errors in parentheses.
\end{tabular}

Table 2.5: Competition treatment. 
though, for the exogenous treatment, where the explanatory power of the SVO measure is not significantly different from zero.

Figure 2.4 depicts jittered scatter plots for each of the four situations, as outlined above. It captures the heterogeneous effect of first stage contribution on subjects' willingness to cooperate in the team project. The solid line represents the fitted values determined by Tobit regression, with clustered standard error at the group level and boundaries at 0 and 100. For the losing teams, the treatment difference in the relationship between lottery tickets and contribution to the team project becomes apparent. While it is a sharply increasing function for the competition treatment, it has a negative slope in the exogenous treatment.

Further evidence is delivered by regression results in Table 2.6, in which we test for the difference in the regression's slope and intercept. When comparing the four aforementioned situations we take losing in the competition treatment (lose,comp) as benchmark. The slopes for the exogenous treatment are significantly lower than in the competition treatment, which debunks inequality 1 of Hypothesis 2.4.3. The second inequality has been rejected by our results from Tables $2.3-2.5$ (as well as Tables 2.7 and 2.8) in favour of Hypothesis 2.4.2. The results in this subsection establish that subjects' second stage behaviour is not consistent with inequality aversion or reciprocity; instead first stage spending is used as costly signalling device for the following team project phase. Furthermore, participants are much more prone to a sunk cost fallacy under deliberate sunk costs, than

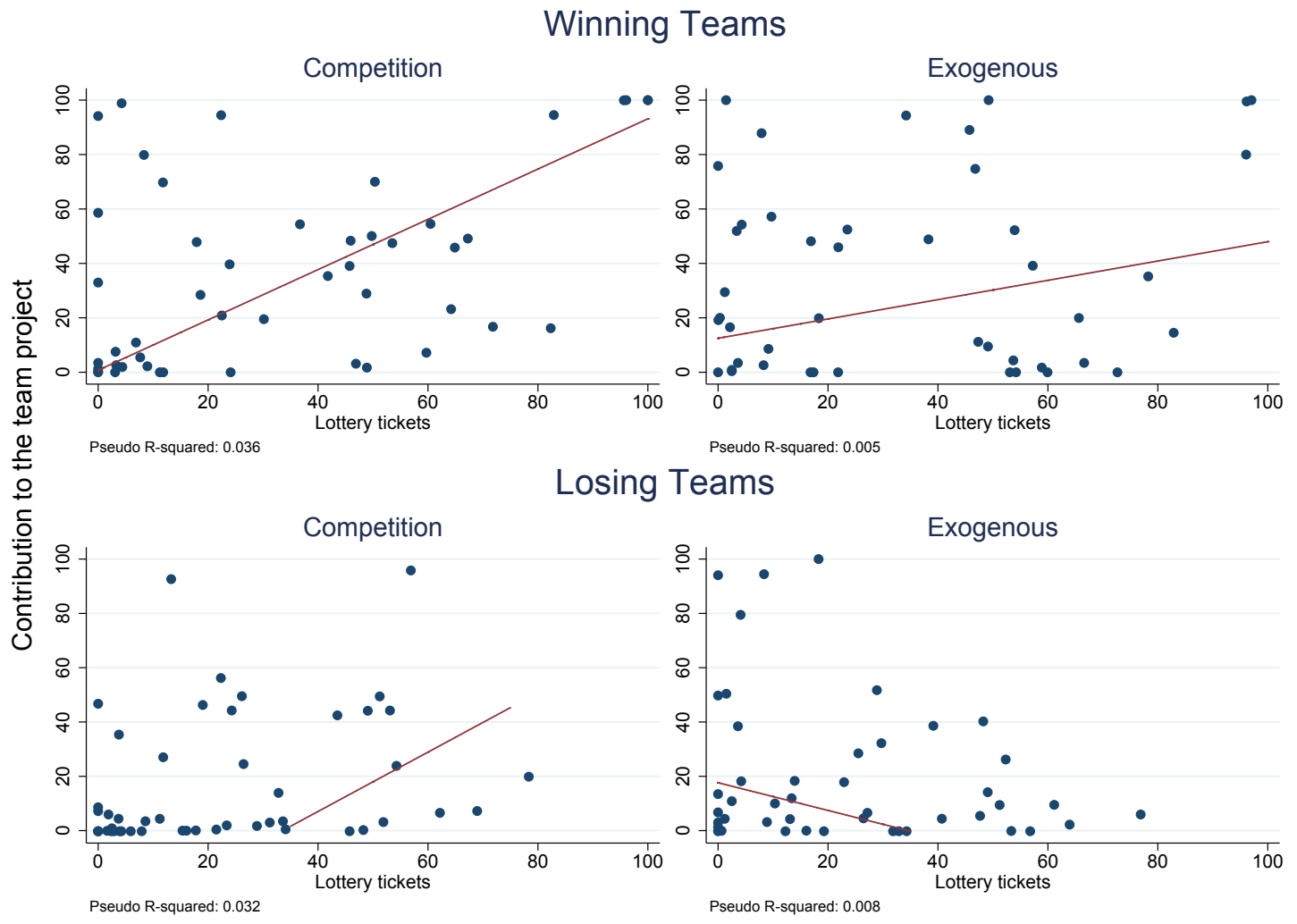

Figure 2.4: Relationship between first stage and second stage contribution and fitted regression line 
if these have been incurred exogenously.

\begin{tabular}{|c|c|c|}
\hline \multirow[b]{3}{*}{ VARIABLES } & (17) & (18) \\
\hline & \multicolumn{2}{|c|}{ Second stage Contribut } \\
\hline & Tobit & OLS \\
\hline First stage & $1.109^{* * *}$ & $0.366^{* *}$ \\
\hline Contribute & $(0.39)$ & $(0.15)$ \\
\hline Slope lose,ex & $\begin{array}{c}-1.649^{* * *} \\
(0.51)\end{array}$ & $\begin{array}{c}-0.681^{* * *} \\
(0.21)\end{array}$ \\
\hline Slope win,ex & $\begin{array}{c}-0.770^{*} \\
(0.42)\end{array}$ & $\begin{array}{c}-0.150 \\
(0.19)\end{array}$ \\
\hline Slope win,comp & $\begin{array}{r}-0.201 \\
(0.46)\end{array}$ & $\begin{array}{c}0.142 \\
(0.21)\end{array}$ \\
\hline Intercept lose,ex & $\begin{array}{l}53.591^{* * *} \\
(16.99)\end{array}$ & $\begin{array}{l}18.729^{* *} \\
(7.26)\end{array}$ \\
\hline Intercept win,ex & $\begin{array}{l}51.753^{* * *} \\
(17.15)\end{array}$ & $\begin{array}{l}19.043^{* * *} \\
(7.03)\end{array}$ \\
\hline Intercept win,comp & $\begin{array}{c}39.128^{* *} \\
(18.78)\end{array}$ & $\begin{array}{l}11.893 \\
(7.97)\end{array}$ \\
\hline Constant & $\begin{array}{c}-37.689^{* *} \\
(14.61)\end{array}$ & $\begin{array}{l}7.903^{*} \\
(4.18)\end{array}$ \\
\hline $\mathrm{N}$ & 186 & 186 \\
\hline (Pseudo) R-squared & 0.034 & 0.179 \\
\hline
\end{tabular}

Robust standard errors in parentheses.

\section{Table 2.6: Comparing Slopes and Intercepts}

Furthermore, the intercept for win,comp in Regression (17) is significantly higher than its counterpart from the losing situation, while the two slopes are about the same. This is some evidence that in the competition treatment, losing the between group contest pans out as constant drag on a group's cooperation level towards the team project, irrespective of the lottery spending in particular. This is also reflected in the number of zero contributions, which is more than twice of what we observe at winning groups in this treatment.

\subsubsection{Regression to the mean}

In Section 2.1 we argue that subjects who find themselves in the position of the group's "workhorse" - by having purchased more lottery tickets than their teammates - could cut back on second stage contribution because of a feeling of entitlement of the sort "I brought us here, now you pay me off". Figure 2.5 illustrates this regression to the mean effect in a jittered scatter plot with individual first stage contribution relative to the average of the other team members on the $\mathrm{x}$-axis and the difference between individual first and second stage contribution on the y-axis. The solid line represents the fitted OLS regression with standard errors clustered at the group level. Indeed, subjects who contribute more relative to their other group members in the first stage, tend to reduce their spending level in the 


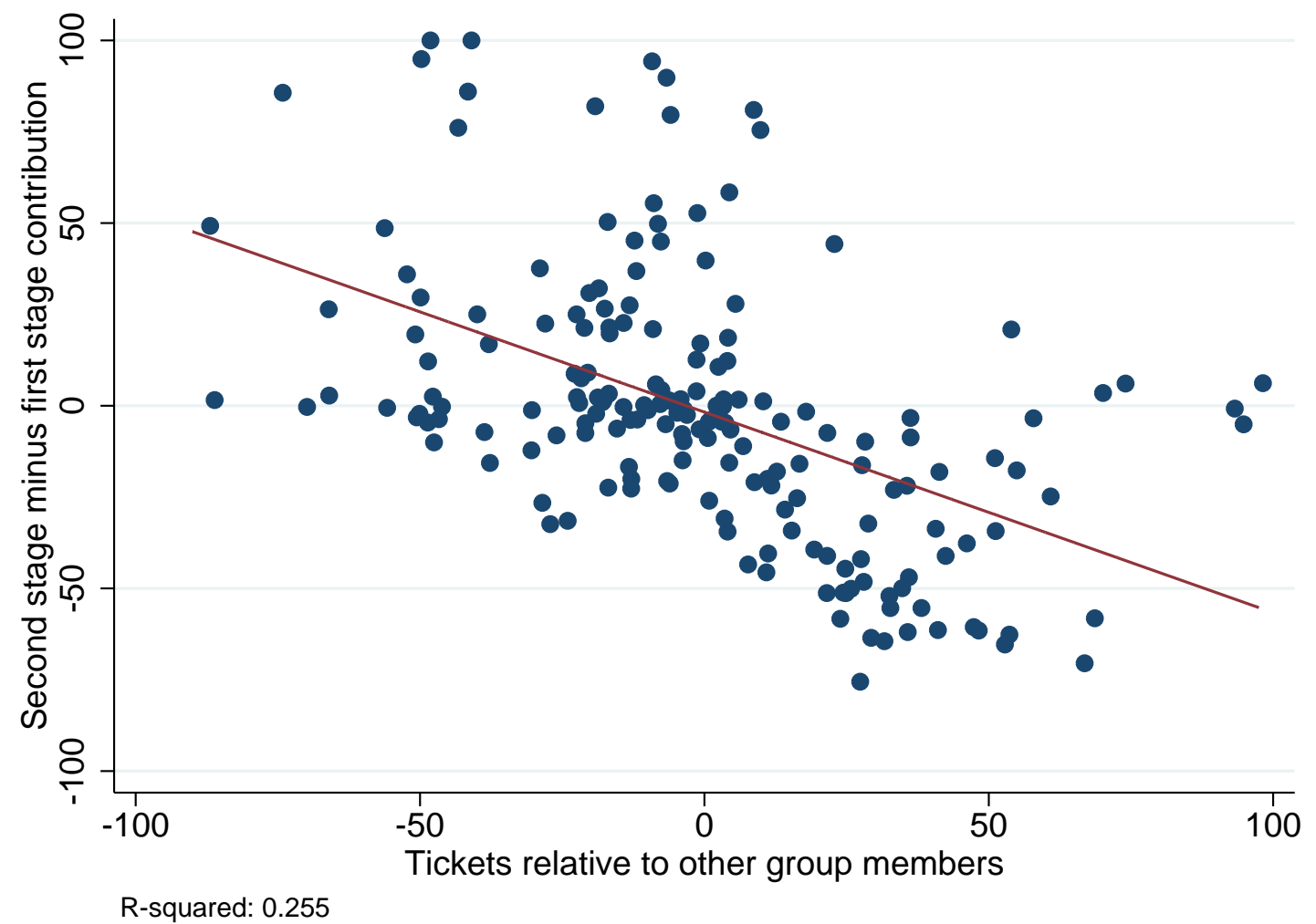

Figure 2.5: Regression to the mean effect

second stage, which is indicated by the fitted line's negative slope (OLS regression with clustered standard errors. $\mathrm{N}=186$, Coef. $=-0.549, \mathrm{P}=0.000)$.

This result relates to our findings discussed above insofar as that the positive relationship between first and second stage contribution prevails from a general perspective. Yet overall spread between contributors and defectors gets weakened.

\subsection{Conclusion}

In this chapter we present an experimental study in which we analyse how individuals react to heterogeneous sunk costs in a public good games setting. In specific, we investigate two types of sunk costs: Deliberately accrued expenses and exogenously imposed deductions. We argue that although they are economically equivalent, subjects will not derive the same consequences.

Subjects in the competition treatment spend resources to influence the probability for getting their group sorted into a public good game with a higher MPCR. Players in the exogenous treatment, on the other hand, do not make this decision themselves. Instead there is a one-on-one matching with the contest from the competition treatment.

In equation 2.4.1 we specify our hypothesis concerning the average contribution levels for the four different scenarios. While our data clearly indicates a higher contribution level 
for those groups that have been sorted to the higher MPCR game, results for the other two inequalities are considerably less clear cut. In our tests for hypotheses 2.4.2 and 2.4.3 we examine the interrelation of first and second stage contribution. Our results corroborate hypothesis 2.4.2 at the expense of its counterhypothesis. The positive relationship between first and second stage contribution mainly prevails in the competition treatment, where it is utilised as costly signalling and sacrifice.

Furthermore, players in the competition treatment have a slightly higher tendency to refrain from contributing to the public good, when their team has lost. An equivalent higher contribution level for winning groups in the competition treatment, however, cannot be observed.

This means that players in the underlying game do not perceive a positive outcome of the between-group contest as signal for their group-mates' willingness to cooperate, as compared to when they reach the high MPCR by exogenous sorting. At the same time, subjects display a reduced willingness to cooperate with their teammates, when the group failed to attain the high MPCR game in the contest, as compared to the exogenous sorting.

Coming back to the aforementioned case of between company competition for a business deal, the implications derived from our results, vindicate a rather sceptical angle on a tendering of commercial covenants. If both candidates dispose of comparable productivity levels, the harm to the losing party is not met by an analogous positive burst of the winning party. From an overall social welfare perspective, devising a method of arbitration which avoids a between group contest would be favourable. To further test this policy advice, different ways of arbitration could be examined: Make both parties pay in equal amounts, or have the winner pay for it completely, amongst other conceivable sharing rules. The caveat of a subliminal latent contest might still apply in most settings, however.

\section{Appendix 2.A Social Value Orientation-Measure}

Prior to the main part of the experiment, we take a measurement of individual social preferences, using the SVO slider measure by Murphy et al. (2011). ${ }^{17}$ Subjects set six sliders to determine mutual sharing of an amount of tokens, as represented in Figure 2.6. This was incentivised in the following way: After all participants cast their decisions, pairs of two were randomly created with one being the Sender and the other participant being the Receiver. One of the Sender's decisions was implemented on both at random, where the Sender gets what she allocated to herself and the Receiver gets what the Sender allocated to her. Participants only got to know, which allocation was chosen to be paid out, after the main part of the experiment.

This technique was a simplification and adjustment of the circle test employed by Brandts, Riedl, and van Winden (2009); Sonnemans, van Dijk, and van Winden (2006). It has demonstrated reliable psychometric properties, yields scores for individuals at the ratio level and is quick and easy to implement (cf. Murphy and Ackermann, 2014).

\footnotetext{
${ }^{17}$ Crosetto, Weisel, and Winter (2012) provide a helpful tool for implementation.
} 

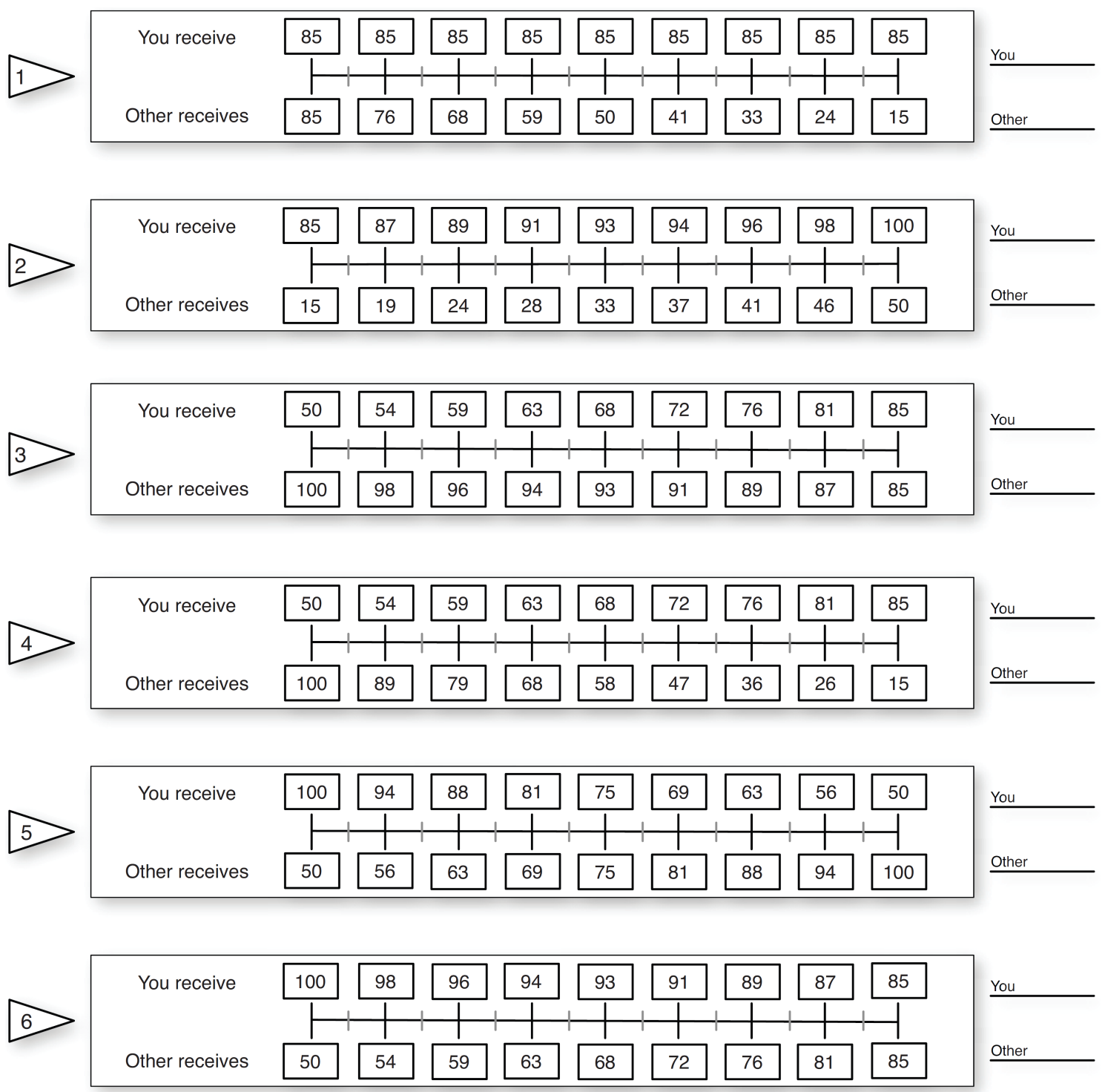

Figure 2.6: Slider questions as seen by the subjects to measure Social Value Orientation.

\section{Appendix 2.B Instructions}

The instructions consisted of two parts. When entering the computer laboratory, participants found a printed copy of the first-part of instructions at their seat. They learned about the structure of the experiment, the exchange rate between points and pound sterling, as well as the SVO measure. The instructions were read aloud before subjects started with the SVO slider task. After this, the second set of instructions was handed out, in which the main part of the experiment was explained. These instructions were read aloud as well. Paragraphs starting with a treatment name in square brackets were only given to subjects of that particular treatment. 


\section{Instructions Part 1}

Welcome and thank you for participating in this experiment. Please read these instructions carefully. If you have any questions, please raise your hand and one of the experimenters will come to your cubicle to answer your question. Talking or using mobile phones or any other electronic devices is strictly prohibited. Mobile phones and other electronic devices should be switched off. If you are found violating these rules, you will both forfeit any earnings from this experiment, and may be excluded from future experiments as well.

This is an experiment about decision making. The instructions are simple and if you follow them carefully you might earn a considerable amount of money which will be paid to you privately and in cash at the end of today's session. The amount of money you earn depends on your decisions, on other participants' decisions and on random events. You will never be asked to reveal your identity to anyone during the course of the experiment. Your name will never be associated with any of your decisions. In order to keep your decisions private, do not reveal your choices to any other participant.

During the experiment you will have the chance to earn points, which will be converted into cash at the end of today's session, using an exchange rate of

$$
1 \text { point }=5 \text { pence. }
$$

Thus, the more points you earn, the more cash you will receive at the end of the session.

This experiment consists of two parts. The following instructions explain Part 1. After finishing this part, you will receive further instructions for Part 2. None of your (or anyone else's) decisions for one part are relevant for your (or anyone else's) performance in the other part.

\section{Part 1:}

In this task you will be randomly paired with another person in this room. You will make a series of decisions about allocating points between you and the other person.

Then one of you will be assigned the role of Sender and the other one the role of Receiver. If you are the Sender, ONE of your decisions will be picked randomly and implemented for both of you (i.e. you receive what you allocated to yourself and the other person receives what you allocated to her).

If you are assigned the role of Receiver, ONE decision of the other person will be picked randomly and implemented for both of you (i.e. you receive what the other person allocated to you and the other person receives what she allocated to herself).

All of your choices are completely confidential. You will learn your results of Part 1 after Part 2 has finished. Points earned in Part 1 and Part 2 will be added up to determine your total earnings. 


\section{Instructions Part 2}

In Part 2, all participants are assigned to teams of three and your team will be matched with another team. None of you will learn the identities of own team members or other team members. Part 2 will consist of two stages:

[Competition treatment:] At the beginning of the first stage you will receive 200 points. Then you can use up to 100 of your points to buy lottery tickets for your team. Each lottery ticket costs 1 point. Any of your points not spent on lottery tickets will be accumulated in your private point balance. Likewise, each of your team members receives 200 points and can use up to 100 of these points to buy lottery tickets for your team. Similarly, each member of the other team will receive 200 points and can buy tickets for their team in exactly the same way.

[Exogenous treatment:] At the beginning of the first stage you will receive 200 points. Then the computer can use up to 100 of your points to buy lottery tickets for your team. Each lottery ticket costs 1 point. Any of your points not spent on lottery tickets will be accumulated in your private point balance. Likewise, each of your team members receives 200 points and the computer can use up to 100 of these points to buy lottery tickets for your team. Similarly, each member of the other team will receive 200 points and the computer can buy tickets for their team in exactly the same way.

Next, a lottery will determine whether your team, or the team you are matched with, wins. One of the tickets is randomly selected to be the winning ticket. Each ticket has the same chance. Hence, the more tickets your team has, the higher is your team's chance of winning.

Examples: If your team and the other team have the same amount of tickets then each team is equally likely to win. If your team has three times as many tickets as the other team, then your team is three times as likely to win as the other team. If only one of the teams has tickets, then this team wins with certainty. If neither your team nor the other team has any tickets, then one of the teams will be randomly selected as the winner with each team equally likely to be selected.

After the winning team is determined you will reach the second stage. You will be able to see the following information: Individual tickets for each of your team mates, other team's tickets and your winning probability. The second stage differs between the winning and the losing team in one way, which will be underlined below.

In the second stage you can invest up to 100 points of your endowment in a team project. Any point you do not invest and keep to yourself will be accumulated in your private point balance. Each point invested in the team project yields 0.8 points for you and every member of your team, if your team has won in the first stage. Similarly, each point invested in the team project yields 0.4 points for you and every member of your 
team if your team has lost in the first stage. Likewise, your team members can invest in the team project in the same way.

A summary of how your Part 2 earnings will be determined is provided on the next page.

This part starts with a trial period in which you will be asked to answer some questions in order to check your understanding and to give you the opportunity to get acquainted with the setup. Points earned in this trial period will not be paid off.

Summary: Your earnings for this part are determined as follows:

\section{Winning team:}

Your Endowment $(=200)$

- Your tickets (between 0 and 100)

- Your contribution to the team project (between 0 and 100)

$+\quad 0.8 \times$ your team's total contribution to the team project

$=$ Your earnings

\section{Losing team:}

Your Endowment $(=200)$

- Your tickets (between 0 and 100)

- Your contribution to the team project (between 0 and 100)

$+0.4 \times$ your team's total contribution to the team project

$=$ Your earnings

\section{Appendix 2.C Risk Neutral Equilibrium}

Second stage Players individually maximise own profit $\pi_{i}$ by setting her contribution $w_{i}$ :

$$
\pi_{i}\left(w_{i}\right)=T 2-w_{i}+M P C R \cdot \sum_{i \in I} w_{i}
$$

with $M P C R \in H i \cup L o$. As $\pi_{i}^{\prime}<0$ and $\pi_{i}^{\prime \prime}=0$, there exists a corner solution $w_{i}=0$.

First stage Under common knowledge of rationality, players know that $w_{i}=0$ and maximise

$$
\pi_{i}\left(v_{i}\right)=T 1-\frac{v_{i}+\sum_{\substack{k \neq i \\ k \in K}} v_{K}}{v_{i}+\sum_{\substack{k \neq i \\ k \in K}} v_{K}+\sum_{m \in M} v_{M}} \cdot z-v_{i}
$$

with $z=0$ being the expected earnings from stage 2. Again, a corner solution exists with $v_{i}=0$. 


\section{Appendix 2.D Contest Expenditures - The Role of Beliefs}

About $10 \%$ of first stage contributions fall in an area which is not rationalisable (i.e. contributions larger than 65), even holding the most optimistic beliefs about the second stage (i.e. all other players contribute fully), while at the same time holding very pessimistic beliefs about groupmates' behaviour in the first stage (i.e. no other groupmate buys lottery tickets). When holding the same beliefs on second stage contributions, while assuming symmetry in first stage spending levels, some $46 \%$ fall in the category of non-rationalisability (contributions larger than $\frac{60}{3}=21 . \overline{6}$ ).

Second stage Player $i$ 's payoff depends positively on her teammates' input towards the team project $w_{k \in K \backslash\{i\}}$, as in:

$$
\frac{\partial \pi_{i}}{\partial w_{k \in K \backslash\{i\}}}>0
$$

Hence, player $i$ 's most optimistic belief for the second stage would involve full contribution by all other group members, i.e. $w_{k \in K \backslash\{i\}}=100 \forall k \in K$, which would amount to an account of $\sum_{k \in K} w_{k}=200$ and expected second stage earnings of $z=T 2+H i \cdot \sum_{k \in K} w_{k}=260$ for a winning group.

First stage Most pessimistic beliefs about teammates' contest spending behaviour are characterised as $v_{k \in K \backslash\{i\}}=0 \forall k, i \in K$. If all teammates do not buy lottery tickets $\left(\sum_{k \in K \backslash\{i\}}=0\right)$ and expected second stage payoff $z=260$, player $i$ maximises equation 2.C.2 at $v_{i}=\frac{z}{4}=65$.

Consider as alternative belief on first stage behaviour, that all teammates contribute symmetrically, i.e. $\sum_{k \in K} v_{k}=3 \cdot v_{k} \forall k \in K$. For this set of beliefs, equation 2.C.2 maximises at $v_{i}=\frac{z}{12}=21 . \overline{6}$.

\section{Appendix 2.E Control Variables and OLS regression}

Tables 2.7 and 2.8 present results for OLS regressions with robust standard errors for intragroup correlation, which correspond to those presented in Tables 2.4 and 2.5. We analyse the relationship between contribution to the team project and first stage contribution, including controls. Results stay relatively stable between the two regression methods in question.

In Table 2.9 we present details for the control variables of Tables 2.4 and 2.5. Those details were generated by a post-experiment questionnaire. We do not have well-established hypotheses for each of those control variables, for why we present this section in an explorative character.

The risk parameter has explanatory power only for regression (15). It was generated by a self-reported risk tolerance indication on a scale from 1 to seven. As players invest resources without knowing the contribution level of other teammates, contributing involves a certain degree of risk taking. Accordingly, it seems intuitively plausible that subjects displaying a higher level of risk tolerance would also contribute more to the team project. 


\begin{tabular}{lcccc}
\hline & \multicolumn{4}{c}{ Contribution to the team project } \\
\cline { 2 - 5 } VARIABLES & \multicolumn{2}{c}{$(19)$} & $(20)$ & \multicolumn{2}{c}{$(21)$} & $(22)$ \\
\hline First stage & -0.430 & $-0.324^{*}$ & -0.153 & 0.211 \\
Contribute & $(0.29)$ & $(0.16)$ & $(0.33)$ & $(0.13)$ \\
Social value & -0.490 & 0.795 & -1.616 & -0.348 \\
orientation (SVO) & $(1.49)$ & $(1.04)$ & $(3.02)$ & $(2.29)$ \\
Constant & 84.189 & -13.805 & 100.986 & 44.876 \\
& $(134.15)$ & $(50.17)$ & $(181.82)$ & $(117.35)$ \\
\hline Controls & $Y e s$ & $N o$ & $Y e s$ & $N o$ \\
N & 43 & 45 & 44 & 45 \\
R-squared & 0.574 & 0.067 & 0.600 & 0.037 \\
\hline
\end{tabular}

$* \mathrm{p}<0.10,{ }^{* *} \mathrm{p}<0.05,{ }^{* * *} \mathrm{p}<0.01$

Robust standard errors in parentheses.

Table 2.7: OLS regression exogenous treatment.

\begin{tabular}{|c|c|c|c|c|}
\hline \multirow[b]{3}{*}{ VARIABLES } & \multicolumn{4}{|c|}{ Contribution to the team project } \\
\hline & $(23)$ & (24) & $(25)$ & $(26)$ \\
\hline & \multicolumn{2}{|c|}{ Competition lose } & \multicolumn{2}{|c|}{ Competition win } \\
\hline First stage & 0.108 & $0.337^{*}$ & 0.191 & $0.366^{*}$ \\
\hline Contribute & $(0.31)$ & $(0.16)$ & $(0.22)$ & $(0.18)$ \\
\hline $\begin{array}{l}\text { Social value } \\
\text { orientation (SVO) }\end{array}$ & $\begin{array}{c}-3.723^{* *} \\
(1.66)\end{array}$ & $\begin{array}{r}-2.490 \\
(1.57)\end{array}$ & $\begin{array}{r}-3.492 \\
(2.26)\end{array}$ & $\begin{array}{l}-5.151^{* *} \\
(2.19)\end{array}$ \\
\hline Constant & $\begin{array}{l}319.675^{* *} \\
(128.73)\end{array}$ & $\begin{array}{l}136.465 \\
(83.24)\end{array}$ & $\begin{array}{r}70.408 \\
(157.83)\end{array}$ & $\begin{array}{l}287.752^{* *} \\
(117.38)\end{array}$ \\
\hline Controls & Yes & No & Yes & No \\
\hline $\mathrm{N}$ & 46 & 48 & 47 & 48 \\
\hline R-squared & 0.656 & 0.171 & 0.763 & 0.330 \\
\hline
\end{tabular}

$* \mathrm{p}<0.10,{ }^{* *} \mathrm{p}<0.05,{ }^{* * *} \mathrm{p}<0.01$

Robust standard errors in parentheses.

Table 2.8: OLS regression competition treatment.

Results for the parameter female seem to paint a clear picture in that female participants tend to follow a more cooperative strategy towards the public good. Unlike our results for gender effects in first stage contribution, this positive relationship seems in line with established literature (eg. Stockard, van de Kragt, and Dodge, 1988). ${ }^{18}$

Another factor that only plays a role in the competition treatment is the age of participants. Interestingly, subjects' age seems to accentuate the difference between winning and

\footnotetext{
${ }^{18}$ In a more recent study, Sell and Kuipers (2009) examine the gender bias in cooperation levels in the context of a structural social psychological framework. They argue that a large part of variation in gender specific willingness to cooperate can be explained by structural differences and identities of institutional rules and norms. Sell and Kuipers (2009) close with the optimistic note that these stereotypical gender roles, which are often perceived as innate, can in fact be overcome and ensuing social dilemmas be solved.
} 


\begin{tabular}{|c|c|c|c|c|}
\hline \multirow[b]{3}{*}{ VARIABLES } & \multicolumn{4}{|c|}{ Contribution to the team project } \\
\hline & (9) & $(11)$ & $(13)$ & $(15)$ \\
\hline & Exogenous lose & Exogenous win & Competition lose & Competition win \\
\hline First stage & $-0.787^{*}$ & -0.239 & $0.516^{*}$ & 0.292 \\
\hline Contribute & $(0.44)$ & $(0.40)$ & $(0.29)$ & $(0.20)$ \\
\hline Social value & -3.760 & -4.063 & $-7.092^{* * *}$ & $-5.044^{*}$ \\
\hline Risk parameter & $\begin{array}{r}(2.00) \\
-9.832 \\
(7.23)\end{array}$ & $\begin{array}{l}(3.49) \\
13.141 \\
(8.62)\end{array}$ & $\begin{array}{c}(2.20) \\
-2.729 \\
(3.83)\end{array}$ & $\begin{array}{l}22.969^{* * *} \\
(6.09)\end{array}$ \\
\hline Female & $\begin{array}{l}35.737^{* *} \\
(14.17)\end{array}$ & $\begin{array}{l}14.085 \\
(18.21)\end{array}$ & $\begin{array}{l}26.291^{* *} \\
(9.70)\end{array}$ & $\begin{array}{l}52.727^{* * *} \\
(17.47)\end{array}$ \\
\hline Age & $\begin{array}{c}0.992 \\
(2.31)\end{array}$ & $\begin{array}{c}0.052 \\
(2.71)\end{array}$ & $\begin{array}{c}-20.391^{* * *} \\
(5.49)\end{array}$ & $\begin{array}{l}9.928^{* * *} \\
(2.22)\end{array}$ \\
\hline Number of siblings & $\begin{array}{l}19.924^{* *} \\
(9.15)\end{array}$ & $\begin{array}{r}-0.270 \\
(6.83)\end{array}$ & $\begin{array}{l}16.754^{* *} \\
(6.88)\end{array}$ & $\begin{array}{c}-13.654^{* *} \\
(6.27)\end{array}$ \\
\hline Smoking & $\begin{array}{c}-59.675^{* *} \\
(25.90)\end{array}$ & $\begin{array}{r}57.434 \\
(42.68)\end{array}$ & $\begin{array}{c}-36.565 \\
(25.19)\end{array}$ & $\begin{array}{c}-150.414^{* * *} \\
(40.08)\end{array}$ \\
\hline Happy & $\begin{array}{c}-6.822 \\
(8.65)\end{array}$ & $\begin{array}{c}-15.315^{*} \\
(8.50)\end{array}$ & $\begin{array}{l}31.942^{* * *} \\
(10.43)\end{array}$ & $\begin{array}{l}27.330^{* * *} \\
(7.73)\end{array}$ \\
\hline Income Equality & $\begin{array}{l}13.046^{* *} \\
(5.08)\end{array}$ & $\begin{array}{l}14.445^{* *} \\
(6.10)\end{array}$ & $\begin{array}{c}-3.642 \\
(3.88)\end{array}$ & $\begin{array}{c}-14.538^{* * *} \\
(4.64)\end{array}$ \\
\hline Hard work & $\begin{array}{c}-11.145^{* * *} \\
(3.81)\end{array}$ & $\begin{array}{r}4.959 \\
(5.78)\end{array}$ & $\begin{array}{c}-7.584^{* *} \\
(2.97)\end{array}$ & $\begin{array}{c}-6.857^{* *} \\
(3.21)\end{array}$ \\
\hline Constant & $\begin{array}{r}299.156 \\
(197.29)\end{array}$ & $\begin{array}{r}89.393 \\
(198.21)\end{array}$ & $\begin{array}{l}839.238^{* * *} \\
(188.87)\end{array}$ & $\begin{array}{l}-22.327 \\
(169.36)\end{array}$ \\
\hline $\mathrm{N}$ & 43 & 44 & 46 & 47 \\
\hline Pseudo R-squared & 0.162 & 0.166 & 0.255 & 0.213 \\
\hline
\end{tabular}

Table 2.9: Effect of first stage contribution and dummies on cooperation level in the team project.

losing groups along the lines of hypothesis 2.4.1. By contrast, number of siblings works in the opposite effect. Furthermore this effect also partly prevails for the exogenous treatment. Experimental results from a trust game in Glaeser, Laibson, Scheinkman, and Soutter (2000) suggest that subjects with siblings are a lot more trustworthy than only child subjects: the latter only returned about half as much money to the senders as the former. In our study, this effect only persists in losing groups with a lower structural contribution level. Therefore, number of siblings could represent a regression to the mean effect that attenuates "extreme" levels of contribution.

In the questionnaire we asked participants whether they smoke or not and if they do so regularly or only sometimes. We include this parameter as proxy for short-sightedness of utility horizons (cp. Slovic, 2001). Indeed, subjects with a higher self-reported level of tobacco consumption, contribute less to the team project. This effect is particularly pronounced in regressions (9) and (15). In consonance with the line of reasoning in Slovic (2001), we construe that (frequent) smokers exhibit a shorter time horizon for their decisions. 
Accordingly, they pick the bird in the hand - keep the 100 tokens to themselves - over the two in the bush - potential gains from the group project.

Curiously, subjects reporting a higher level of momentary happiness in general, tend to give more in the competition treatment, but not in the exogenous treatment. If anything, regressions for the latter treatment even find a negative relationship. To our knowledge, while there exists some literature presenting cooperativeness as cause of happiness ( $\mathrm{Lu}$ and Argyle, 1991), the opposite causal relationship has not yet received equal attention.

Again, for the factor income equality, individuals stated their proximity to which of the two following statements they feel closer on a scale from one to seven: "We need larger income differences as incentives for individual effort." - "Incomes should be made more equal." Accordingly, this factor aims at capturing individual preferences for either a steep or flat income curve. Similar to the previously discussed regressor, income equality displays opposite effects for the two treatments. While there seems to be a positive relationship in the exogenous treatment, the parameter turns negative for regressions using subjects from the competition treatment.

The last parameter, hard work intends to pick up a certain dog-eat-dog mentality as in whether subjects believe that everyone is the architect of ones own fortune or if success is a matter of luck. On a scale from one to seven, subjects express their proximity to one of the two statements: "Hard work doesn't generally bring success; it's more a matter of luck and connections." - "In the long run, hard work usually brings a better life." Those participants who rather believe that hard work pays off - "man forges his own destiny" are less willing to contribute to the group account in the team project phase of the game. 


\section{Chapter 3}

\section{Reward and Punishment in a Team Contest ${ }^{1}$}

\subsection{Introduction}

Cooperation in alliances or social groupings is commonly observed in many applications. On a higher tier, many living organisms build cooperative societies - but it already begins on the level of mutual assistance, for example within a neighbourhood. The central idea is that by working together, everyone benefits from the efforts of the other, resulting in a more efficient outcome than if everyone was working on their own. From the classical economic point of view, though, rational individuals do not contribute at an optimal level. As a result, positive welfare effects from efficient organisation cannot come to play.

There exists a strong tradition in philosophical and economic literature discussing the role of institutions to overcome this dilemma (Hobbes, 1651; Locke, 1698; Williamson, 1985; Ostrom, 1990). A simple form of institutionalising would be social ostracism or mobbing on the one hand, or promotion or appraisal on the other - mechanisms we frequently use in the absence of complete contracts. Earlier studies suggest that the installation of these systems can overcome the free-rider problem in dilemma games. In these studies, mobbing or appraisal are represented by the opportunity to punish or reward co-players, respectively (e.g. Rand, Dreber, Ellingsen, Fudenberg, and Nowak, 2009; Sefton, Shupp, and Walker, 2007; Sigmund, Hauert, and Nowak, 2001; Fehr and Gächter, 2000). Furthermore, punishment seems to work better in this regard than reward (Andreoni, Harbaugh, and Vesterlund, 2003; Balliet, Mulder, and Van Lange, 2011). The results are not yet fully conclusive, but already give a first indication for policy advice: Use the stick rather than the carrot.

Most related studies, however, focus on isolated groups, abstracting from a large class of situations where groups are not detached, but embedded in some form of competition. Examples for this are public tenders, sports team competition or alliances in military conflicts. We name these situations team contests or group contest games. The contest slightly changes the nature of the game: Contribution still has positive external effects onto other group members, but full free-riding is only a dominant strategy in a few cases

\footnotetext{
${ }^{1}$ Based on an article by Florian Heine and Martin Strobel (under review).
} 
(Konrad, 2009).

Exposing groups to an antagonistic competition might also change the relationship between reward and punishment. Indeed, it is difficult to imagine that punishment provides the glue to hold a team together when facing off against a common competitor. Imagine a football team when things are going badly. Would you imagine having one team member giving another a dressing down make the latter provide more effort or perform better? In point of fact, studies suggest that "in-group cohesiveness is associated with positive treatment (...) of the in-group" (Stephan, 1985).

Furthermore, when there is no distinction between an in-group and an out-group, like in standard public goods games, "people are unlikely to attend to the fact that they are interacting with in-group members" (Stephan, 1985). The differentiation between an own group and an out group creates a favouring atmosphere towards the own group from the get-go (Brewer, 1979) and can lead to the "ultimate attribution error" (Pettigrew, 1979). This is a social schema to explain away positive actions of out-group members as exceptions to the rule, for example. ${ }^{2}$

The central issue we investigate in this experimental study is the comparison of reward and punishment in team contests. Specifically, we consider which institution leads to more effort and the efficiency implications. Our hypothesis is that while punishment can bring about high contributions in team contest situations (like in Abbink et al., 2010), rewarding plays a more dominant role in this regard. In other words, the carrot will be preferred over the stick. On that account we employ two different environments, as will be explained in detail below: 1) A public good embedded in a team contest. 2) The same public good without a team contest. The purpose is to compare two environments that are strategically equivalent, but to eliminate the between group contest aspect as a factor in one environment. We execute this study as controlled computerised laboratory experiment, as this allows us to neatly design the environment and administer the appropriate institutional system.

Our results indicate a higher contribution level to the contest in the reward treatments, compared to the punishment treatments. Also, as well comparing between and within treatments, players distribute more reward than punishment. This gives a new perspective on group dynamics in interactive economic games. We argue that the environment a group faces, has significant influence on its social dynamics and preferences within the group. In line with the vast majority of research on rent-seeking or contest games, we find a drastic over-contribution across all our treatments, as compared to the Nash-equilibrium. ${ }^{3}$ This leads to an inefficient outcome and rent over-dissipation.

The remainder of this article is structured as follows: First, we discuss the nature of reward and punishment systems in economic games; in Section 3.3 we explain the setup of the experiment and the equilibrium prediction; Section 3.4 contains our results and interpretation; and in Section 3.5 we provide concluding comments and some suggestions for further research.

\footnotetext{
${ }^{2}$ Pettigrew (1979) mentions that this pattern of attributions is stronger if groups are in conflict with each other.

${ }^{3}$ Cf. Sheremeta (2015); Dechenaux et al. (2012); Öncüler and Croson (2005)
} 


\subsection{Reward and Punishment in Economic Games}

Providing the option to punish and / or reward other group members in public good games has repeatedly led to higher contributions in both experimental (Fehr and Gächter, 2000; Sefton et al., 2007; Rand et al., 2009; O'Gorman, Henrich, and Van Vugt, 2009) and theoretical (Sigmund et al., 2001; Sasaki, Brännström, Dieckmann, and Sigmund, 2012) studies. Furthermore, it seems that punishing works slightly better than rewarding in rendering higher contribution. Balliet et al. (2011) conduct a meta-analysis of the effectiveness of reward or punishment in social dilemmas. Their analysis includes 187 effect sizes from 76 papers. They find a higher effect of punishment for generating cooperation as compared to reward. Although being just marginally significant, a definite trend is evident towards a higher effectiveness of punishment in this regard.

Things might look differently though, when groups compete for a group prize. Previous studies suggest that engagement in a project or a group prize is higher if there is a conflict or a competition with another group (cf. Sherif, 1961; Bornstein and Ben-Yossef, 1994; Tan and Bolle, 2007; Goette et al., 2012). At the same time, in-group favouritism and out-group spite increases, a desire to benefit players from the own group and harm those from the competing group (Konrad and Morath, 2012). This can change the relative effectiveness of rewarding and punishing, as well as players' preference for either rewarding or punishing as means to reciprocate other group mates' actions.

There are two groups of psychological motivations for an in-group - out-group bias in a competitive game like the contest game. The first one considers cognitive factors. Doise (1976) argues that being categorised in competitive groups, an anticipatory-justification process is active, devaluing one's antagonists. Alternative explanations for the in-group out-group bias consider motivational factors. According to Tajfel (1978), people desire to compare the in-group in a favourable way towards the out-group.

The studies above suggest that the economic environment shapes social preferences. In changing the economic environment of a public goods game, introducing a contest for a group prize between groups, we expect to find contrasting results. In public goods games there is no competition between groups, but investment is socially beneficial, not unproductive effort, as in the contest game. Furthermore, reciprocity is one social preference and it is a prominent cause for conditional cooperation (play cooperatively if others do) (Gächter and Herrmann, 2009). ${ }^{4}$ The degree at which reciprocity is endogenous towards the economic environment determines whether a change in players' behaviour can be found.

Another major issue in experimental studies on contest games is players' persistent tendency to over-contribute and the ensuing effects on efficiency (cf. Öncüler and Croson, 2005). In an experimental study, Abbink et al. (2010) find that allowing for the opportunity to punish other group members in a contest game renders expenditure levels that are as far as $60 \%$ above those in the control treatment. Although it would be socially beneficial to reduce contributing to the contest, players incentivise group mates to increase their spendings to the contest. As a consequence, introducing the option to punish other group members leads to even higher over-contribution than in the control treatment with negative effects on total welfare. Including the costs for punishment, subjects' material losses are almost nine times higher than the loss at the equilibrium level with respect to the social

\footnotetext{
${ }^{4}$ Another cause for conditional cooperation would be conformity - players just do what others do.
} 
optimum.

\subsection{Experimental Design}

Our project brings together the two concepts of interaction in a contest game on the one hand and reward and sanctioning systems on the other. Experimental research in this field has mainly focused on either of the concepts. In combining these systems, insight can be gained into the interaction of the institutional system of rewarding / punishing with the contest / non-contest-environment. More specifically, we also consider what effect the presence of another competing group has in this regard. In related experiments by Sefton et al. (2007), agents are not in a competitive situation and in Abbink et al. (2010), participants have no opportunity to give rewards.

Comparison of contest vs. non-contest requires a design that makes both comparable. To this end we modify the classical group contest environment. In the non-contest environment we substitute the rival group by an equilibrium playing virtual mechanism. To subjects of the prevailing group this means that they are acting in a public good game in which overall effort decides about the likelihood to win the prize. We eliminate everything that relates to the between group contest - i.e. all mentioning of the teammates as a group / team or mentioning of a possible rival group and the level of strategic uncertainty, which stems from the other group's actions. What we do keep constant, however, is everything else in the game, that has nothing to do with the other group - i.e. players are subject to a degree of uncertainty about whether ot not they will attain the prize; we also keep the stage game Nash equilibrium constant.

Players are automatically sorted in groups of four. In the field, agents repeatedly interact with the same set of others; hence also throughout the experiment participants play with the same players both in the own and in the opponent group. ${ }^{5}$ Each player also keeps the same label throughout the experiment. The experiment is conducted over 15 rounds. This and all other features of the experiment are disclosed and are known to the participants.

The experiment is set up in a $2 \times 4$ design, with each four treatments with and four treatments without opponent group. In the treatments with opponent group, every group $K$ of four subjects competes against another group $M$ of four subjects. They compete by buying lottery tickets for their own group. Then one ticket will be drawn by the computer and this group wins a fixed prize. For the groups without opponent group, the other group is replaced by a fixed number of 25 blank tickets which do not result in rent payments if drawn. Furthermore, in the latter treatments, there is no mentioning of other groups at any time. Every round is partitioned into three distinct stages as described in what follows:

1. Each player receives an endowment (budget) of $B=100$ tokens and decides how much of it to invest in order to buy lottery tickets. The price for a ticket is one token. Investment of subject $k \in K$ of group $K$ is labelled $v_{k}$ and $m \in M$ of group $M$ is $v_{m}$. All tokens that a player does not invest will be added to her private account.

2. The winning probability, or contest success function, is as in Tullock (1980); Katz

\footnotetext{
${ }^{5}$ Not all treatments have an opponent group though.
} 
et al. (1990). For the contest environment:

$$
p_{K}\left(\left(v_{k}\right)_{k \in K},\left(v_{m}\right)_{m \in M}\right)= \begin{cases}\frac{\sum_{k \in K} v_{k}}{\sum_{k \in K} v_{k}+\sum_{m \in M} v_{m}} & \text { if } \max _{i \in K \cup M}\left\{v_{i}\right\}>0 \\ 1 / 2 & \text { otherwise }\end{cases}
$$

For the non-contest environment:

$$
p_{K}\left(\left(v_{k}\right)_{k \in K}\right)=\frac{\sum_{k \in K} v_{k}}{\sum_{k \in K} v_{k}+25}
$$

where $p_{K}$ is the probability that group $K$ wins (over group $M$ ). For the treatments without opponent, group $M$ is replaced by a total of 25 blank tickets, which is known to all players. As will be discussed in Section 3.3.1, this represents the Nash equilibrium group contribution. For this, imagine $\sum_{m \in M} v_{m}=25$ constantly in equation (4.E.1) to represent the blank tickets as in equation (4.E.2). The winning probability is the sum of all lottery tickets of the own group divided by one of the two (depending on the environment): a) the total lottery tickets bought by both groups, or $b$ ) the sum of total lottery tickets and blank tickets. After each investment phase, one ticket is drawn by the computer. Hence, the more tickets a group buys, the higher the chances of winning the lottery (ceteris paribus). Players of the winning group each receive a prize of $z=100$ tokens, the other group gets nothing. In the non-opponent treatments, if a blank ticket is drawn, the prize is forfeited.

3. The players get to know whether their group has won or not and how much the others in their group, each, contributed. They also get to know the number of lottery tickets bought by the opponent team, but not the opponent players' individual contributions (if applicable). As well, participants get to know, what their probability of winning was, which takes into account the sum of contributions of the opponent group / blank tickets. They now receive another $F=50$ tokens (response tokens), ${ }^{6}$ which they can either keep in their own account or spend to give a response to their own group members. ${ }^{7}$ To this end there are four treatments, each played with and without opponent (thus $2 \times 4$ setup):

[Baseline:] Players receive the aforementioned 50 response tokens at the end of each round to be added to their account directly. As in this treatment there is no further interaction between the players, these tokens are presented as extra tokens.

[Reward:] Players can reward co-players in their own group. For this, they assign response tokens to one or more players of their own group. Each response token player $k$ assigns to another player $l$ is subtracted from $k$ 's account and added to $l$ 's account. However, $k$ can also keep all response tokens for herself and let them be added to her own account. The players can at most invest all 50 response tokens per period (as sum of all response assigned to all co-players) and they cannot save tokens to be spent in upcoming rounds.

\footnotetext{
${ }^{6}$ These tokens were called Feedback tokens in the instructions (see Appendix 3.A).

${ }^{7}$ Throughout the chapter we regularly use the expression response when referring to the reward and punishment mechanism in order to ease the reading flow. As well, we make use of the term sanctioning as synonymous term for punishment.
} 
[Punish:] This is similar to the reward treatment, but with punishment instead. Consider again two players, $k$ and $l . k$ can assign deduction points to any other player of her own group, say $l$. For this, the same amount of response tokens spent by $k$, is deducted from $l$ 's account. In this treatment, it is possible that a player gets punished such that her round payoff would theoretically turn negative. However, if a player gets punished by more tokens than there are on her account for this period, the excess punishment is discarded and the round payoff set to zero. ${ }^{8}$

[Reward and Punishment (R\&P):] In this treatment each player can choose to either reward or to sanction another co-player of the same group. Players can give both rewarding and sanctioning response to different co-players in the same round; ${ }^{9}$

The prize to be won, $z$, constitutes a sort of local public good, as its consumption is non-rival and non-excludable within the group: It is independent of group size, all group members receive it and no-one can be excluded.

Note that players do not get to know from whom they get response points assigned. So neither do they know in the punishment treatment, which of the co-players sanctioned them, nor do participants get revealed by whom they receive reward tokens in the reward setup (equivalent for the $\mathrm{R} \& \mathrm{P}$ treatment). This is to circumvent that players react on response behaviour of particular co-players - think hereby of retaliation or gift exchanging. Furthermore, participants do not get to know about the response other players received. It also needs to be pointed out, that by rewarding other group members, participants shift around tokens in a way that leaves total welfare unchanged. Punishing others, in contrast, reduces overall welfare.

We apply a cost for response-giving of one (as in Sefton et al., 2007). This means if player $k$ punishes player $l$ by $6, k$ has to pay 6 for this action. Some studies incentivise responsegiving by relatively cheapening it (cf. Abbink et al., 2010; O'Gorman et al., 2009). ${ }^{10}$ Fehr and Gächter (2000) apply a non-linear cost function, where higher punishments are more costly. We opt for a constant cost of one in order to keep both the punishment and the reward leverage small to mitigate confounds from efficiency preferences. Also, in case we applied unequal leverage for the two types of response, the difference could be confounding as well.

We formulate the following four main hypotheses: Being in a contest with another group induces competitive behaviour, so 1) we expect contributions to the team contest to be higher in the contest environment than in the non-contest. Furthermore, a group contest encourages in-group favouritism and out-group spite dynamics, an inclination to benefit players from the own group and harm those from the competing group. We predict 2) More rewarding in the contest environment. 3) Less punishing in the contest environment. 4) More total response in the contest environment.

\footnotetext{
${ }^{8}$ This case never occurred in the experiment.

${ }^{9}$ It is not possible to both reward and sanction the same player in one round.

${ }^{10}$ For convenience, imagine the cost to be one half. Sticking to the aforementioned example, if player $k$ punishes player $l$ by 6 again, $k$ now has to pay 3 for this action.
} 


\subsubsection{Equilibrium Strategies}

A natural benchmark to compare our data with is the sub-game perfect equilibrium of the single-shot game. We derive this by backward induction. In the second stage, costly response only reduces own payoff. Hence, individualistic subjects do not give any response. Given this second-stage behaviour, players do not take punishment or reward into account when making the optimal decision about how many lottery tickets to buy for their group. They maximise their expected payoff which is

$$
\pi\left(v_{l}\right)=\frac{v_{l}+\sum_{\substack{k \neq l \\ k \in K}} v_{k}}{v_{l}+\sum_{\substack{k \neq l \\ k \in K}} v_{k}+\sum_{m \in M} v_{m}} \cdot z-v_{l} .
$$

This is the Tullock (1980) winning probability (as introduced in Section 3.3) times the prize minus the cost for investing in the group project. For treatments without opponent $\sum_{m \in M} v_{m}$ is set to 25 . In this type of contest game with homogeneous groups, first order conditions yield a unique equilibrium with respect to the aggregate group contribution. On the individual level, however, multiple equilibria exist (as explained in Konrad, 2009, 2007b; Katz et al., 1990).

For all treatments, the equilibrium investment level for group $K$ is $\sum_{k \in K} v_{k}=\frac{z}{4} \cdot{ }^{11}$ For $z=100$, this results in a Nash-equilibrium of 25 tokens per group. ${ }^{12}$ One conceivable solution to the within-group "burden-sharing" would be to assume symmetry as in Katz et al. (1990). For $z=100$ and $|K|=4$ this would result in an individual contribution of $v_{l}=6.25$ tokens. Of course, this is only one example among other possible solutions to the within-group problem. Note that only integer amounts of investment are allowed, so 6.25 can best be viewed as a theoretical benchmark.

The multiplicity of equilibria in the single-shot game allows for a plethora of equilibria in the repeated game. This set is not only restricted to sequences of single-shot equilibria. The possibility to use grimm-trigger strategies also enables off-equilibrium behaviour in single rounds. ${ }^{13}$ For the comparison with the data we neglect these equilibrium strategies as possible benchmarks, because the immense amount of coordination needed to establish them, render them rather implausible.

Unlike the single-shot Nash-equilibrium, the social optimal strategy differs somewhat between the cases with or without an opponent and whether one regards the opponent team as part of the social system. In the treatments without opponent, the prize is forfeited and goes to nobody if it is not won. Hence, the Nash equilibrium coincides with the optimal

\footnotetext{
${ }^{11}$ Find a derivation in Appendix 3.C.

${ }^{12}$ Note that the equilibrium investment level is independent of the endowment with tokens or group size. The only factor influencing equilibrium behaviour at the group level is the prize at stake. Note further that the investment level is strictly positive. If the other group is only investing a small amount or nothing into lottery tickets, it is very cheap to change the odds of the Tullock lottery. Hence investing might even be attractive for an individual.

${ }^{13}$ For example assume that a player contributes seven tickets in the first round and continues to do so if all the others contributed eight tickets in the first round. If not, the player contributes only one ticket for all the consecutive rounds. In this case it is a best response to indeed contribute eight tickets in the first round and play the single-shot best response strategy for the consecutive rounds. In a similar way players can credibly threaten others to switch from a "nice" single-shot equilibrium strategy to a less nice one if they are not rewarded after the first round.
} 
strategy for maximising expected total monetary welfare in these treatments. Things look differently, however, if two groups compete against each other. Now the optimal strategy to maximise total monetary welfare across groups would be for both groups to invest nothing and face a 50:50 chance of winning. The proof for this is straightforward: First of all no reward or punishment will be distributed, as this is either welfare neutral (rewarding) or reducing welfare (punishing). Buying lottery tickets is unproductive effort that only influences winning probabilities. One of the two groups wins the prize anyway and regarding total welfare of both groups, it does not matter, which of the two wins it. These steps of analysis are true for all periods of the game. If the opponent group is not regarded as part of the social system, then the Nash equilibrium would constitute the strategy that maximises expected total monetary welfare for the group.

\subsubsection{Realisation of the Experiment}

We used the system ORSEE by Greiner (2004) to recruit a total of 372 participants (most of them students) for our experiment. Each participant received a financial compensation for taking part in the experiment. This compensation was dependent on the total amount of tokens earned over the fifteen rounds. The experiment took about one hour, including reading the instructions, a trial period, the contest game as such, a questionnaire and payment. The mean income was $€ 16.94$ across all treatments. ${ }^{14,15}$ While players in treatments without opponent received an average of $€ 19.61$, players in treatments with opponent received $€ 15.60$ on average.

The experiment was conducted as computerised laboratory experiment ${ }^{16}$ in the facilities of the BEElab (Behavioral \& Experimental Economics Laboratory, Maastricht University, Netherlands). Each participant sat in their own cubicle, where she made her decisions, physically and visually separated from other participants. Upon entering the cubicle, each participant found the instructions at her place. ${ }^{17}$ After reading the instructions, participants answered some trial questions, in order to become familiar with both the conceptual setup of the game, as well as with its user interface. When the experiment was finished, players were asked to fill out a short questionnaire about personal features to be used in the analysis of the game.

In the trial phase, players were confronted with randomly generated game situations and answered control questions. They were aware of the randomness of the numbers presented and also knew that they were not yet interacting with other participants. In general, participants got to see three different screens per period: First there was a screen where each player decided how much to contribute for the group account. Then the player got to know whether her group has won, own winning probability and the contributions of fellow group members. She then had the opportunity to assign response tokens to co-players. In the baseline treatment, this was just an overview page, without the opportunity to assign response tokens. On the third screen, the total profit (in tokens) for this period was displayed in a detailed overview for the participant. ${ }^{18}$

\footnotetext{
${ }^{14}$ About $£ 14.05$ or $\$ 22.48$ under the exchange rate at the time of the experiment.

${ }^{15}$ Consider 3.4.4 for the effects of over-contribution on final payoff.

${ }^{16}$ For this we made use of the experimental software "z-Tree" by Fischbacher (2007).

${ }^{17}$ Find a copy of the instructions in Appendix 3.A.

${ }^{18}$ Find an example of the three stages in Appendix 3.B.
} 


\subsection{Results}

We begin by comparing contribution levels and response over time. Then we examine, which effects drive the differences in behaviour at the individual level. We find that players' actions are heavily influenced by what happened in previous rounds. Therefore we take a closer look at the dynamics of this experiment in Section 3.4.6. There is a strong relationship between contribution to the group account and response-giving. We analyse the relationship between contributions and receiving reward or punishment in Section 3.4.7.

\subsubsection{Statistical Methodology}

In this study, individual observations per period are not independently distributed, as the actions of other players and previous rounds influence own behaviour. In line with this, contribution shows a high degree of autocorrelation and heteroscedasticity. ${ }^{19}$ This is why we use Newey-West standard errors for our regressions (as devised by Newey and West, 1987) with a lag length of two periods. ${ }^{20}$ As alternative regression method, we run OLS regressions with standard errors that cope for heteroscedasticity and clustering between subjects, as described in Angrist and Pischke (2009, Chapter 8).

Since our data is not normally distributed ${ }^{21}$ we use non-parametric methods to test the hypotheses: Mann-Whitney U tests (MWU) (Mann and Whitney, 1947) for independent sample tests and Wilcoxon signed-rank test (Wilcoxon, 1945) for paired tests. While in the non-contest environment, group level data (four players) constitutes an independent observation, we use paired group data (eight players) in the contest environment. ${ }^{22}$

\subsubsection{Contributions to the Group Account}

Average group level contributions over all treatments is at about 142, which is significantly higher than the Nash equilibrium as benchmark (as deducted in Subsection 3.3.1). ${ }^{23}$ This is also true for both environments and treatments, if analysed separately.

Figure 3.1 illustrates average contribution to the group account per player over all 15 rounds. Results for the contest environment are on the left and for the non-contest on the right. For both environments, contribution levels for the punishment treatments are considerably lower than in the reward treatments. ${ }^{24}$ Furthermore, there is even a positive trend in contributions for the reward treatment in the contest environment until the $12^{\text {th }}$ round.

\footnotetext{
${ }^{19}$ Level of Both the White's test and the Beusch-Pagan test constantly report high evidence for inhomogeneous variance.

${ }^{20}$ Rule of thumb by Stock and Watson (2012): use lag length of $0.75 \cdot T^{1 / 3}$ with $T$ being the number of rounds in the experiment. The Newey-West autocorrelation consistent covariance estimator is nicely explained in Greene (2012, pp. 960-961).

${ }^{21}$ It is skewed to the right and slightly platykurtic: Shapiro-Wilk test for normality. H0: Contribute $\sim \mathbb{N}\left(\mu, \sigma^{2}\right), \mathrm{P}=0.00$. Skewness: 0.82, Kurtosis: 3.15

${ }^{22}$ For the analysis we use Stata 14.

${ }^{23}$ Wilcoxon test: H0: group contr. $=25, \mathrm{H} 1: \operatorname{diff} \neq 0, \mathrm{~N}=62 . \mathrm{P}=0.000$. Higher rank sum than expected.

${ }^{24}$ Wilcoxon test: $\mathrm{H} 0$ : diff $=0, \mathrm{H} 1$ : diff $\neq 0, \mathrm{~N}=32 . \mathrm{P}=0.024$. Higher rank sum than expected for reward treatments.
} 


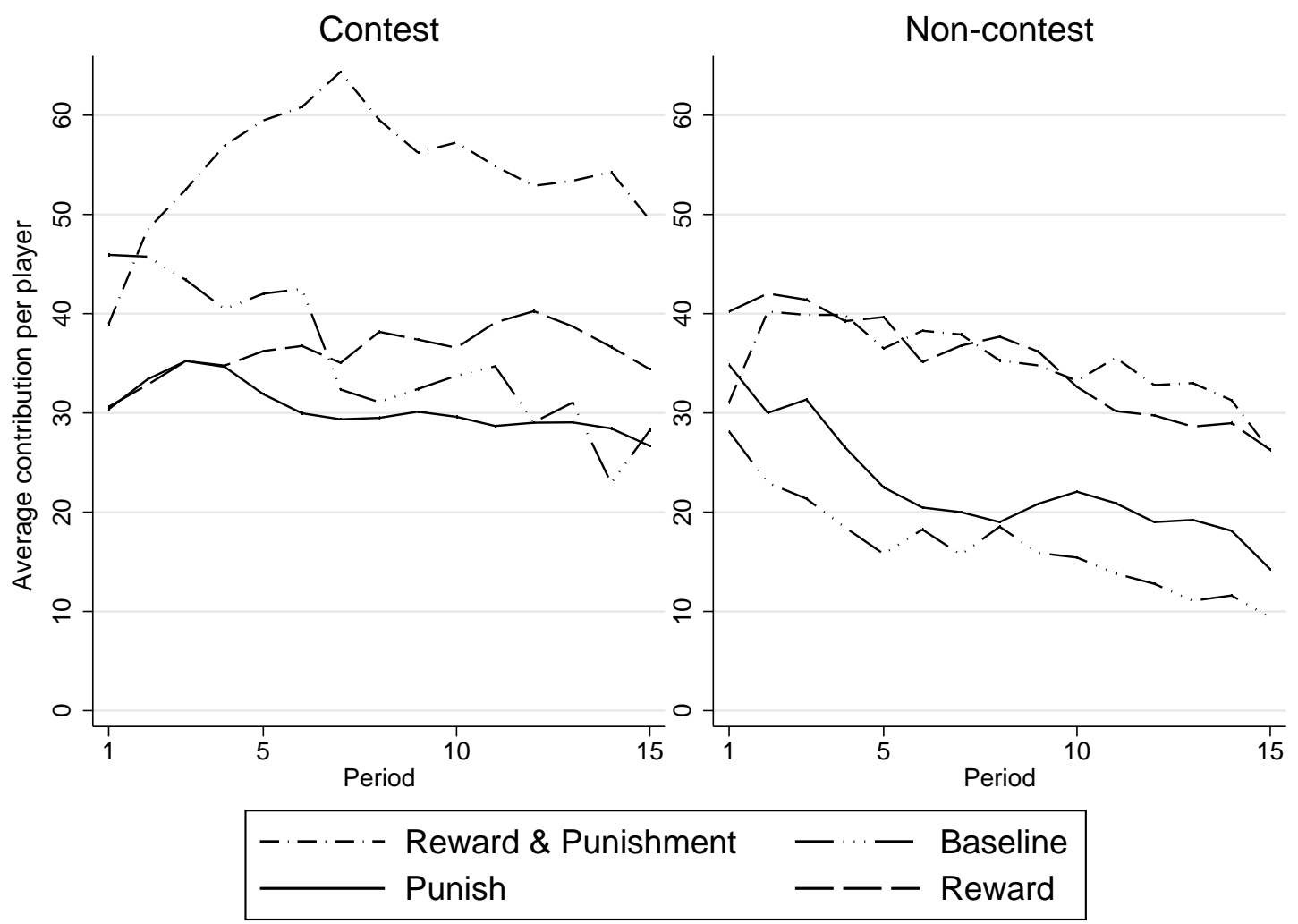

Figure 3.1: Individual contribution to the group account per treatment. Contest environment on the left, non-contest environment on the right.

Most striking, however, is the result for the $\mathrm{R} \& \mathrm{P}$ treatment in the contest environment, which clearly peaks out over all other ones. ${ }^{25}$ Also, the comparably high contribution rate for the baseline treatment in the contest environment is pretty remarkable.

In Figure 3.2, average group contribution per treatment can be compared. The error bars give the $5 \%$ confidence interval, on the basis of independent observations, which is the average contribution per pair of groups over all 15 periods.

By and large, contribution levels averaged over all rounds are on a fairly similar level for the reward treatment in both environments. Averaged contribution levels drop in all other treatments, compared between the environments. At the same time, though, even within the treatments, there exists considerable heterogeneity between groups' contribution levels. For a break down into individual group behaviour see Appendix 3.D.

\subsubsection{Response giving}

As Figure 3.3 illustrates, also for the response-giving, a systematic difference can be identified between the treatments, but also within the R\&P treatment. As for Figure 3.1, we report mean values for each treatment and period per player. The two graphs in the left

\footnotetext{
${ }^{25}$ MWU test: $\mathrm{H0}:$ diff $=0, \mathrm{H} 1:$ diff $\neq 0, \mathrm{~N}=62 . \mathrm{P}=0.001$. Higher rank sum than expected for $\mathrm{R} \& \mathrm{P}$ treatment.
} 


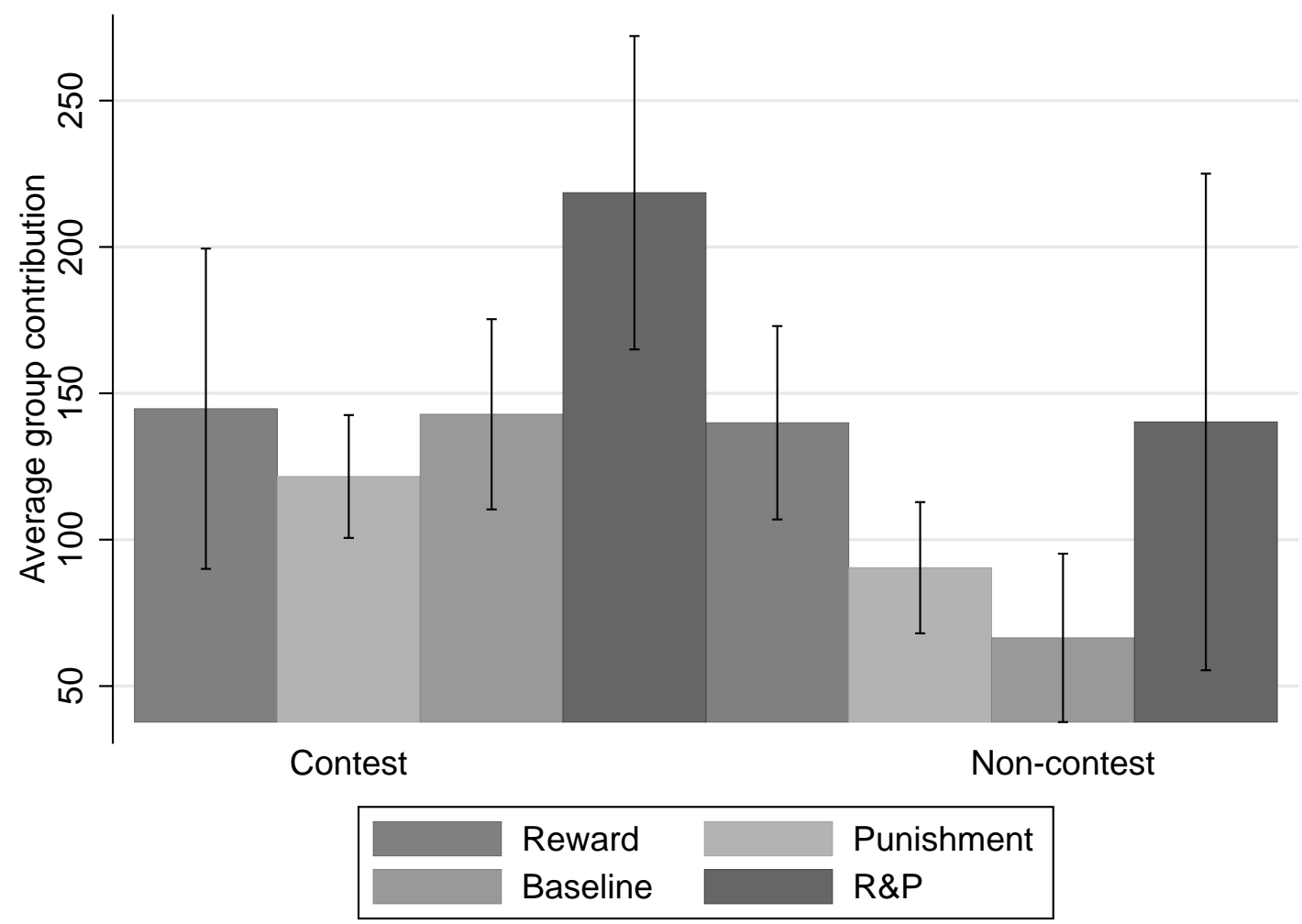

Figure 3.2: Average contribution to the group account per treatment. Contest environment on the left, non-contest environment on the right.

column depict average spending levels for the treatments with response. On the right hand column, rewarding and punishing in the $\mathrm{R} \& \mathrm{P}$ treatment are compared. The first row is for the contest and the second row for the non-contest environment.

Comparing rewarding and punishing behaviour, it seems that the former is slightly more extensively used, especially in the beginning of the experiment. In the $\mathrm{R} \& \mathrm{P}$ treatments (analysing both environments together and separably), rewarding is significantly higher than punishing. ${ }^{26}$ This relationship also holds between the reward and punishment treatments when both environments are analysed together, ${ }^{27}$ but does not deliver a significant result for the separate environments.

Especially in the beginning of the game, reward giving is used more than punishing, while the two approach each other over time, even turning punishing into the preferred form of response giving for the last period in the $\mathrm{R} \& \mathrm{P}$ treatment. ${ }^{28}$ We conclude that players tend to behave more favourable towards other group members in the beginning, which confirms our hypothesis. In the course of the game, however, friendliness fades out.

Also, overall response giving is significantly higher in the $\mathrm{R} \& \mathrm{P}$ treatment than in the

\footnotetext{
${ }^{26}$ E.g. Wilcoxon test including both environments: $\mathrm{H} 0$ : diff $=0, \mathrm{H} 1$ : diff $\neq 0, \mathrm{~N}=16 . \mathrm{P}=0.03$.

${ }^{27}$ MWU test: $\mathrm{H} 0$ : diff $=0, \mathrm{H} 1$ : diff $\neq 0, \mathrm{~N}=32 . \mathrm{P}=0.029$. Higher rank sum than expected for reward treatments.

${ }^{28}$ E.g. Wilcoxon test including both environments: H0: diff $=0, \mathrm{H} 1:$ diff $\neq 0, \mathrm{~N}=16 . \mathrm{P}=0.012$.
} 


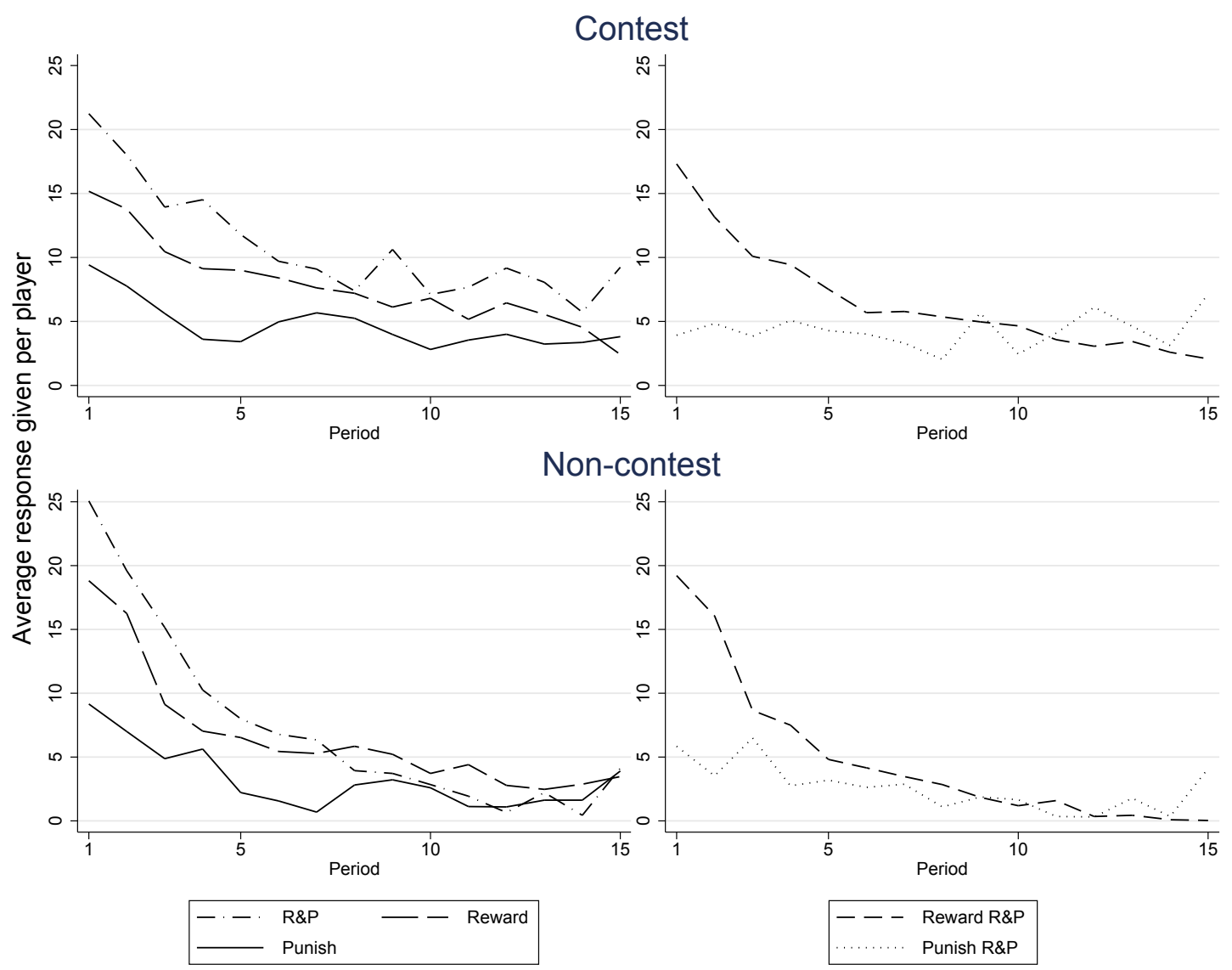

Figure 3.3: Response given per treatment

other treatments. ${ }^{29}$ Especially in the contest environment there seems to exist a somewhat robust demand for rewarding or punishing, respectively. This means that subjects seem to not have a mental budget for overall response. ${ }^{30}$ Instead, if subjects can spend resources on both reward and punishment, they seem to spend as much on each of the two, as they would if they could only spend the resources on one of the two. For this consider also Figure 3.4.

Table 3.1 and 3.2 show the propensity to engage in rewarding and / or punishing behaviour for each environment. It shows the percentage of non-negative response per treatment and the type of response being sent. While the propensity to punish is fairly similar between the $\mathrm{R} \& \mathrm{P}$ and the punishment treatment in each environment (around 26 and $19 \%$, respectively), more players engage in rewarding behaviour in the reward treatment, as compared to the $\mathrm{R} \& \mathrm{P}$ treatment (56\% in reward, $44 \%$ and $25 \%$ respectively in $\mathrm{R} \& \mathrm{P})$. Unlike in the $\mathrm{R} \& \mathrm{P}$ treatment, players in the reward treatment can only reciprocate negatively by not sending rewarding tokens. The spectrum of reciprocal actions shifts accordingly. In the punishment treatment this shift does not happen.

Between the environments, notice the close resemblance of percentages in the reward treatment. Notice also an increase in response giving behaviour for the contest environment,

\footnotetext{
${ }^{29}$ MWU test: $\mathrm{H0}$ : diff $=0, \mathrm{H} 1:$ diff $\neq 0, \mathrm{~N}=48 . \mathrm{P}=0.001$. Higher rank sum than expected for $\mathrm{R} \& \mathrm{P}$ treatments.

${ }^{30}$ Like what they actual received as budget in the experiment, which was for response in general.
} 


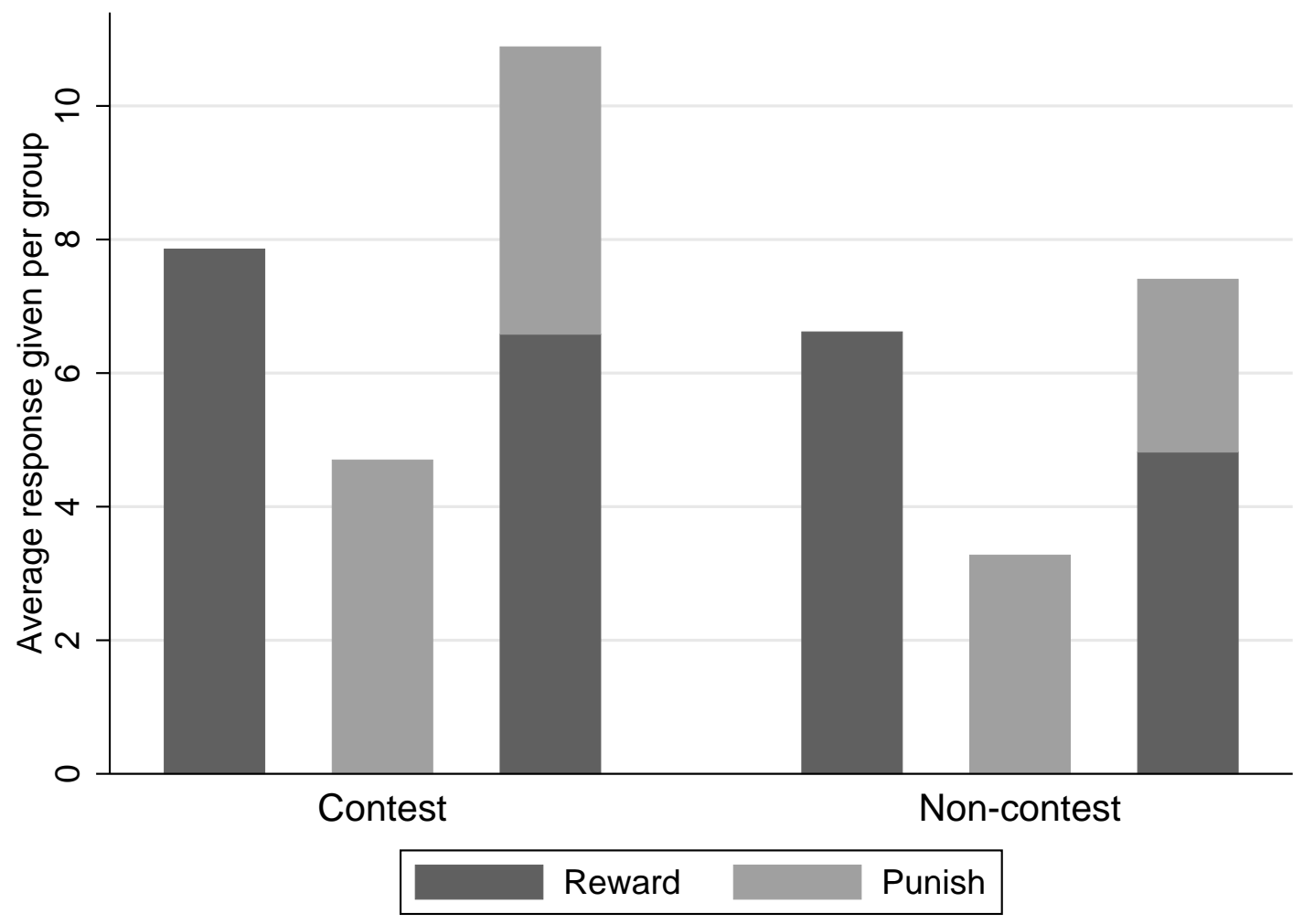

Figure 3.4: Response given per treatment

\begin{tabular}{lrrr}
\hline & \multicolumn{3}{c}{ Punish } \\
Reward & No & Yes & Total \\
\hline No & 46 & 11 & 56 \\
Yes & 29 & 14 & 44 \\
Total & 75 & 25 & 100 \\
\hline
\end{tabular}

$\mathrm{R} \& \mathrm{P}$

\begin{tabular}{lr}
\hline Reward & \\
\hline No & 44 \\
Yes & 56 \\
Total & 100 \\
\hline
\end{tabular}

Reward

\begin{tabular}{|c|c|}
\hline \multicolumn{2}{|c|}{ Punish } \\
\hline No & 73 \\
\hline Yes & 27 \\
\hline Total & 100 \\
\hline
\end{tabular}

Table 3.1: Share of response cases, contest environment (in percentages)

\begin{tabular}{lrrr}
\hline & \multicolumn{3}{c}{ Punish } \\
Reward & No & Yes & Total \\
\hline No & 62 & 11 & 74 \\
Yes & 18 & 8 & 26 \\
Total & 80 & 19 & 100 \\
\hline
\end{tabular}

$\mathrm{R} \& \mathrm{P}$

\begin{tabular}{lr} 
Reward & \\
\hline No & 43 \\
Yes & 57 \\
Total & 100 \\
\hline
\end{tabular}

Reward

\begin{tabular}{lr} 
Punish & \\
\hline No & 81 \\
Yes & 19 \\
Total & 100 \\
\hline
\end{tabular}

Punish

Table 3.2: Share of response cases, non-contest environment (in percentages)

except for the reward treatment. 


\subsubsection{Rent dissipation}

Deviations from equilibrium strategy (as devised in Section 3.3.1) of course have payoffrelevant consequences. As mentioned before, mean income was $€ 16.94$ taken across all treatments. This translates to an amount of 2,540 tokens per player. If all players exhibited equilibrium behaviour all throughout the experiment, everyone could have earned on expectation

$$
E\left(\pi_{\text {tot }}^{\text {Nash }}\right)=\left(B+p_{K} \cdot z-\frac{\sum_{k \in K} v_{k}}{4}+F\right) \cdot 15
$$

or

$$
(100+0.5 \cdot 100-6.25+50) \cdot 15=2,906.25
$$

tokens, or $€ 19.38$, respectively. So overall, players earn almost $15 \%$ less than what they could earn in Nash equilibrium. The social optimal expected payoff with $v_{i}=0 \forall i \in K \cup M$, in comparison, amounts to $E\left(\pi_{\text {tot }}^{\text {soc }}\right)=3,000$ tokens or $€ 20.00$.

Losses in total monetary welfare result from higher contributions, as compared to more payoff-optimal strategies. ${ }^{31}$ This particularly emerges in the R\&P treatment of the contest environment, where mean income was about $€ 3.94$ or 591 tokens (about $22 \%$ ) lower than in the other treatments. Also, as a result of higher spending and punishing, average income in the contest environment was roughly $€ 4.00$ lower than in the non-contest (about 601 tokens, $20 \%$ ).

Table 3.3 gives an overview on the extent and composition of overspending per treatment. We compare the total sum of individual contest expenditures and response giving with the Nash equilibrium benchmark and report the respective spending level that exceeds this threshold. The total level of overspending in each treatment of the non-contest environment is lower as its counterpart in the contest environment. For the Baseline treatments this

\begin{tabular}{|c|c|c|c|c|}
\hline \multicolumn{2}{|c|}{ Treatment } & $\begin{array}{l}\text { Overspending } \\
\text { contribution }\end{array}$ & $\begin{array}{l}\text { Overspending } \\
\text { response }\end{array}$ & Total \\
\hline \multirow{4}{*}{ 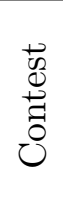 } & $\mathrm{R} \& \mathrm{P}$ & 725.73 & 163.27 & 889.00 \\
\hline & Reward & 448.98 & 117.84 & 566.83 \\
\hline & Punish & 362.19 & 70.48 & 432.67 \\
\hline & Baseline & 441.91 &.-- & 441.91 \\
\hline \multirow{4}{*}{ 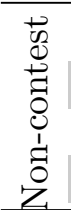 } & $\mathrm{R} \& \mathrm{P}$ & 432.09 & 111.06 & 543.16 \\
\hline & Reward & 431.03 & 99.25 & 530.28 \\
\hline & Punish & 245.34 & 49.13 & 294.47 \\
\hline & Baseline & 155.46 &.-- & 155.46 \\
\hline
\end{tabular}
decline is even as high as $60 \%$.

Table 3.3: Individual overspending compared to the Nash equilibrium benchmark

\footnotetext{
${ }^{31}$ As discussed earlier, contribution to the group account is unproductive effort which has no positive influence on the amount of tokens that can be won, as the prize at stake is fixed. Tokens put in the group account only influence the winning probability.
} 


\subsubsection{Individual Level Analysis}

We analyse, which factors influence individual behaviour in this game, using clustered Tobit regression with treatment and group dummies. ${ }^{32}$ For this, we include answers from the questionnaire that each participant filled in after the experiment. ${ }^{33}$ Analogous to Subsection 3.4.3, we drop the baseline treatment for conceptual reasons, as players in this particular treatment cannot give a response. Table 3.4 presents the results. Regressions (1) and (2) show individual contribution, averaged over all 15 periods, on a number of factors. In (3) and (4) we regress own response on a similar set of factors.

\begin{tabular}{lcccc}
\hline & $(1)$ & $(2)$ & $(3)$ & $(4)$ \\
VARIABLES & Contribute & Contribute & Own response & Own response \\
\hline Contribute & & & $0.28^{* * *}$ & $0.333^{* * *}$ \\
& & & $(0.05)$ & $(0.05)$ \\
Own response & $0.686^{* * *}$ & $0.837^{* * *}$ & & \\
& $(0.15)$ & $(0.14)^{* * *}$ & $-0.072^{* * *}$ & $-0.041^{* *}$ \\
Group contribution & $0.252^{* * *}$ & $0.181^{* *}$ & $(0.01)$ & $(0.01)$ \\
level & $(0.00)$ & $(0.02)^{* * *}$ & $0.250^{* * *}$ & -0.160 \\
Group response level & $-0.158^{* * *}$ & $0.342^{* *}$ & $(0.00)$ & $(0.09)$ \\
& $(0.04)$ & $(0.12)$ & $-0.004^{* * *}$ & $0.098^{* * *}$ \\
Other group & $0.000^{* * *}$ & $-0.135^{* * *}$ & $(0.00)$ & $(0.03)$ \\
contribute & $(0.00)$ & $(0.04)$ & $0.773^{* * *}$ & $-35.781^{* * *}$ \\
Constant & $-0.331^{* * *}$ & $70.418^{* * *}$ & $(0.15)$ & $(10.26)$ \\
& $(0.04)$ & $(15.05)$ & $N o$ & $Y e s$ \\
\hline Controls & No & Yes & Yes & Yes \\
Treatment and Group & Yes & Yes & 0.120 & 0.160 \\
dummies & 0.192 & 0.225 & 288 & 270 \\
Pseudo R-squared & 288 & 270 & & \\
N & & &
\end{tabular}

Table 3.4: Individual level analysis

As for the factors "Contribute" and "Own response" it can be seen that players who give more response, tend to also be those who contribute more and vice versa. This should not come as too much of a surprise, considering the argument that players who display more involvement in the project, both contribute more and give more response in order to induce higher contribution by other group members as well.

In a nutshell, results for "Group contribution level" indicate that players in a competitive group tend to spend more themselves on the contest. At the same time, response giving is slightly reduced. For the "Group response level", the opposite relationship applies - even though on a very low scale. We will have a closer look at the effect of response on individual behaviour in Subsection 3.4.6. Individuals are not only affected by their own group's actions, but also by those players across the aisle. To this end, "Other group contribute" is the sum

\footnotetext{
${ }^{32}$ As discussed in Subsection 3.4.1

${ }^{33}$ In Appendix 3.E we discuss additional control factors in an explorative analysis.
} 
of contributions of the opposing group, averaged over the 15 periods. Note that although being of minuscule size as well (for example about $3.4 \cdot 10^{-9}$ in Regression (1)), it's very small standard error (about $3.5 \cdot 10^{-10}$ for the same regression) results in a pretty robust confidence interval.

\subsubsection{Dynamics in Decision Making}

For this part, we closely follow the analysis technique of Ashley, Ball, and Eckel (2010). We use both OLS regression with Newey-West standard errors with the contribution to the group account as dependent variable. ${ }^{34}$ The explanatory variables are the contribution to the group account lagged for one and two periods, individual positive or negative deviation from the mean of own group's contribution level lagged one period and response received one period ago. ${ }^{35}$ We analyse the effect of receiving reward or punishment, respectively, on subsequent contribution levels. Results are presented in Table 3.5.

\begin{tabular}{lc}
\hline & $\begin{array}{c}(5) \\
\text { Newey- } \\
\text { West }\end{array}$ \\
\hline VARIABLES & Contribute \\
\hline Contribution to group & $0.460 * * *$ \\
account in previous period & $(0.04)$ \\
Contribution to group & $0.252 * * *$ \\
account lagged two periods & $(0.03)$ \\
Contribution exceeding & $-0.201 * *$ \\
group mean previous period & $(0.06)$ \\
Contribution below & -0.080 \\
group mean previous period & $(0.05)$ \\
Reward received & $0.130 *$ \\
previous period & $(0.06)$ \\
Punishment received & 0.049 \\
previous period & $(0.04)$ \\
\hline$* \mathrm{p}<0.05, * * \mathrm{p}<0.01, * * * \mathrm{p}<0.001$ \\
Standard errors in parentheses. Period \\
effect, NLB, treatment, environment, group \\
and study major dummies not reported.
\end{tabular}

\section{Table 3.5: Dynamic analysis}

This analysis delivers three main insights: First of all, again there is significant autocorrelation for contribution levels. Second, the lagged relative comparison of own contribution to the mean group contribution reveals that students contributing relatively more to the project reduce their spending for the group account in the subsequent period, whereas the opposite does not happen. Players who contribute less than their group mean do not

\footnotetext{
${ }^{34}$ We also use multivariate Tobit regression, obtaining substantially similar results.

${ }^{35}$ We also include a period factor, Netherlands \& Belgium dummy and treatment, environment, group and study major dummies as control variables.
} 
increase their spending, ceteris paribus. Third, in line with Sefton et al. (2007), receiving rewards induces an increase in contribution for the following round, while sanctions do not have this effect. Sefton et al. (2007) argue that this explains the negative trend for punishment-giving over the periods. Furthermore they say that reward-giving also declines in the course of the experiment, but at a faster pace than punishment-giving. This is the case, although reward induces higher changes in other players' behaviour and shows efficiency-enhancing features. It might seem odd that participants do not stick to a strategy that seem to be effective in inducing other players' contribution. Sefton et al. (2007) do not elaborate further on this point.

\subsubsection{Who receives Response?}

In The Theory of Moral Sentiments, Adam Smith suggests: "Actions of a beneficent tendency, which proceed from proper motives, seem alone to require reward; because such alone are the approved objects of gratitude, or excite the sympathetic gratitude of the spectator. Actions of a hurtful tendency, which proceed from improper motives, seem alone to deserve punishment; because such alone are the approved objects of resentment, or excite the sympathetic resentment of the spectator" Smith, Raphael, and Macfie (1976, Part II, Section II, Chapter I, Paragraph 1-2). This early characterisation of reciprocity nicely captures our hypothesis concerning who will be punished or rewarded in this game.

For the contest environment, simple OLS regressions with Newey-West standard errors indicate that in the punishment treatment, players who contribute less are more likely to receive punishment from their teammates. The opposite holds for the reward treatment. Players, who contribute more, are more likely to receive reward from their teammates (see Tables 3.6 and 3.7). This relationship is much less pronounced in the non-contest environment. While lower contributors receive more punishment in the punish treatment, there is no significant effect for other treatments of the non-contest environment.

Figure 3.5 displays response received as a function of individual's deviation from the mean of contributions per group in the contest environment. These deviations are grouped into intervals, which illustrates the gradient nature of response-giving. The higher the own deviation from the mean towards the positive region, the more reward and less punishment does a player receive. We observe the contrary for punishment. The higher the deviations from the group's mean contribution towards the negative array, the more punishment and less reward does a player receive. We observe a small amount of asocial punishment, as well as some reward for players that contribute less than the mean of the group contribution level.

Figure 3.5 suggests that the response methods are well in place, such that they are used to punish defectors and reward high contributors. Furthermore, the gradient of responsegiving seems to be rather smooth. There seems to be an exponential relation between contributing and receiving response, such that players who contribute much more than the mean of the group contribution, receive disproportionate reward. The same holds for the punishment treatment. Players can expect to get disproportionately punished if they contribute much less than their fellow group members.

We observe a similar, gradual composition of response received over deviations from average group contributions in the non-contest environment in Figure 3.6. Although the 


\begin{tabular}{lcccc}
\hline & $(6)$ & $(7)$ & $(8)$ & $(9)$ \\
& Punish & Reward & Punish R\&P & Reward R\&P \\
\hline VARIABLES & response received & & \\
\hline Contribute & $-0.624 * * *$ & $0.239 * * *$ & $-0.265 * *$ & -0.016 \\
& $(0.08)$ & $(0.04)$ & $(0.09)$ & $(0.05)$ \\
Squared & $0.005 * * *$ & 0.000 & 0.00128 & $0.000907 *$ \\
Contribute & $(0.00)$ & $(0.00)$ & $(0.00074)$ & $(0.00047)$ \\
\hline$* \mathrm{p}<0.05, * * \mathrm{p}<0.01, * * * \mathrm{p}<0.001$ \\
Standard errors in parentheses. Period effect, NLB dummy, treatment, group \\
and study major dummies not reported.
\end{tabular}

Table 3.6: Contest environment.

\begin{tabular}{|c|c|c|c|c|}
\hline & $\begin{array}{c}(10) \\
\text { Punish }\end{array}$ & $\begin{array}{c}(11) \\
\text { Reward }\end{array}$ & $\begin{array}{c}(12) \\
\text { Punish R\&P }\end{array}$ & $\begin{array}{c}(13) \\
\text { Reward R\&P }\end{array}$ \\
\hline VARIABLES & \multicolumn{4}{|c|}{ response received } \\
\hline Contribute & $\begin{array}{l}-0.697 * * * \\
(0.16)\end{array}$ & $\begin{array}{c}0.094 \\
(0.09)\end{array}$ & $\begin{array}{r}-0.219 \\
(0.12)\end{array}$ & $\begin{array}{c}0.069 \\
(0.08)\end{array}$ \\
\hline Squared & $0.005 * * *$ & 0.001 & -0.000 & 0.000 \\
\hline Contribute & $(0.00)$ & $(0.00)$ & $(0.00)$ & $(0.00)$ \\
\hline
\end{tabular}

Table 3.7: Non-contest environment.

data is considerably more noisy than for the contest environment, a definite trend can be observed towards higher punishment of group-mates whose contribution deviates negatively from the group average, as compared to the contest environment. At the same time, this is not true for the positive domain: positive contributions are not rewarded more than in the contest environment.

Alternatively, subjects might actually compare others' contribution levels to their own ones, when making their decision of whom to reward or to punish. Hence, it must not necessarily be the case that the mean of group contribution delivers the relevant benchmark. To capture this, we use a dyadic relation, instead of an average group contribution level. This means that clusters for relative contribution are not formed by comparing own contribution level to the group mean, but by comparing it to the contribution of the "response giver". Hence, the deviation of own contribution to the contribution of those who punish or reward. This relative contribution, $d e v_{l}^{k}=v_{l}-v_{k}$, gives a term of relative contribution for each of the three co-players in the group for a given period $t . d e v_{l}^{k}$ measures the difference between contribution between player $l$ and player $k$. Consequently, we get three $d e v_{l}^{k}$-terms per player.

Results depicted in Figure 3.18 and 3.19 (in Appendix 3.F) stay qualitatively similar. 


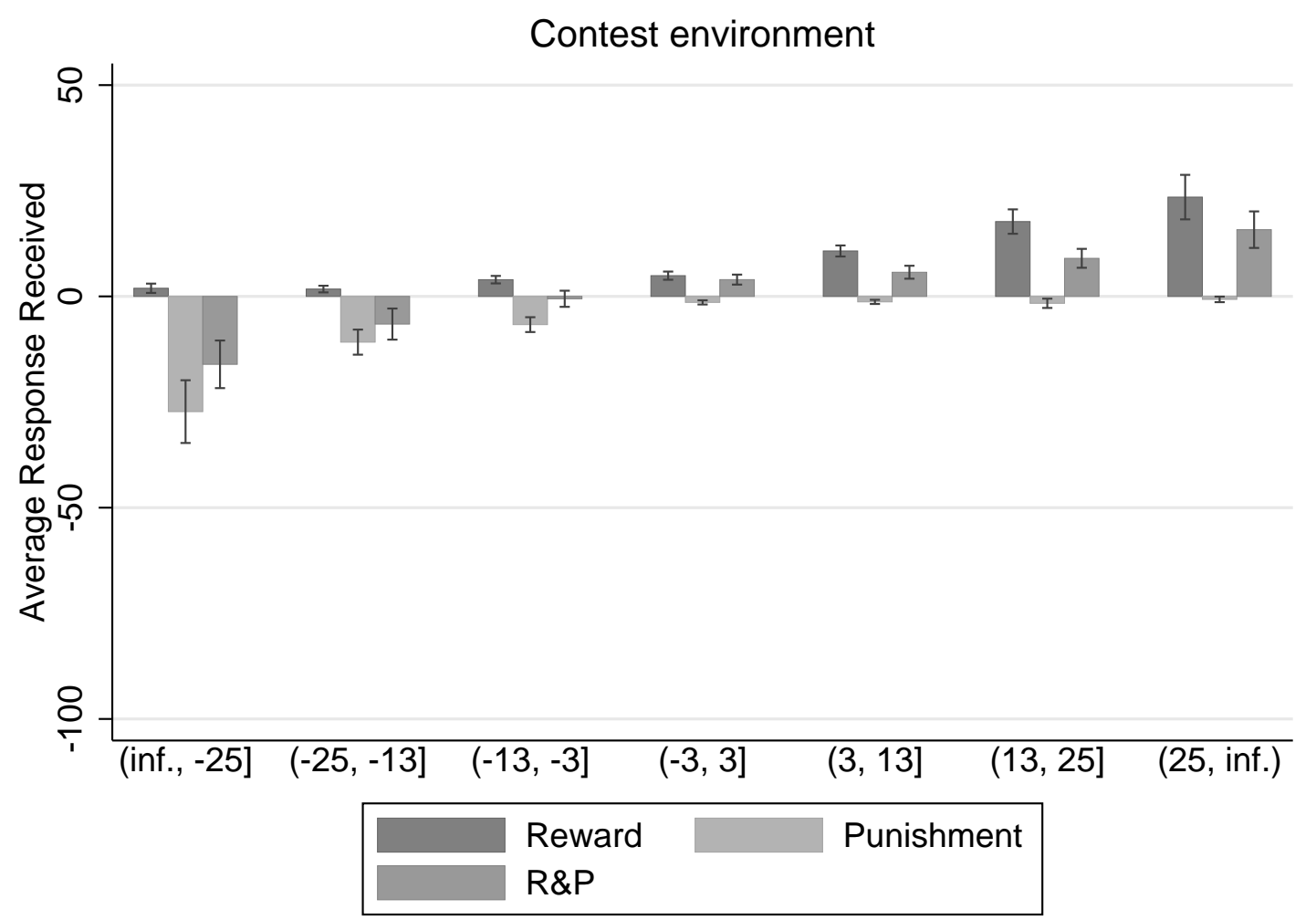

Figure 3.5: Response received in relation to deviation from average group contribution with $5 \%$ confidence interval.

They show, however, that reward and punishment mechanisms are used in a redistributive way. Players tend to recompense team mates who contribute more to the contest by means of reward and reduce the payoff of lower contributors (those who earn more in the contest) by punishing. Comparing Figure 3.18 and 3.19 also suggests that low contributors are punished more heavily in the non-contest environment.

\subsection{Concluding Comments}

In this chapter we complement related work by Sefton et al. (2007), Abbink et al. (2010) and Fehr and Gächter (2000). The common conceptual starting point of this type of experimental research lies on the focus of reciprocity as a behavioural norm. In an experimental study, we investigated a team contest for a group prize. Furthermore, we varied the economic environment between treatments, such that the effect of competing with another group can be isolated. In this study we answer four main hypotheses, which are: 1) Contributions to the team contest are higher in the contest environment. 2) More rewarding in the contest environment. 3) Less punishing in the contest environment. 4) More total response in the contest environment.

Our results give definite support for hypotheses 1), 2) and 4). Results for Hypothesis 3), however, are considerably less clear-cut. While it seems that low contributors are more heavily punished, overall propensity to punish and average total punishing are not higher 


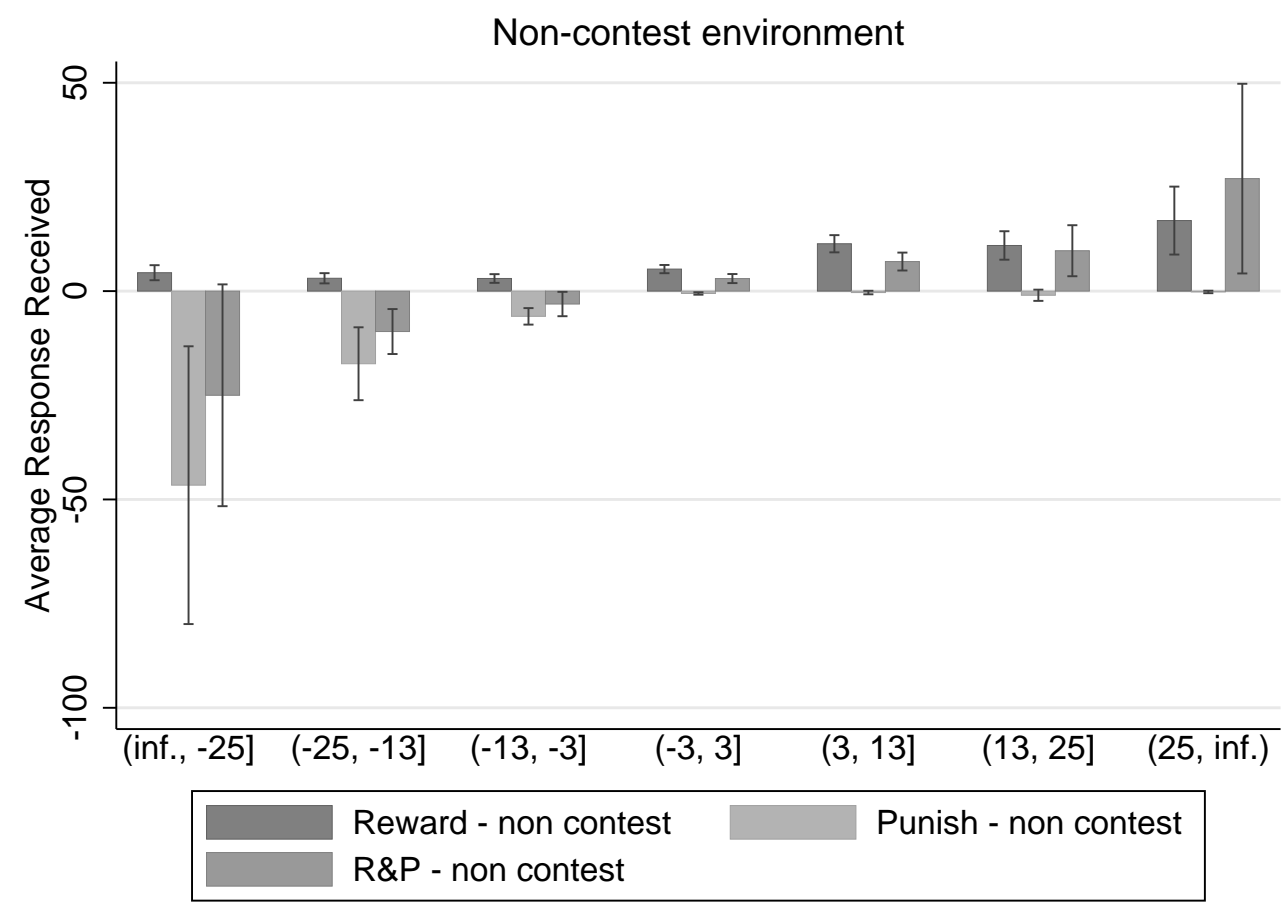

Figure 3.6: Response received in relation to deviation from average group contribution with $5 \%$ confidence interval.

in the non-contest environment.

Furthermore, we find that across both environments, contribution to the group project is higher in the reward treatment than in the punishment treatment. Especially during the first rounds of the game, participants distribute more rewarding than punishing response to their group mates. We also find that for response-giving, the own contribution in relation to the contribution of other group members is an important determinant of the severity of punishment, or reward, respectively. This means that in the punishment treatment, the further a player's contribution to the group account is below the mean of the group's contribution level, the higher punishment this player can expect to receive from fellow group members. The opposite holds for the reward treatment. Here, the higher the relative contribution, the higher the expected reward from other group mates. Also, we find two dynamic patterns of behaviour: Players who contribute more than their group mates reduce contribution in subsequent periods, while the opposite does not hold. Players who contribute comparably less do not increase their contribution significantly. Most strikingly, however, players react on being rewarded by increasing their contribution, while players who get punished do not change their contribution level.

The results of our experiment paint a gloomy picture of within-group punishment and reward systems in team contests. When confronted with a rival group, subjects show a clear tendency to exhibit a more competitive behaviour. The opportunity to reciprocate teammates' actions (by the means of reward or punishment), is utilised to fan the flames of the intergroup conflict, even though this comes at a price. Our results contribute to explaining the high humanitarian and material costs in socio-political conflicts. When confronted with a rival party, subjects seem willing to accept a materially inefficient outcome 
to outrun the opponent. All the more so, subjects incite their comrades to join in arms. In the anonymous and abstract environment of this computer laboratory, we find these outcomes absent of any religious or ethnic spur. In field environments, the emotional impetus attached to these kind of conflicts will be even stronger, given a usually higher social identity within the conflict parties.

In a corporate context, consider a construction firm running for a tender. Although each unit has some incentive to not invest resources in the project of the firm, high inputs increase the probability for the firm to win the tender and to get the project awarded. Our research suggests that in this kind of situation, the company should not only point out to their employees that they are in a competitive situation in order to encourage higher effort. The implementation of a rewarding scheme should particularly trigger up individual effort in the contest. Results by Balliet et al. (2011); O'Gorman et al. (2009) suggest that it should not matter if there exists a scheme of mutual rewarding, similar to the setup in our experiment, or whether one central agent is entrusted with this task.

There are a number of conceivable extensions: Allowing for communication could formalise a sort of non-binding contract between the participants. In an experimental study using a group contest game with a weakest-link production function (total group contribution is determined by the lowest individual effort in that group), Cason, Sheremeta, and Zhang (2012) allow for inter- and intra-group communication via a free form chat in a $2 \times 2$ design. ${ }^{36}$ They show that communication between groups has an abating effect on contest spending, which positively influences overall welfare. Within-group communication, by contrast, displays the opposite effect, leading to an escalation of the contest with a more than doubling of contest expenditures. In a treatment with both communication types, the two effects cancel out, leading to a level of competition and payoffs being not significantly different from the baseline treatment.

By randomising identification numbers of players, reputation building would be excluded. Hypothetically, this should lead to a decrease in response-giving and also to a reduction in contribution to the group account. Going one step further, groups could even be set up in a randomized way. Group cohesion is expected to be even smaller than in the previous case, resulting in less response-giving and lower contribution levels.

In our design of the contest game, the prize for winning a round is set such that the Nash equilibrium for contribution is on a rather low level of players' endowment with tokens. Throughout the game we constantly observe a massive over-investment across treatments. By varying the prize at stake, which changes the game's Nash equilibrium, can elicit subjects' elasticity towards the contest prize. This might also have an effect on response-giving, making subjects react more aggressively towards free-riders, with an increase in rewarding and punishing.

\footnotetext{
${ }^{36}$ Sutter and Strassmair (2009) study a similar team tournament game with chat communication. The main differences between their game setup and the one employed by Cason et al. (2012) and in our study is twofold: First, in Cason et al. (2012) and in our study, efforts are socially wasteful and social welfare increases when players coordinate on a lower spending level. Second, Cason et al. (2012) and our study employ a probabilistic contest success function, while in Sutter and Strassmair (2009), the prize is given to the group with the higher (stochastic) effort. By and large, chat communication leads to higher contribution levels in Sutter and Strassmair (2009), which in their setup has positive welfare implications.
} 


\section{Appendix 3.A Instructions}

When entering the cubicle, each participant found a printed version of the following experiment instructions at her seat. Paragraphs headed by a treatment name in square brackets were only given to the subjects of the corresponding treatment. The following example is from the contest treatments. Instructions for the non-contest treatments are slightly adjusted such as to not mention another group and avoid referring to teams or team mates. ${ }^{37}$

\section{CG Experiment}

Welcome and thank you for participating in this experiment. Please read these instructions carefully. If you have any questions, please raise your hand and one of the hosts of the experiment will come to your cubicle to answer your question. Talking or using mobile phones or any other electronic devices is strictly prohibited. Mobile phones and other electronic devices should be left in the waiting room or switched off. If you are found violating these rules, you will both forfeit any earnings from this experiment, and may be excluded from future experiments as well.

This is an experiment about decision making. The instructions are simple and if you follow them carefully you might earn a considerable amount of money which will be paid to you privately and in cash at the end of today's session. The amount of money you earn depends on your decisions, on other participants' decisions and on random events. You will never be asked to reveal your identity to anyone during the course of the experiment. Your name will never be associated with any of your decisions. In order to keep your decisions private, do not reveal your choices to any other participant.

During the experiment you will have the chance to earn points, which will be converted into cash at the end of today's session, using an exchange rate of

$$
15 \text { points }=0,1 € \text {. }
$$

Thus, the more points you earn, the more cash you will receive at the end of the session.

You and three other participants are assigned to a team. Four other participants are assigned to another team. All participants will remain in their teams for the entire experiment. None of you will learn who the own team members or the other team members are.

The experiment will consist of 15 periods, and in each period your team and the other team are competing for a prize in the following way:

At the beginning of each period you will receive 100 points. Then you can use these points to buy lottery tickets for your team. Any point you invest gives one lottery ticket for the team. Any point you do not invest in lottery tickets will be accumulated in your private point balance. Likewise, your team members can buy tickets for your team and the members of the other team can buy tickets for their team in exactly the same way.

As soon as everybody has chosen how many tickets to buy, a lottery will determine whether your team or the other team wins a prize of 400 points (100 for each team member).

\footnotetext{
${ }^{37}$ Details available upon request.
} 
One of the sold tickets is randomly assigned the winning ticket. Each ticket has the same chance. Hence, the more tickets your team buys, the higher is your chance of winning the prize.

Examples: If your team and the other team buy the same amount of tickets then the chance of winning the prize is 50:50. If your team buys three times as many tickets as the other team, then also your team's chances are three times as high as those of the other team. If only one of the teams buys tickets then this team wins the prize with certainty.

If neither your team nor the other team buys a ticket, then the prize is randomly allocated to one of the teams with equal chances.

After the winning team is determined the prize of 400 points is equally shared and added to the private point balances of the winning team (100 points for each team member).

[Reward treatment:] At the end you get 50 feedback points. You can put these points to your private point balance or you can assign them to one or more of your team members (not to members of the other team). Each feedback point assigned to a team member increases this team member's private balance by one point.

[Punishment treatment:] At the end you get 50 feedback points. You can put them to your private point balance or you can assign the feedback points to one or more of your team members (not to members of the other team). Each feedback point assigned to a team member decreases this team member's private balance by one point. A team member's balance for one particular round cannot turn negative. If this happens then the balance for this particular round is set to zero and all excess feedback points are invalidated.

[Baseline treatment:] At the end you get 50 extra points which will add to your account.

[REP treatment:] At the end you get 50 feedback points. You can put them to your private point balance or you can assign the feedback points to one or more of your team members (not to members of the other team). You can decide whether you assign the points to be added to the respective team member's account or to be subtracted from that account. Each feedback point assigned to a team member increases or decreases this team member's private balance by one point âĂŞ depending on what you choose. A team member's balance for one particular round cannot turn negative. If this happens then the balance for this particular round is set to zero and all excess feedback points are invalidated.

The points you earn in each period will be added together. At the end of the session you will be paid based on your total point earning from all 15 periods.

The experiment starts with a trial period in which you will be asked to fill in some questions in order to check your understanding of the experiment and to give you the opportunity to get acquainted with the setup. Points earned in this trial period will not be paid off. 


\section{Appendix 3.B Stages}

Figure 3.7 to Figure 3.9 show screenshots from the punishment treatment. Other treatments look similar, adjusting only references to the payoff consequences of receiving response and leaving out mentioning of another group in the treatments without competing group.

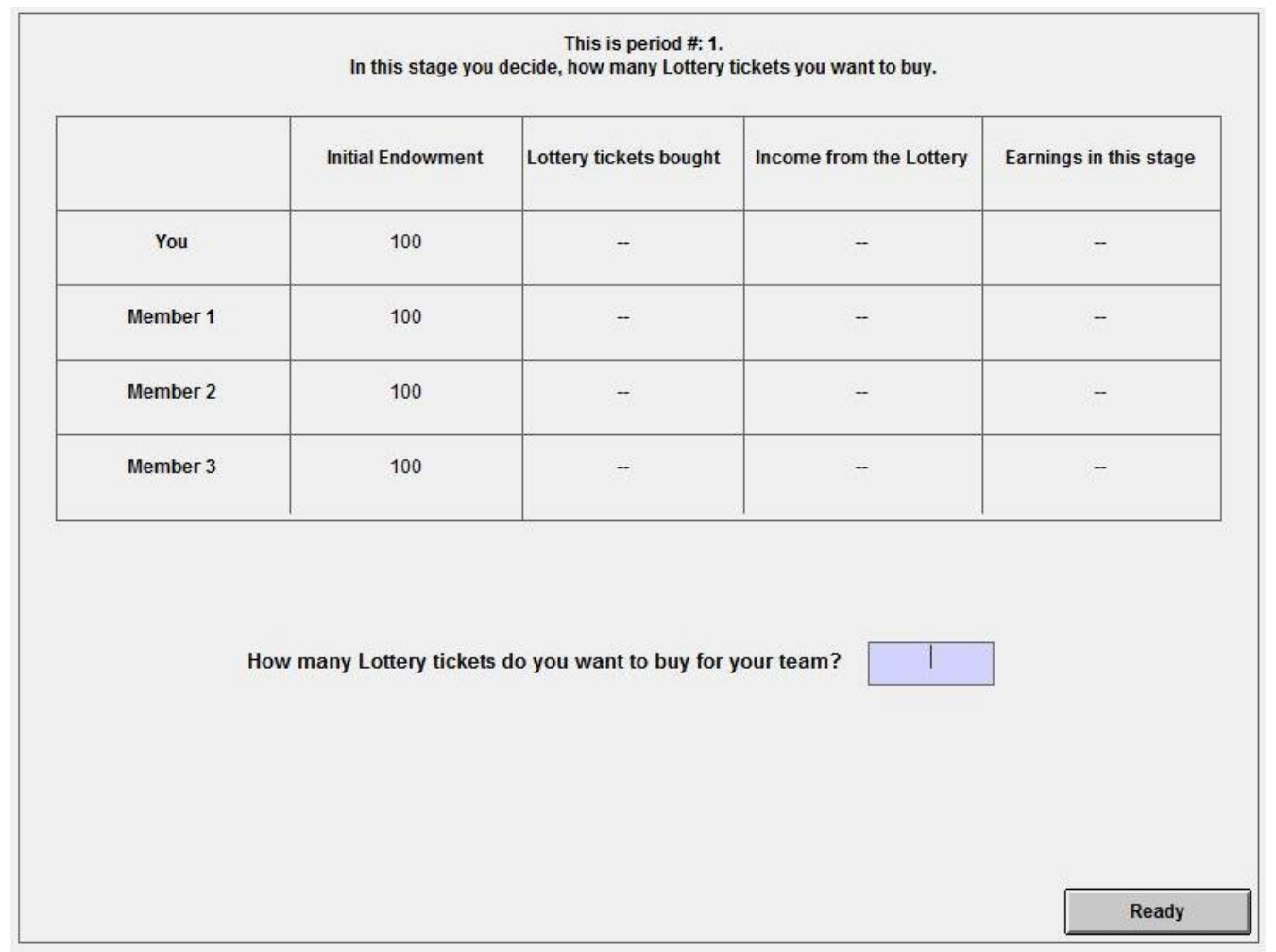

Figure 3.7: First stage 


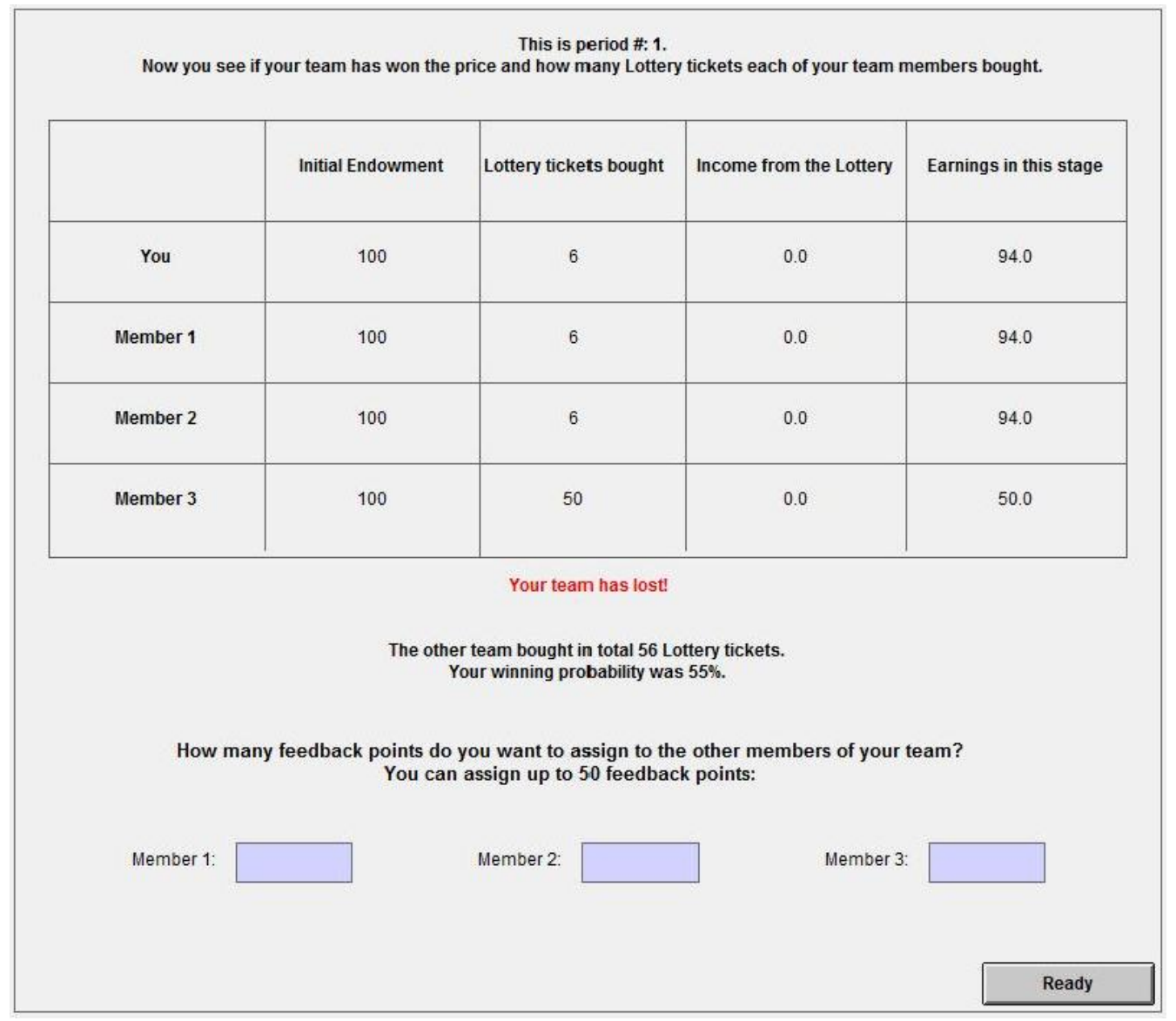

Figure 3.8: Second stage

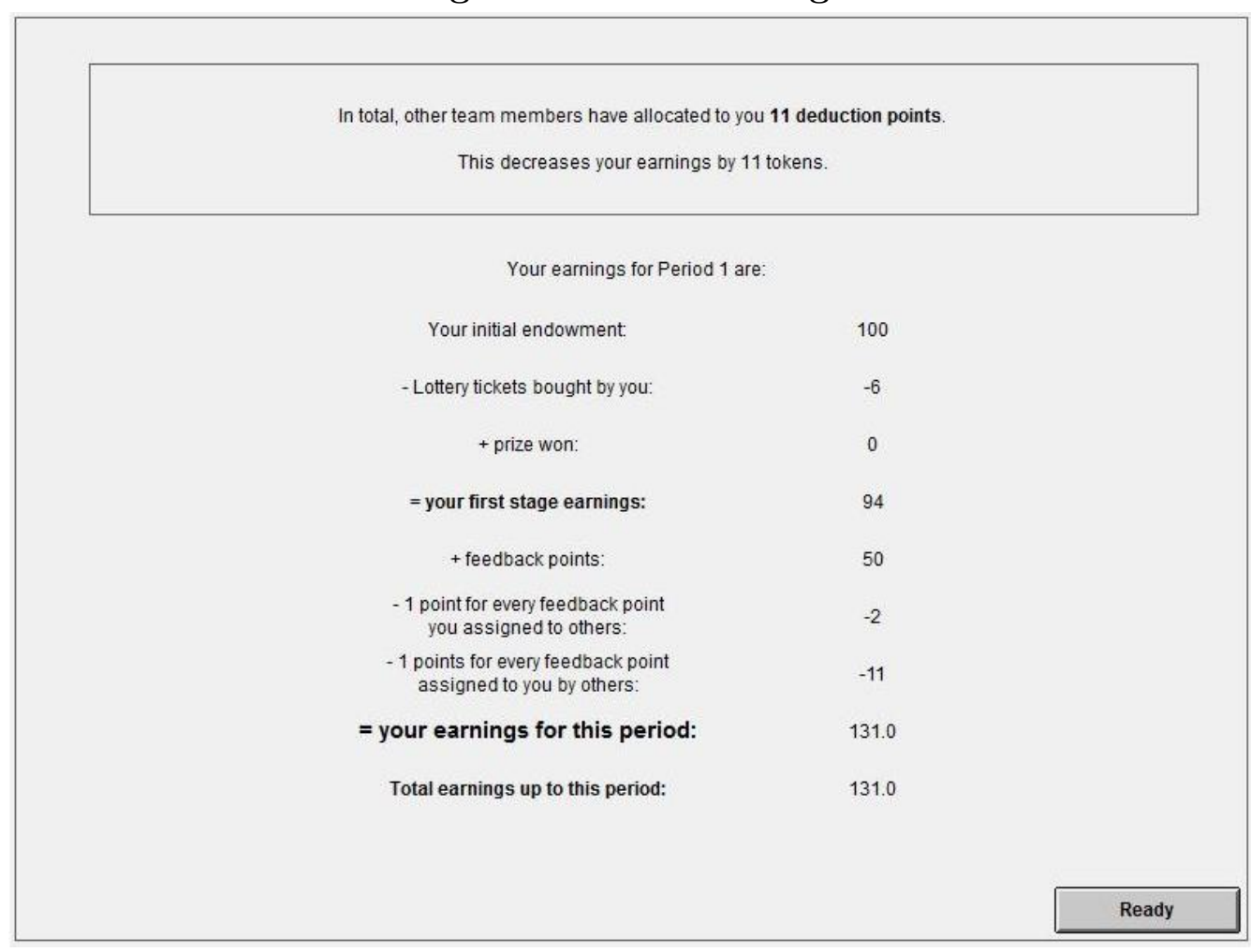

Figure 3.9: Third stage 


\section{Appendix 3.C Mathematical Appendix}

Player $l$ maximises expected profit $\pi_{l}$ by setting own contribution $v_{l}=\left(v_{i}\right)_{i \in K \cup M}$. Investment of players $k \in K$ of own group $K$ is labelled $\sum_{k \in K} v_{k}$, while players $m \in M$ in the other disjoint group $M$ invest $\sum_{m \in M} v_{m}$. Individual prize for winning a round is $z$. Solve individual optimisation problem for any period $t$, time indices are omitted.

$$
\pi_{l}\left(\left(v_{i}\right)_{i \in K \cup M}\right)=\frac{v_{l}+\sum_{k \in K \backslash\{l\}} v_{k}}{v_{l}+\sum_{k \in K \backslash\{l\}} v_{k}+\sum_{m \in M} v_{m}} \cdot z-v_{l}
$$

Deriving delivers the best response function for any player $l$ of group $K$ :

$$
\frac{\partial \pi_{l}\left(\left(v_{i}\right)_{i \in K \cup M}\right)}{\partial v_{l}}=0 \Leftrightarrow v_{l}=\sqrt{\sum_{m \in M} v_{m} \cdot z}-\sum_{m \in M} v_{m}-\sum_{k \in K \backslash\{l\}} v_{k}
$$

Checking the second order condition confirms that we find a maximum:

$$
-\frac{2 \sum_{m \in M} v_{m} \cdot z}{\left(\sum_{k \in K} v_{k}+\sum_{m \in M} v_{m}\right)^{3}}<0
$$

Using the first order condition of group $M$, we find a multiplicity of equilibria, characterised by $\sum_{m \in M} v_{m}=\frac{z}{4}$ and $\sum_{k \in K} v_{k}=\frac{z}{4}$. If we assume symmetry in own group: $v_{l}=\frac{z}{16}$.

\section{Appendix 3.D Group wise Analysis of Contribution}

Figures 3.10 - 3.17 depict average contribution per player across each of the 15 periods for each group. In Figures 3.10 - 3.13, odd-numbered group always plays against a group with a number that is one higher than the own one. The opposite is the case for even-numbered groups. This means that, for example, group 1 plays against group 2 or group 12 against group 11. As mentioned before, there has been no session of a group $3 \& 4$ in the baseline contest and group 6 in the baseline non-contest treatments, for why they are left blank. 


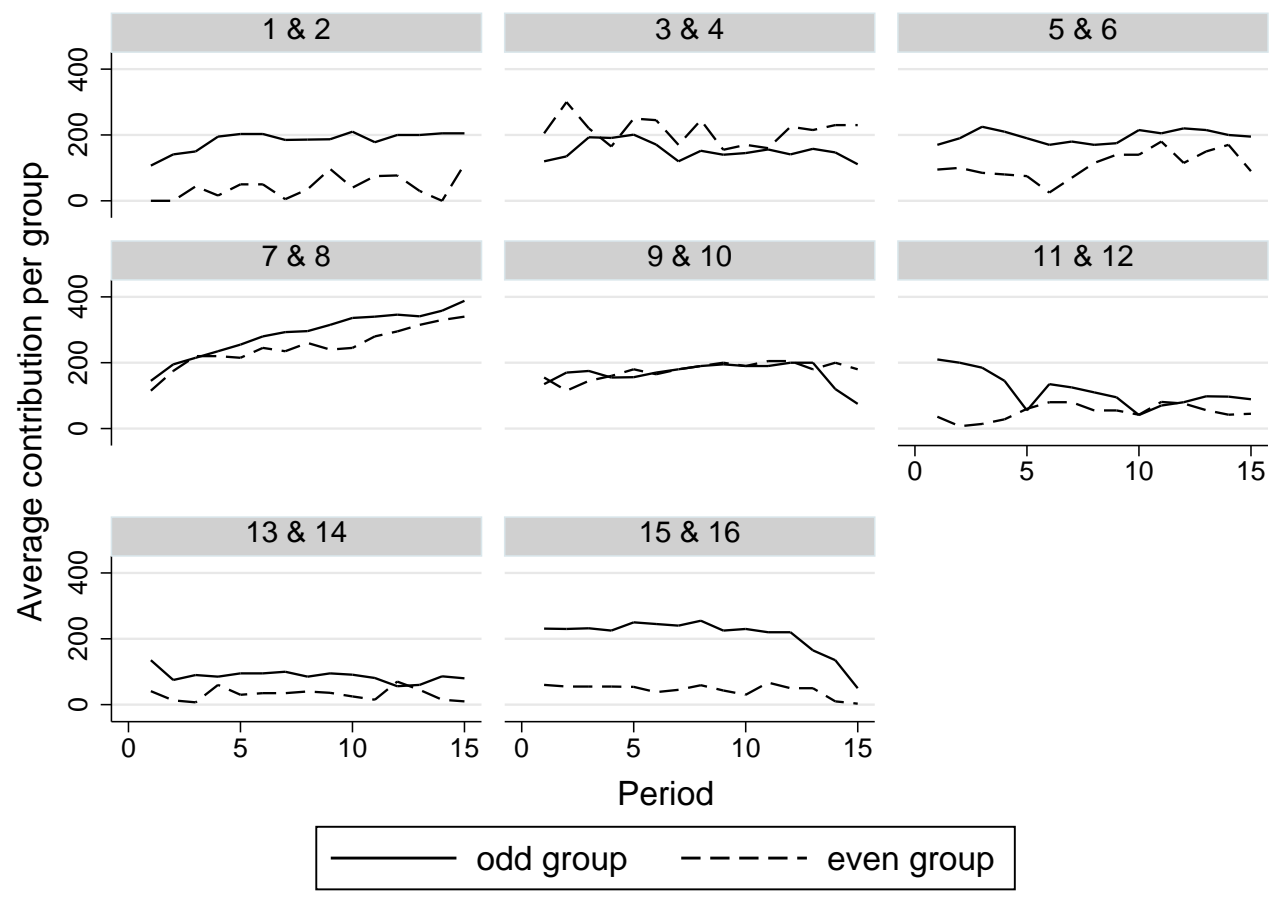

Figure 3.10: Average contribution per group, reward treatment, contest environment. Paired groups are displayed together.

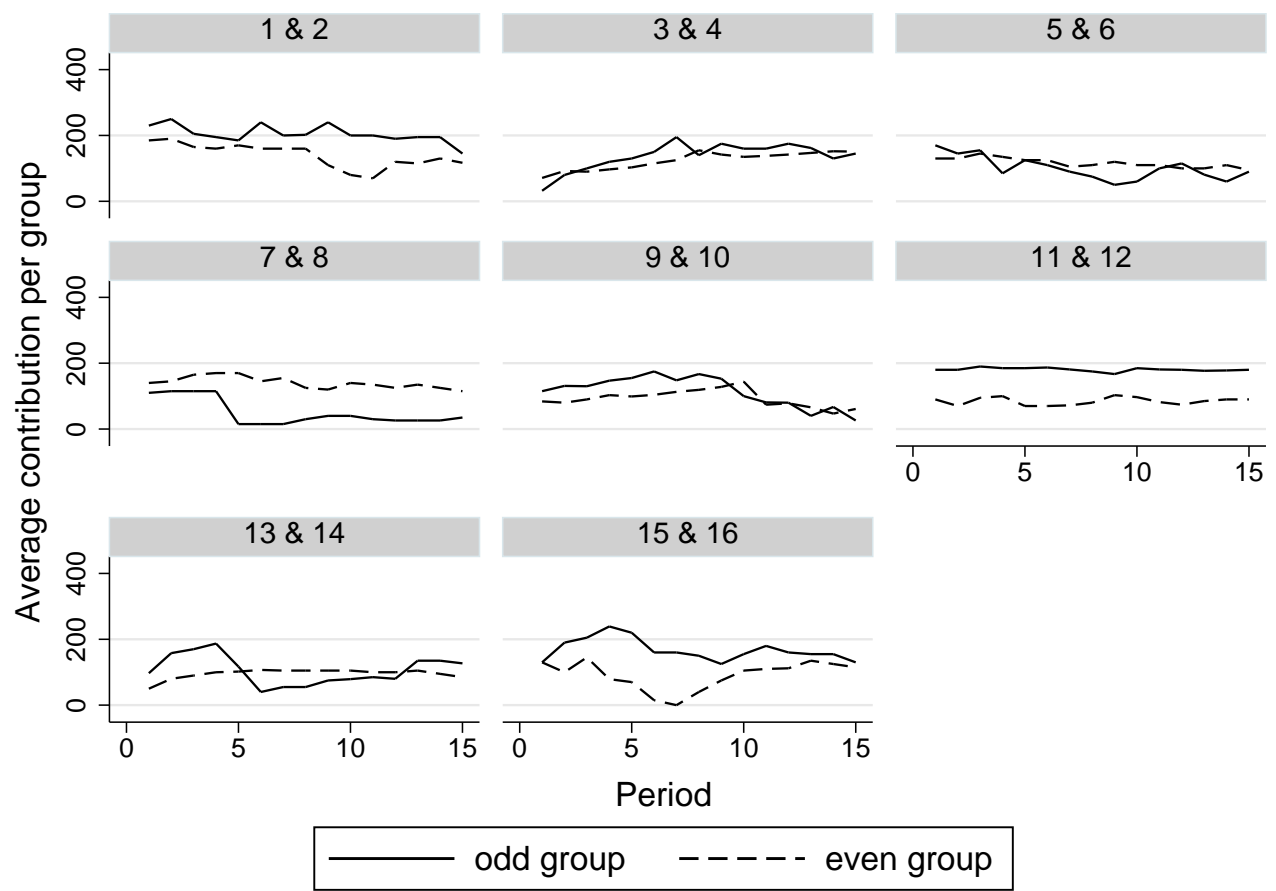

Figure 3.11: Average contribution per group, punishment treatment, contest environment. Paired groups are displayed together. 


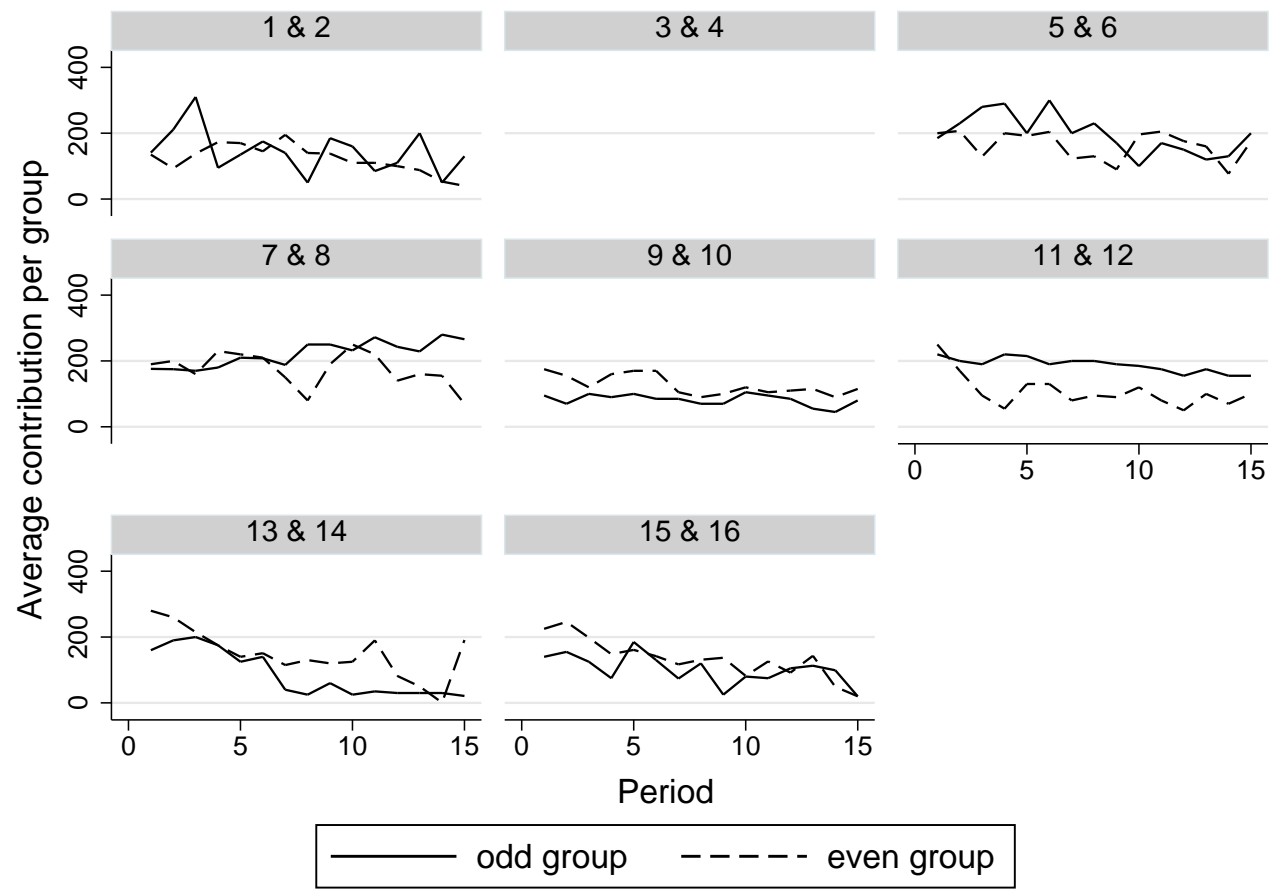

Figure 3.12: Average contribution per group, baseline treatment, contest environment. Paired groups are displayed together. Session for groups $3 \& 4$ did not take place due to no-shows.

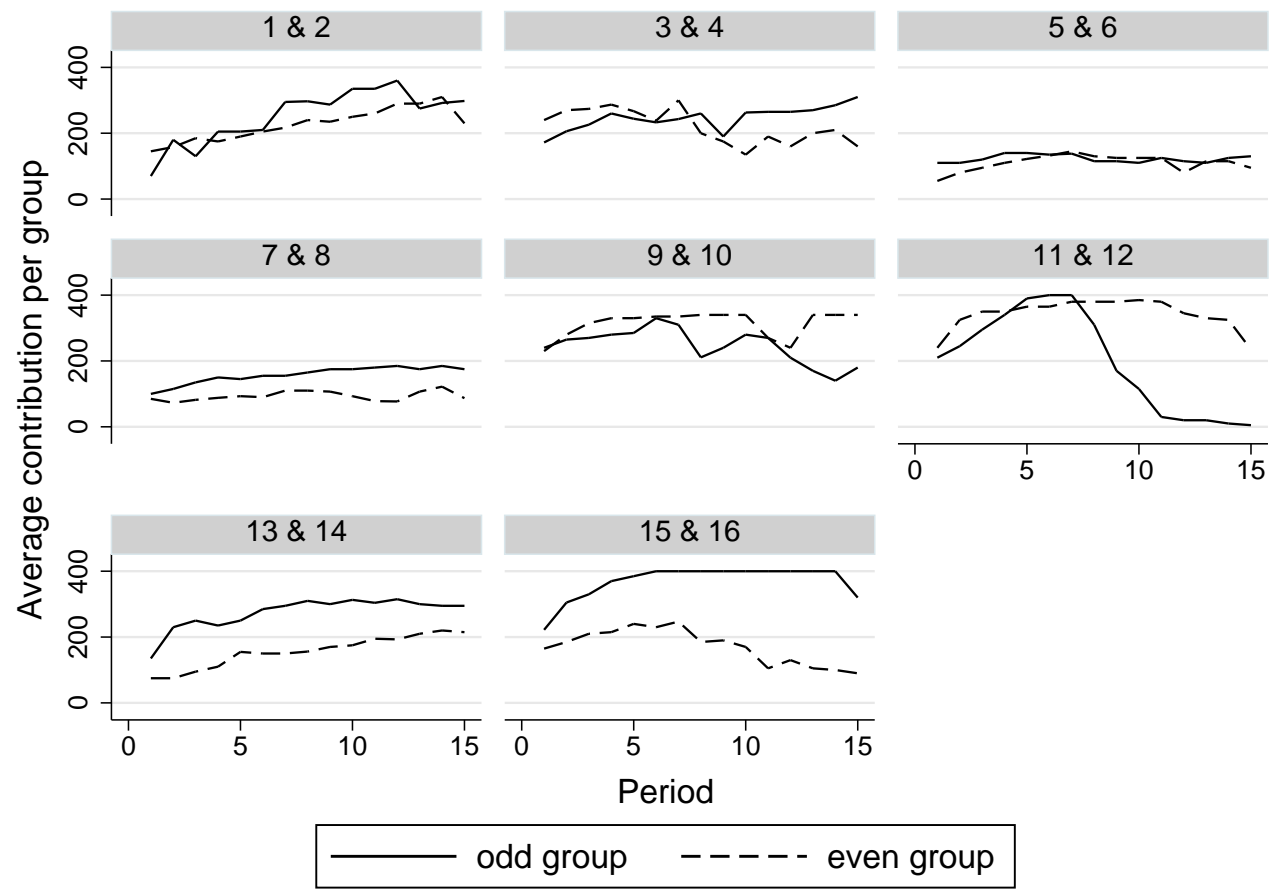

Figure 3.13: Average contribution per group, $\mathbf{R} \& \mathbf{P}$ treatment, contest environment. Paired groups are displayed together. 


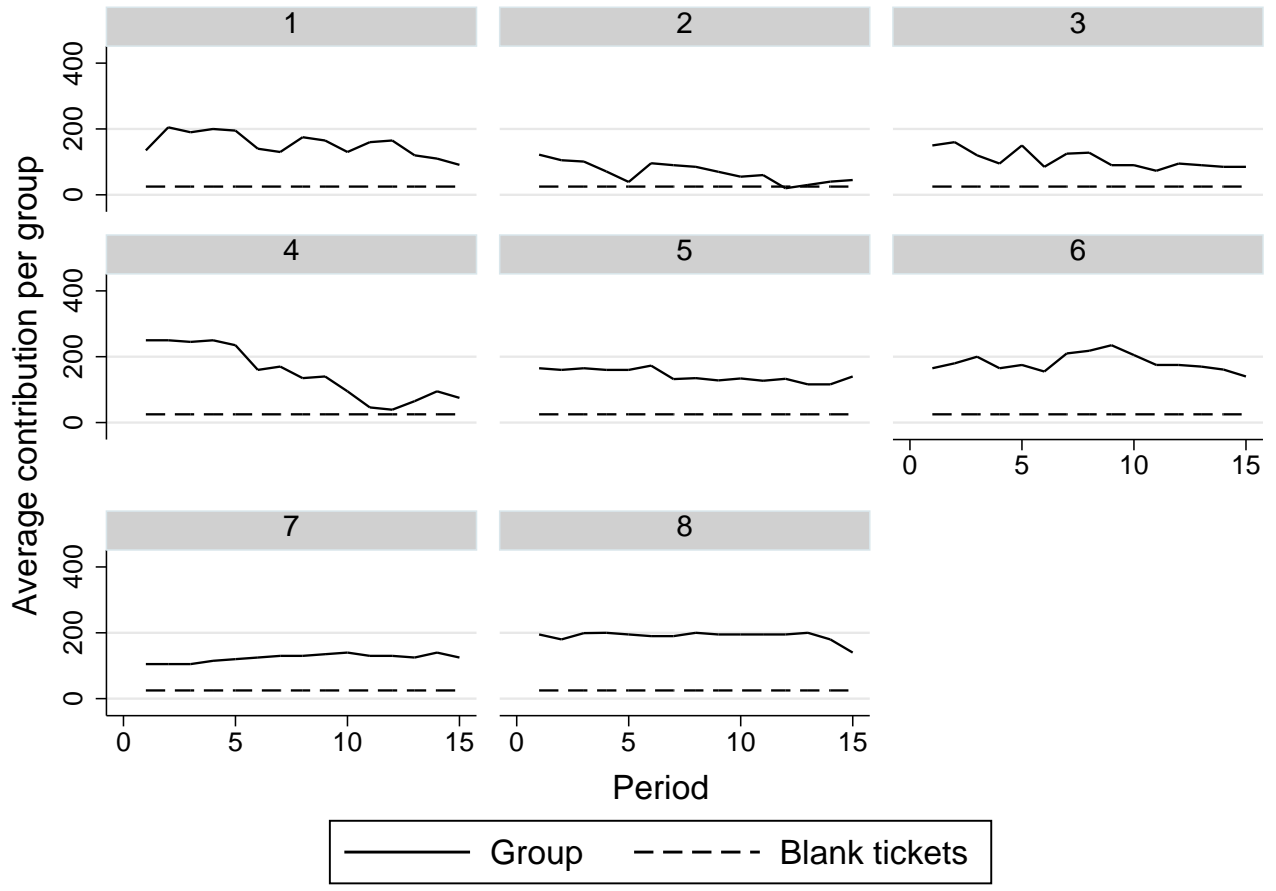

Figure 3.14: Average contribution per group, reward treatment, non-contest environment.

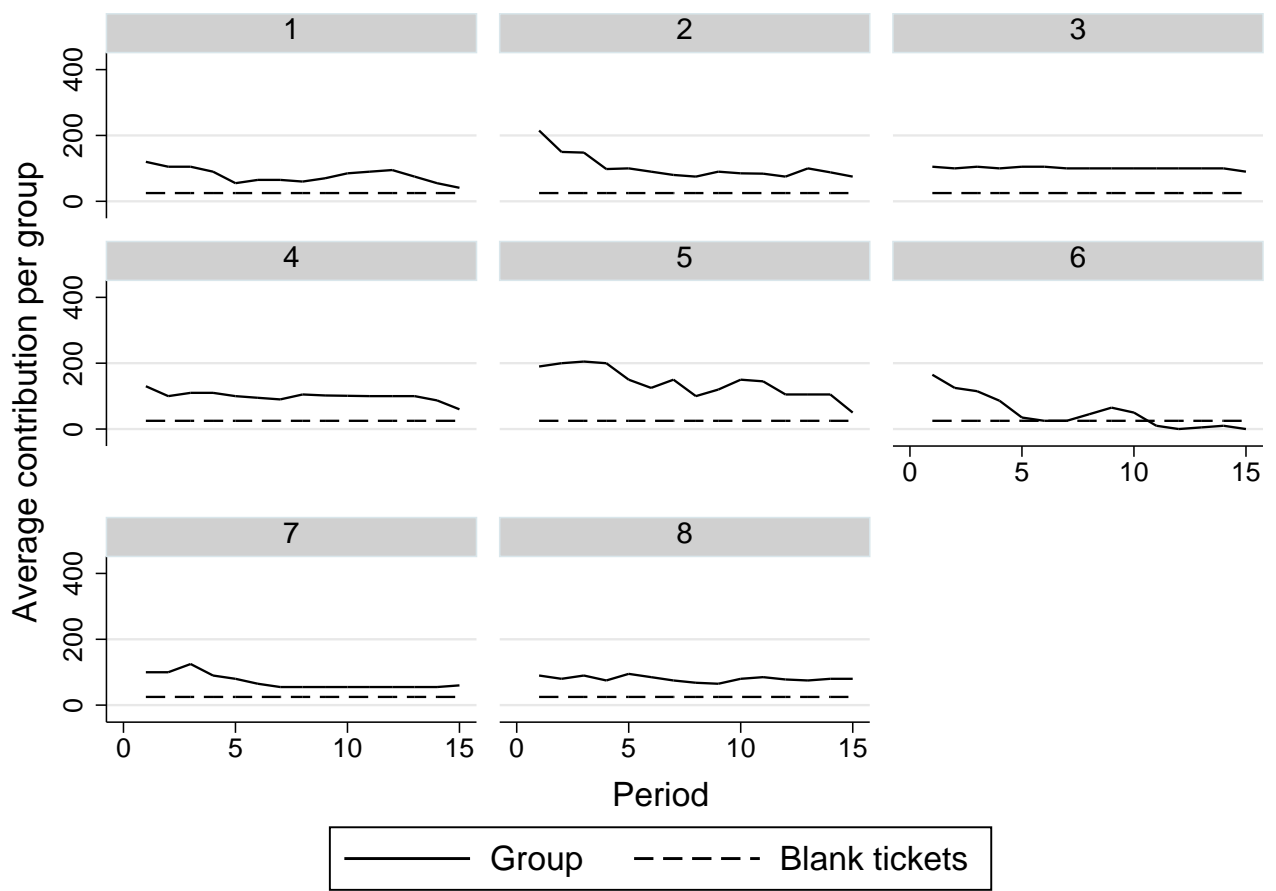

Figure 3.15: Average contribution per group, punishment treatment, noncontest environment. 


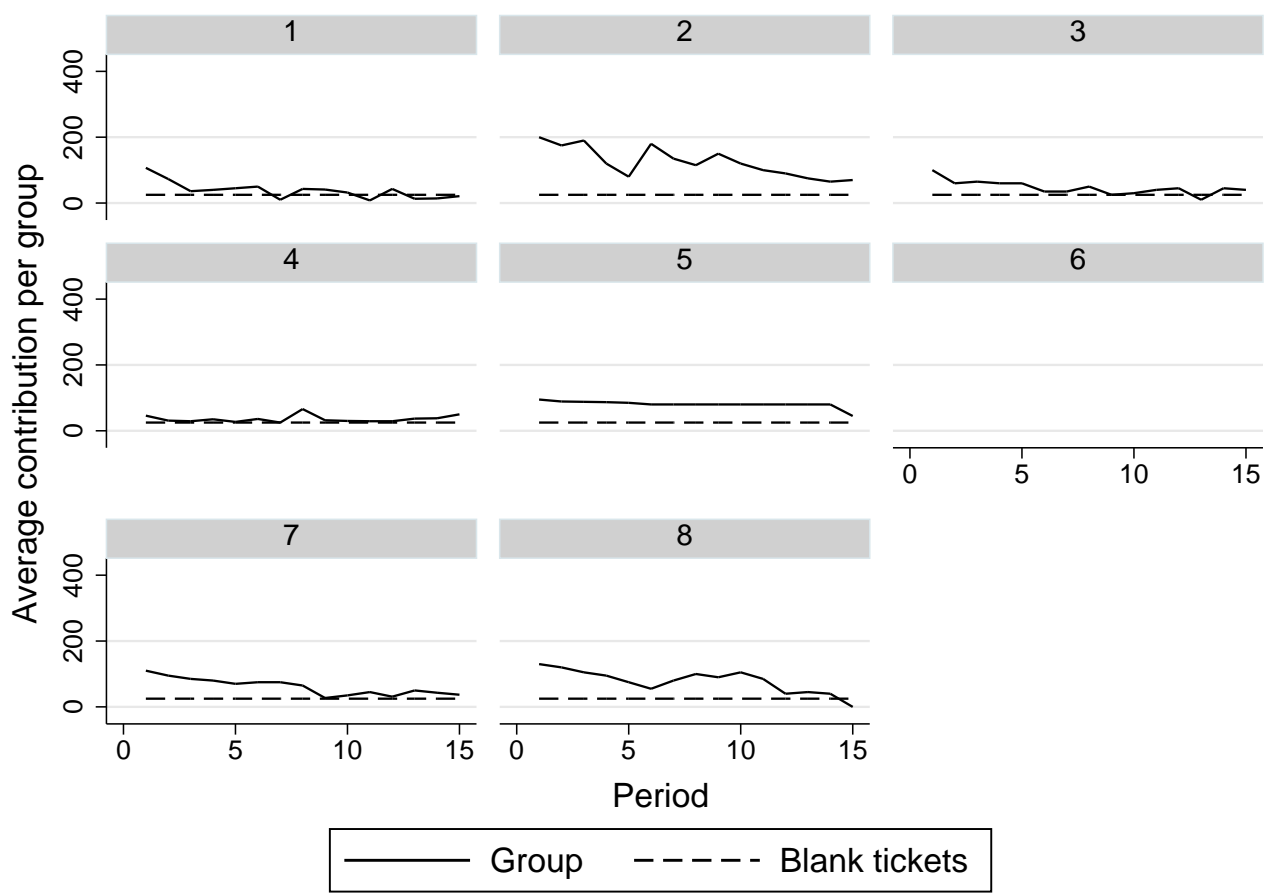

Figure 3.16: Average contribution per group, baseline treatment, non-contest environment. Session for group 6 did not take place due to noshows.

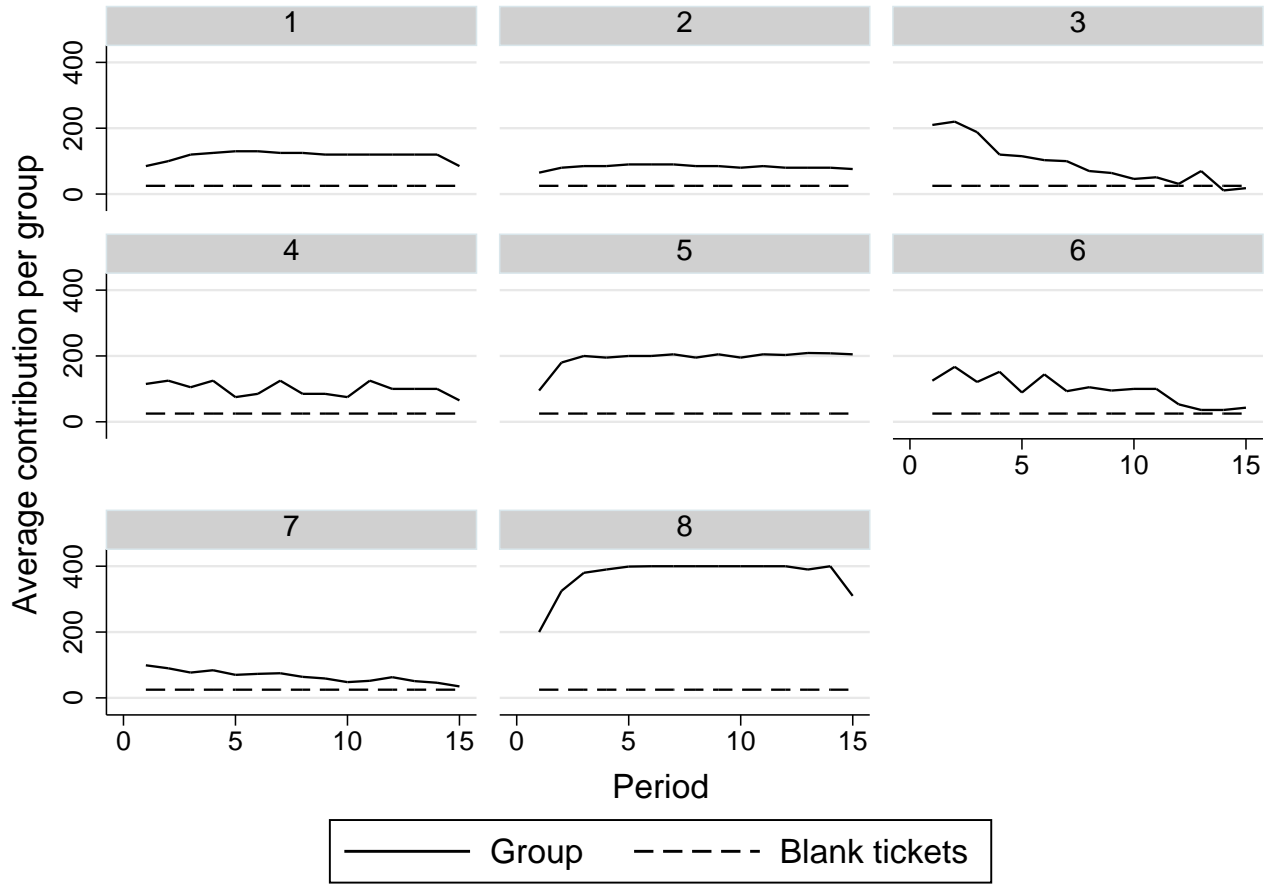

Figure 3.17: Average contribution per group, R\&P treatment, non-contest environment. 


\section{Appendix 3.E Personal attributes}

Table 3.8 corresponds to regressions (2) and (4) from Table 3.4 with explicit control parameters. They were generated by subjects' answers to a post-experiment questionnaire, in which we ask about a few personal features and stances. For this, we used questions from the World Values Survey (Inglehart and Archivo de Estudios Sociales, 2000). In this section we examine the control factors in more detail.

Most notably, domestic students from the Netherlands and Belgium contribute substantially less to the contest than their colleagues from other countries do. This is the only significant country effect and its magnitude is somewhat impressive.

Players who state to place more importance on individual responsibility (as opposed to governmental responsibility) contribute less to the contest, but give more response. This factor was created on a scale from one to seven where individuals stated their proximity to which of the two statements they feel closer. ${ }^{38}$ Players with a higher preference for individual responsibility hence tend to be reluctant towards spending their money for the group project, but are willing to reciprocate by the means of response. "Preference for working alone" was also created on a scale of one to seven with the statement that the individual prefers working in groups or alone at the extremes, to which she expresses proximity. ${ }^{39}$ Players who prefer to work alone give less response, which means they act less reciprocal.

Both factors "Work important" and "Smoking" influence response-giving positively. The former was created on a seven point scale in which participants express the importance of labour in their life. Furthermore, we enquire on our subjects' smoking behaviour as proxy for short-sightedness as in e.g. Slovic (2001). Next to a more reactionary response behaviour, individuals who indicate that they smoke also tend to spend less resources towards the contest.

Other items displaying a lowering effect towards contest spendings are "Family and friends important" (Participants' stated preference on a scale from $1-7$ ) and "Politics important". They have been generated like the factor "Work important" on a seven point scale. The following three parameters, by contrast, display a positive effect on contest contributions: "Trust parameter" (Proximity to the two statements: Most people can be trusted - Need to be very careful), "Siblings" and "Study phase". Placing tokens into the group account involves some degree of trust towards ones teammates that they will not renege or pursue an abating strategy. Additionally, participants in a later "Study phase" use less tokens to reciprocate teammates' actions. Lastly, relatively older participants tend to spend less tokens to the contest, but more on reciprocating, which is reflected in regressor "Age". Given the participant body of our study is comprised almost exclusively of students, this result could open up an interesting pathway towards a follow-up study, employing a subject pool with a wider age structure.

Two factors for which we contemplated having explanatory power in this game remain toothless. Those are "Current happiness" and "Ever practised a team sport", which have neither an influence on players' contest spendings nor response giving behaviour.

\footnotetext{
${ }^{38}$ The two extremes were "The government should take more responsibility to ensure that everyone is provided for." versus "People should take more responsibility to provide for themselves."

${ }^{39}$ The two extremes were "I like working in groups" versus "I like working on my own"
} 


\begin{tabular}{|c|c|c|}
\hline VARIABLES & $\begin{array}{c}(2 \mathrm{a}) \\
\text { Contribute }\end{array}$ & $\begin{array}{c}(4 \mathrm{a}) \\
\text { Own response }\end{array}$ \\
\hline Contribute & & $\begin{array}{l}0.333^{* * *} \\
(0.05)\end{array}$ \\
\hline Own response & $\begin{array}{l}0.837^{* * *} \\
(0.14)\end{array}$ & \\
\hline $\begin{array}{l}\text { Group contribution } \\
\text { level }\end{array}$ & $\begin{array}{l}0.181^{* * *} \\
(0.02)\end{array}$ & $\begin{array}{l}-0.041^{* * *} \\
(0.01)\end{array}$ \\
\hline Group response level & $\begin{array}{l}0.342^{* * *} \\
(0.12)\end{array}$ & $\begin{array}{c}-0.160^{*} \\
(0.09)\end{array}$ \\
\hline $\begin{array}{l}\text { Other group } \\
\text { contribute }\end{array}$ & $\begin{array}{l}-0.135^{* * *} \\
(0.04)\end{array}$ & $\begin{array}{l}0.098^{* * *} \\
(0.03)\end{array}$ \\
\hline $\begin{array}{l}\text { Netherlands and } \\
\text { Belgium }\end{array}$ & $\begin{array}{l}-7.473^{* * *} \\
(1.76)\end{array}$ & $\begin{array}{c}1.805 \\
(1.59)\end{array}$ \\
\hline $\begin{array}{l}\text { Preference for } \\
\text { working alone }\end{array}$ & $\begin{array}{c}0.501 \\
(0.49)\end{array}$ & $\begin{array}{l}-0.965^{* * *} \\
(0.35)\end{array}$ \\
\hline $\begin{array}{l}\text { Individual } \\
\text { Responsibility }\end{array}$ & $\begin{array}{l}-1.394^{* * *} \\
(0.44)\end{array}$ & $\begin{array}{l}0.764^{* *} \\
(0.31)\end{array}$ \\
\hline Work important & $\begin{array}{r}0.308 \\
(0.92)\end{array}$ & $\begin{array}{l}1.535^{* *} \\
(0.71)\end{array}$ \\
\hline Smoking & $\begin{array}{c}-4.573^{* *} \\
(2.17)\end{array}$ & $\begin{array}{l}4.342^{* * *} \\
(1.60)\end{array}$ \\
\hline Trust parameter & $\begin{array}{l}2.395^{* *} \\
(1.19)\end{array}$ & $\begin{array}{r}-0.508 \\
(0.91)\end{array}$ \\
\hline $\begin{array}{l}\text { Family and friends } \\
\text { important }\end{array}$ & $\begin{array}{c}-2.872^{* *} \\
(1.16)\end{array}$ & $\begin{array}{r}-0.510 \\
(0.98)\end{array}$ \\
\hline Politics important & $\begin{array}{c}-1.475^{*} \\
(0.85)\end{array}$ & $\begin{array}{c}0.384 \\
(0.45)\end{array}$ \\
\hline Current happiness & $\begin{array}{c}0.878 \\
(1.08)\end{array}$ & $\begin{array}{r}-0.759 \\
(0.61)\end{array}$ \\
\hline $\begin{array}{l}\text { Ever practised a } \\
\text { team sport }\end{array}$ & $\begin{array}{r}-1.517 \\
(1.15)\end{array}$ & $\begin{array}{r}1.530 \\
(1.10)\end{array}$ \\
\hline Siblings & $\begin{array}{c}1.286^{*} \\
(0.72)\end{array}$ & $\begin{array}{c}-0.484 \\
(0.41)\end{array}$ \\
\hline Study phase & $\begin{array}{c}3.194^{*} \\
(1.66)\end{array}$ & $\begin{array}{l}-3.316^{* * *} \\
(1.17)\end{array}$ \\
\hline Age & $\begin{array}{l}-0.812^{* * *} \\
(0.30)\end{array}$ & $\begin{array}{l}0.531^{* *} \\
(0.24)\end{array}$ \\
\hline Constant & $\begin{array}{l}70.418^{* * *} \\
(15.05)\end{array}$ & $\begin{array}{c}-35.781^{* * *} \\
(10.26)\end{array}$ \\
\hline $\begin{array}{l}\text { Pseudo R-squared } \\
\mathrm{N}\end{array}$ & $\begin{array}{l}0.225 \\
270\end{array}$ & $\begin{array}{l}0.160 \\
270\end{array}$ \\
\hline
\end{tabular}

Standard errors in parentheses. Treatment, group and study major dummies not reported.

\section{Table 3.8: Individual level analysis}




\section{Appendix 3.F Response received, dyadic analysis}

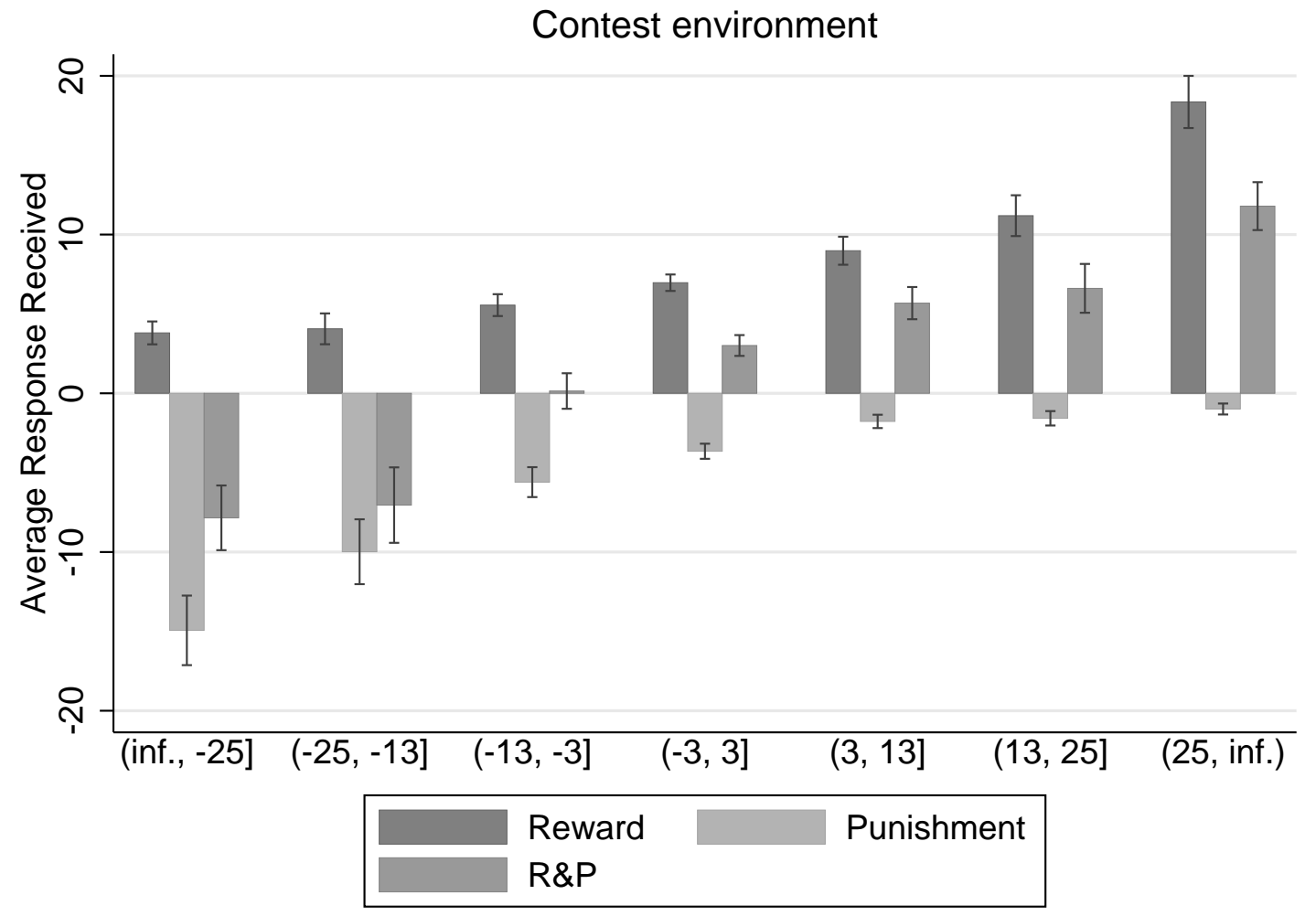

Figure 3.18: Response received in relation to deviation from sender's contribution with $5 \%$ confidence interval.

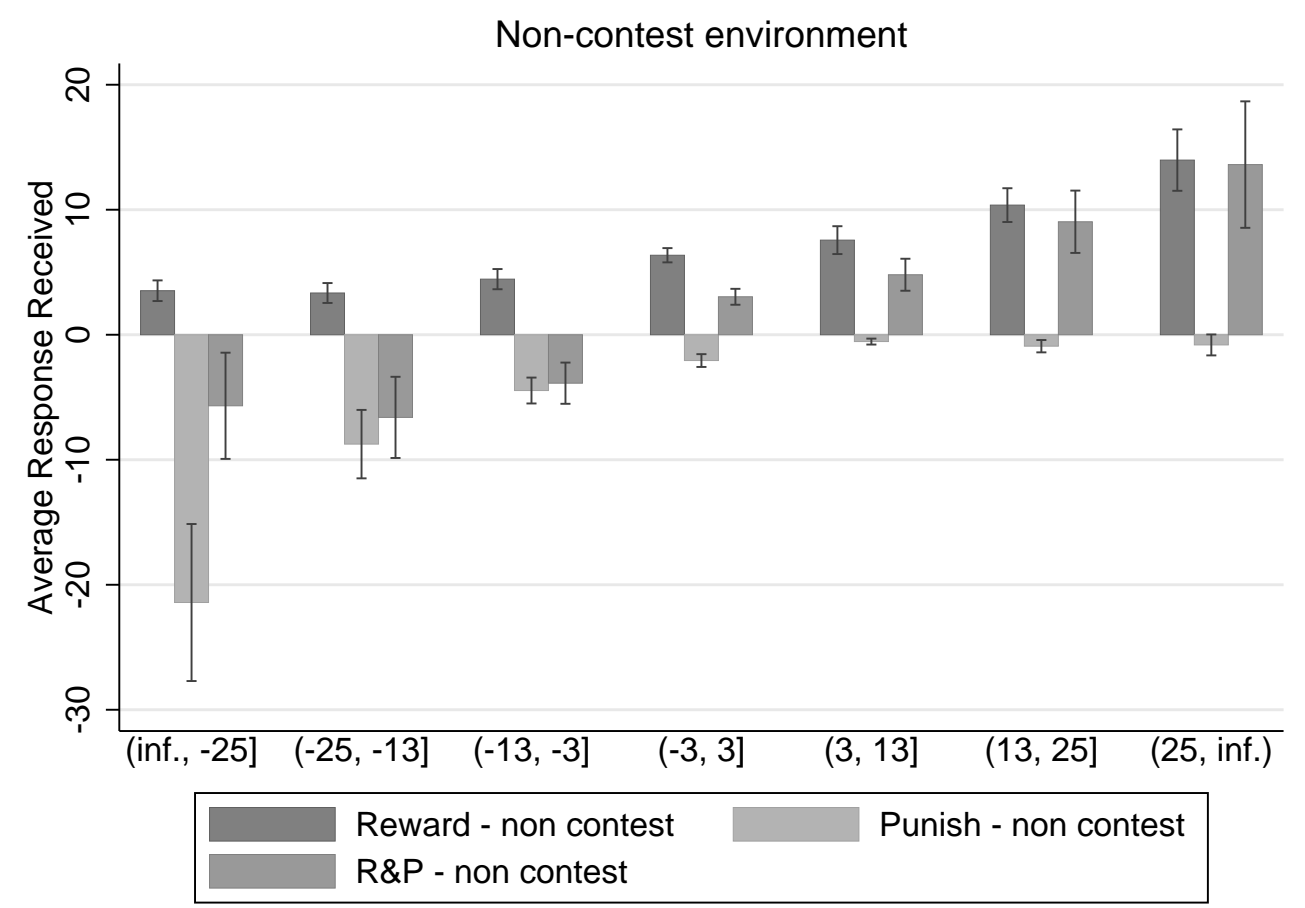

Figure 3.19: Response received in relation to deviation from sender's contribution with $5 \%$ confidence interval. 



\section{Chapter 4}

\section{Let's (not) escalate this! Intergroup leadership in a team contest $^{1}$}

\subsection{Introduction}

Research on leadership repeatedly finds an efficiency enhancing effect of a leader in public goods games or group production both in the lab and in the field (Kosfeld and Rustagi, 2015; Arbak and Villeval, 2013; van der Heijden, Potters, and Sefton, 2009; Potters, Sefton, and Vesterlund, 2007). In the field, however, many situations are of a competitive kind and a group's fate is not independent of competing agents' actions. In order to outperform competitors, considerable resources are spent without direct productive value. We examine the effect of a leader on contributions and over-dissipation in a group contest game.

Consider soldiers in a battle who could "conclude that no matter what their comrades do they personally are better off taking no chances; yet if no one takes chances, the result will be a rout and slaughter worse for all the soldiers than is taking chances" (Dawes, 1980). This is true, unless the soldiers of the enemy do not consider the same: Clearly, if both sides decided not to fight, everybody could be better off whereas a high level of engagement in such kind of military conflict could result in drastic casualties and damage.

Even though not in an equally bloody way, also in economics and in society in general, many situations are of a competitive kind. Be it the competition for publishing scientific papers, between lobby groups or rivalry on an inter-country level. What all these examples have in common is the fact that there is a considerable amount of unproductive resources spent in this rat race.

In 2014, for example, the Joint Transparency Register Secretariat of the European Parliament and the European Commission lists a total of 6,570 registered lobby groups operating in the immediate vicinity of the aforementioned European bodies. With a focus on lobbying in the United States, Fang (2014) suggests though, that most lobbying activities in fact occur unregistered. Although there were around 12,000 lobbyists registered with

\footnotetext{
${ }^{1}$ Based on an article by Florian Heine and Arno Riedl
} 
the US Senate Office of Public Records in 2010, Thurber (2011) estimates the real number to be well above 100,000. This figure also translates into money investments for lobbying: $\$ 3.49$ Billion were spent in 2009 officially, representing the third largest business in DC after government and tourism. The real spendings might be up to three times higher, however (Thurber, 2009). Another fundamental example of rivalry are military conflicts e.g. for a political cause or socio-political conflicts between ethnic groups. These types of conflict are very costly considering both humanitarian impacts and material damage.

One of the most widespread models for (team) contests is the lottery game by Tullock (1980) or Katz et al. (1990), where the winning probability increases with higher relative spending. ${ }^{2}$ There exists a Nash equilibrium in pure strategies, in which both parties invest positive amounts in the contest. As the prize at stake is fixed, the resources invested have no productive value, but only influence the winning probability. Consequently, these investments represent a socially wasteful expense. In Katz et al. (1990), groups are competing in a team competition for a public good, where the prize is nonrival and nonexcludable within the group. Hence, the prize constitutes a local public good.

The vast majority of experiments on rent-seeking or contest games find contributions that are even higher than the equilibrium prediction (Sheremeta, 2015, 2013; Dechenaux et al., 2012; Öncüler and Croson, 2005) causing rent over-dissipation and inefficiency. Abbink et al. (2010) mention a number of motivational factors for this deviant behaviour: Most prominently, there is evidence for a motivational drive for coming out ahead of the other party. Herrmann and Orzen (2008) call this the homo rivalis - an agent driven by spiteful, envious or malevolent preferences.

In the field, it is often not individuals competing against each other, but groups. Think hereby of political parties, trade unions or lobbyists. Although this brings along the advantage that groups can be a lot more powerful than individuals, it also entails coordination problems. Furthermore, groups are oftentimes not homogeneous entities, but inherit a particular structure. In a company for instance, there is a leader supervising a number of subordinates. The prominence of the concept of leaders can as well be found in other contexts, for example party leaders in politics or team captains in sports. Calvert (1992) argues that the "coordination problem is the ultimate source of the need for leadership in real-world groups."

Research on leadership often finds an effect towards higher contribution and earnings in presence of a leader if contributing is socially beneficial, like in public goods games (Arbak and Villeval, 2013; van der Heijden et al., 2009; Potters et al., 2007). Rondeau and List (2008) find evidence for this in a field experiment in the context of charitable donations. If a leading donor is mentioned having invested a considerable amount in a given project, following donations from individuals are up to $71 \%$ higher than in control treatments. Other results show a lowering effect of negative externalities from individuals in public bad games and common-pool resource games, if a leader is in place (Moxnes and van der Heijden, 2003; Vyrastekova and van Soest, 2003). In a team contest, however, things might very well look different: Pittinsky and Simon (2007), for example, point out that "(t)he very foundations of strong leadership, such as fostering strong group cohesion, can become stepping stones to intergroup conflict." The reason for this is the existence of an ingroup / outgroup leadership trade-off, where strong leadership comes to the detriment of outgroup relations. To date there is no empirical evidence, if - or under which conditions - the

\footnotetext{
${ }^{2}$ See Konrad $(2009,2007 a)$ for a detailed discussion of this game concept.
} 
efficiency enhancing characteristic of a leader also prevails in a group conflict situation.

As way out of this pitfall, Pittinsky and Simon (2007) bring forward the concept of intergroup leadership, where positive relations between the groups are promoted. Relating back to the Contact Hypothesis by Allport (1954, Chapter 16), encouraging contact between members (or representatives) of the groups "will increase the in-group's positive regard for the out-group." 3 This could ultimately lead to a reduction of conflict expenses and to overall efficiency gains. Until now, no empirical study investigates the effect of intergroup leadership in a team contest.

In this chapter we present an experiment designed to examine whether having a leader can curtail over-contribution and improve group welfare in a team competition for a group prize. Furthermore, we examine if intergroup leadership can reduce between-group conflict and increase social welfare. To understand the role of individual Social Value Orientation (SVO) and risk preferences in this game, we take an incentivized measure of those factors prior to the main part of the experiment. We regard executing this in a laboratory experiment as most suitable, as it allows for a controlled environment that could not possibly be found in the field.

Our main findings indicate that the way leaders influence contest spending behaviour depends on the distinct communication channels, leaders can employ. Our setup handles three ways to transfer information: As first mover, followers learn about the action of the leader before making their move. This level of communication is applied in all of our leadership treatments and delivers ambivalent results. We believe that the outcome hinges more on the following two levels of communication. With monetary authority, a leader's redistribution of finances can deliver a message as to what kind of follower's behaviour will be appreciated by the leader. In point of fact, leaders tend to incentivise high contest expenditures by allocating more money to those followers spending more resources in the contest. Thus, this communication method obstructs any potential compatibility between groups. By contrast, intergroup leadership through free form chat communication between leaders of competing groups can mitigate the contest.

This chapter is structured as follows: First in Section 4.2 we provide an overview of research on leadership in economic games, then in Section 4.3 we explain the setup of our study and give details on the realisation of the experiment in Subsection 4.3.1. We discuss equilibrium strategies for the treatments in Section 4.4, as well as alternative hypotheses in Subsections 4.4.1. In Section 4.5, we present the results of this study, which will be followed by this study's implications and conclusion in Section 4.6.

\subsection{Leadership in Economic Games}

In this study we combine two forms of leadership: The first form, leading-by-example applies an informal way of leadership, where the leader is not entitled to any form of authority. Instead, one player leads the group by moving before the others, setting a benchmark for

\footnotetext{
${ }^{3}$ For the sake of completeness it needs to be pointed out that mere contact probably is not enough to improve group relations. In Allport's Contact Hypothesis, for example, there are four fundamental conditions defined for improving relations between groups: Equal-status groups, common goals, intergroup cooperation, and the support of a legitimate authority. These conditions can be met in a team contest.
} 
them. The second model of leadership is "transactional leadership" (Burns, 1978; Bass, 1985), where the leader is in a direct exchange relationship with other players. For example, she might determine how to divide the earned money over the players of the own group. Being in such kind of a hierarchically superordinate position she can try to steer group members towards a common goal, for example by specifically assigning a higher payoff to players who behave according to this goal. In the following we give two examples for each form of leadership, starting with leading-by-example.

Moxnes and van der Heijden (2003) use a public bad game and experimentally examine the effect of a first-mover. They find that "leaders ... have a statistically significant and persistent effect on the followers". This means that if a first mover invests less in the public bad, this has some significant lowering effect on the followers' investment level into the public bad.

Another example of a leading-by-example setup is given by Potters et al. (2007). They run a two person public goods game with and without a first-mover. They also vary the Marginal Per Capita Return (MPCR) of the public good investment in three ways. Either it is very low, such that it is even socially inefficient to invest in the public good (they use a factor of 0 ). As second alternative, the MPCR makes it socially desirable but individually irrational to contribute for a self-interested agent. Consequently, the third MPCR is chosen as high as to render it even individually profitable to invest in the public good. Potters et al. (2007) also vary the information structure, such that the follower either knows the factual multiplication factor at hand or stays uninformed about it. In the uninformed setting, the followers only get to know the distribution of possible multiplication factors and the leader's action. Potters et al. (2007) find that "leading-by-example improves group performance in the presence of asymmetric information." In case the second mover is informed about the multiplication factor, however, this effect dwindles considerably.

One example using transactional leadership is the study by van der Heijden et al. (2009). They experimentally examine the effect of leaders on group productivity in a public goods game with convex production function. They set up their experiments with two treatments: One where revenues are shared equally between group members, and another one where a leader is in the position to freely decide about the distribution of the payoffs per round. They find that under the leader setting, players contributed more to the group project and accrued higher earnings on average. Also, the vast majority of leaders divides the share equally amongst those members of the group who actually contributed.

Vyrastekova and van Soest (2003) provide another experimental study with central monitoring. They consider a common-pool resource game, where one player is put in the position of a police officer who tries to collect fines from those who over-extract. They find a substantial reduction of over-extraction in presence of the police officer.

\subsection{Setup}

Prior to the team contest we take an individual measure for risk preference (called Part 1 in the instructions) and for social preferences (Part 2). To this end we make use of techniques by Eckel and Grossman (2002) for eliciting risk aversion and Murphy et al. (2011) for individuals' social value orientation. See Appendices 4.A and 4.B for more details. 
First we implement a leading-by-example treatment only. This way we elicit the effect of a first mover and can disentangle it from having a leader with authority over the other players. ${ }^{4}$

In another setup, we use both leading-by-example and transactional leadership. While for leading-by-example, leaders might be followed because of signalling and reciprocity (as in Hermalin, 1998; Potters, Sefton, and Vesterlund, 2001; Meidinger and Villeval, 2002), transactional leaders might be followed because it is in the subordinate's self interest to do so (the instrumental perspective in De Cremer and Van Vugt, 2002).

Players are sorted in groups of four, with two groups competing for a fixed prize repeatedly. They interact with the same other players throughout the experiment. Identities of participants are not being disclosed at any time during or after the experiment, player identification numbers within groups and group composition remain unchanged. The game consists of 15 periods and it will include investment decisions that are discussed in the following.

Each period consists of distinct stages. The following overview explains the Baseline treatment. Thereafter paragraphs headed by a treatment name in square brackets elaborate on the other treatments, followed by Table 4.1 for an overview:

1. Each player receives an endowment of $E=120$ tokens and decides how much of it to invest in order to buy lottery tickets. The price for a ticket is one token. Investment of subject $k$ of group $K$ and $m$ of group $M$ are labelled $v_{k}$ and $v_{m}$, respectively. All tokens that a player does not spend on lottery tickets will be added to her account.

2. The winning probability, or contest success function (CSF), is as in Tullock (1980); Katz et al. (1990)

$$
p_{K}\left(\left(v_{k}\right)_{k \in K},\left(v_{m}\right)_{m \in M}\right)= \begin{cases}\frac{\sum_{k \in K} v_{k}}{\sum_{k \in K} v_{k}+\sum_{m \in M} v_{m}} & \text { if } \max _{i \in K \cup M}\left\{v_{i}\right\}>0 \\ 1 / 2 & \text { otherwise }\end{cases}
$$

where $p_{K}$ is the probability that group $K$ wins over group $M$. It is the sum of all lottery tickets of the own group divided by the total lottery tickets bought by all groups. After each investment phase, one ticket will be drawn out of the ballot box to determine the winner. Hence, the more tickets a group buys, the higher the chances of winning the lottery (ceteris paribus).

At the end of a period, each player's contribution will be made available to all members of the same group. Also, information of the opposing team's aggregated contribution will be revealed, as well as the corresponding winning probability. The winning team receives a fixed prize of $4 z=1,920$ which will be divided equally, such that players of the winning group each receive $z=480$ tokens as premium - the other group gets nothing.

[Ingroup leading-by-example treatment (Ingroup lbe):] In each group, one person - the leader - buys lottery tickets first and the amount she purchases is made public to other

\footnotetext{
${ }^{4}$ We do not use a transactional leader treatment without prior example-setting, because followers would not know what the leader expects from them, or what norm she tries to incentivise.
} 
members of the own group before everyone else decides simultaneously how much to spend. Throughout the experiment, the same players will stay leaders in their groups. Players of the winning group each receive $z=480$ tokens as premium, the other group gets nothing.

[Ingroup transactional leader treatment (Ingroup trans):] As in the ingroup leading-byexample treatment the leader buys lottery tickets before everyone else and the amount she purchases is made public to all members of the own group before the followers decide how much to spend. In this treatment, though, the leader of the winning group receives $4 z=1,920$ tokens as premium, nobody else receives anything. However, the leader can redistribute $4 z$ among own group members and herself, as she wishes. The factual redistribution is made public to other group members.

[Intergroup leading-by-example treatment (Intergroup lbe):] Same as the ingroup leadingby-example treatment with one adaption: leaders now can privately communicate via a chat window prior to casting their decisions. They both still make their decisions before everyone else and this information will be available to the own group.

[Intergroup transactional leader treatment (Intergroup trans):] A combination of aforementioned treatments. The two leaders can privately chat before making the contribution. The leaders still move first, receive $4 z=1,920$ if own group wins and have the option to reassign as explained above.

Table 4.1: Treatment overview

\begin{tabular}{lccc}
\hline & $\begin{array}{c}\text { Leader moves } \\
\text { first }\end{array}$ & $\begin{array}{c}\text { Leader receives prize } \\
\text { and may redistribute }\end{array}$ & $\begin{array}{c}\text { Leaders } \\
\text { communicate }\end{array}$ \\
\hline Baseline & & & \\
$\begin{array}{l}\text { Ingroup leading- } \\
\text { by-example }\end{array}$ & $\checkmark$ & $\checkmark$ & \\
$\begin{array}{l}\text { Ingroup } \\
\text { transactional leader }\end{array}$ & $\checkmark$ & & $\checkmark$ \\
$\begin{array}{l}\text { Intergroup leading- } \\
\text { by-example }\end{array}$ & $\checkmark$ & & $\checkmark$ \\
$\begin{array}{l}\text { Intergroup } \\
\text { transactional leader }\end{array}$ & $\checkmark$ & $\checkmark$ & \\
\hline
\end{tabular}

\subsubsection{Realisation of the Experiment}

Using the recruitment system ORSEE by Greiner (2004) we recruited 360 subjects to participate in the experiment (this is 9 pairs of groups per treatment). The sessions took place in the BEElab at Maastricht University, Netherlands, between September and November 2015. Each participant received a financial compensation dependent on the sum of tokens earned. The experiment took about 80 minutes in total, including instructions, a trial period and payment. ${ }^{5}$ Average earnings were $€ 11.75$ across all treatments. ${ }^{6}$

\footnotetext{
${ }^{5}$ Due to technical problems, we shortened the game to eight periods for two pairs in the Intergroup lbe treatment. This has been announced clearly before the start and results stay robust when dropping the data of this session.

${ }^{6}$ About $\$ 12.80$ or $£ 8.90$ at the exchange rate at the time of the experiment.
} 
In this computerised laboratory experiment ${ }^{7}$ subjects sat in an own cubicle, physically and visually separated from other participants. When entering the laboratory, subjects found a printout of both general and Part 1 instructions at their seat. Instructions for Parts 2 and 3 were distributed after the respective previous part has been completed by everyone. Find a copy of the instructions in Appendix 4.C. Prior to the main part (Part 3 in the experiment), subjects answered a few trial questions to ensure the understanding of the game. After Part 3, participants filled a questionnaire on personal attributes, risk preferences (as in Dohmen, Falk, Huffman, Sunde, Schupp, and Wagner, 2005), reciprocity (as in the German Socio-Economic Panel (SOEP)) and personal convictions.

\subsection{Equilibrium Strategies}

Consider first the Baseline treatment. The other treatments are discussed thereafter and Table 4.2 provides an overview. Assume risk-neutrality and that each player maximises her individual expected earnings, which is

$$
\pi_{i}\left(v_{i}\right)=E+\frac{v_{i}+\sum_{\substack{k \neq i \\ k \in K}} v_{K}}{v_{i}+\sum_{\substack{k \neq i \\ k \in K}} v_{K}+\sum_{m \in M} v_{M}} \cdot z-v_{i}
$$

$E$ is the initial endowment, $v_{i}$ is the player's own contribution, $\sum_{\substack{k \neq l \\ k \in K}} v_{K}$ is the total contribution of her other three group mates, $\sum_{m \in M} v_{M}$ is the total contribution of the other team, $z$ is the prize to win.

This finitely repeated game has a multiplicity of symmetric Nash equilibria which are characterised by $\sum_{k \in K} v_{k}=\frac{z}{4}$ for each group $K{ }^{8}$ For this experiment with $z=480$, this results in 120 tokens per group. As discussed in Konrad (2007a, 2009); Abbink et al. (2010), for this type of group contest game a unique solution only results with regard to group contributions. Concerning individual level contributions, multiple equilibria exist: All combinations of individual contribution that add up to 120 tokens per group constitute an equilibrium. The reason for this is the fact that although players optimise their individual contributions, the first-order conditions only contain aggregate contribution levels and do not determine the allocation of contribution within the group.

As the game is symmetric, a reasonable selection criterion could be that every player contributes equally (cf. Katz et al., 1990). This would result in an individual contribution of $v_{i}=\frac{z}{4 \cdot K}$ or 30 tokens, given a group size of $K=4$. So in this case, a risk neutral homo œconomicus would contribute $25 \%$ of the endowment $E=120$ to the project. Of course, this is only one example among other possible solutions to the within-group problem. ${ }^{9}$

When loosening the assumption of risk-neutrality, contribution to the contest reduces with increasing risk-aversion. See Appendix 4.E; Abbink et al. (2010); Katz et al. (1990) for

\footnotetext{
${ }^{7}$ We used the software "z-tree" by Fischbacher (2007)

${ }^{8}$ See Appendix 4.D for computations.

${ }^{9}$ Leininger (2002) shows that for this type of group contest games, there exists no evolutionary stable strategy (ESS), as an "extreme free-rider, who puts in zero effort ... can ... invade the only candidate ESS." The Nash-equilibrium, however, constitutes a local evolutionarily stable strategy (local ESS) if competing groups are of the same size, which is the case here (Alós-Ferrer and Ania, 2001).
} 
a discussion of most conventional functional forms, such as constant absolute risk aversion (CARA) and constant relative risk aversion (CRRA). Katz et al. (1990) also show that for differing levels of risk aversion between the groups, the one with higher risk aversion contributes less. Furthermore they show that for an individual player, the added expected utility gain from an additional unit of investment decreases with the level of risk aversion. By the nature of this game's equilibrium, players desiring a higher contribution (i.e. having a relatively lower level of risk aversion) would ship in for the lower contributors. ${ }^{10}$

Additionally to the set of Nash equilibria, as outlined above, in the other treatments there exist subgame perfect equilibria: The leader in the ingroup leading-by-example treatment would contribute $v_{l}=0$ in the subgame perfect Nash equilibrium. She can expect the followers to fully compensate for this and spend $\sum_{i \in K \backslash\{l\}} v_{i}=\frac{z}{4}-v_{l}$, which is $\sum_{i \in K \backslash\{l\}} v_{i}=120$ under the given parameters of the game. As before, if every follower contributes equally, each would invest $v_{i}=\frac{z}{4(K-1)}-v_{l}$, or $v_{i}=\frac{120}{3}=40$.

The situation is different, though, if the leader is faced with risk averse followers. Given (the leader's belief of) the followers' level of risk aversion, she would contribute $v_{l}=120-\sum_{i \in K \backslash\{l\}} v_{i}$, where $\sum_{i \in K \backslash\{l\}} v_{i}$ decreases with the level of risk aversion of followers (Appendix 4.E; Abbink et al., 2010; Katz et al., 1990). This is also true for the leader's level of risk aversion: $v_{l}$ will be lower for higher levels of the leader's risk aversion.

In the ingroup transactional leader treatment, a leader motivated by only her own earnings would not redistribute $4 z$, but keep it for herself. Knowing this, followers would not contribute to the contest. The leader, moving before her group mates contributes $v_{l}=120$ tokens. Note that in this treatment, the leader behaves as if she was a one-person competing party, delivering all tokens to the contest by herself and also keeping the prize, if won. As before, under risk aversion, the leader's contribution would decrease with her level of risk aversion. Followers, however, would not ship in for a lowered contribution of the leader, as they would still not expect the leader to redistribute the prize, if won.

In the intergroup leading-by-example treatment, leaders would not contribute and followers would pitch in for them. After all, communication between leaders is just cheap talk and has no influence on the equilibrium strategies. Hence, leaders would invest $v_{l}=0$ and followers $\sum_{i \in K \backslash\{l\}} v_{i}=\frac{z}{4}-v_{l}$ being $\sum_{i \in K \backslash\{l\}} v_{i}=120$. Again, if everyone contributes equally this would be $v_{i}=\frac{120}{3}=40$.

Under the same assumptions, also in the intergroup transactional leader treatment, leaders would again not redistribute $4 z$, for why followers would contribute nothing and leaders spend $v_{l}=120$ themselves. Communication between leaders does not have an influence on the equilibrium prediction.

Looking at Table 4.2 and bearing in mind the line of reasoning from above, note the following:

First This equilibrium prediction is structurally different from the ones in standard public goods games, where it is not individually rational to contribute anything (as discussed in van der Heijden et al., 2009). For example consider a player $k$ who is only interested

\footnotetext{
${ }^{10}$ However, players do not know what their group mates contribute when casting their decision. (Risk neutral) players wishing to compensate for the lower contributions of risk averse co-players can only base their decisions on past rounds of the game or on their beliefs about others' risk aversion.
} 
Table 4.2: Equilibrium predictions

\begin{tabular}{lccc}
\hline & Leader & Followers total & Followers each if symmetric \\
\hline $\begin{array}{l}\text { Baseline } \\
\begin{array}{l}\text { Ingroup leading- } \\
\text { by-example }\end{array}\end{array}$ & 0 & 90 & 30 \\
$\begin{array}{l}\text { Ingroup } \\
\text { transactional leader }\end{array}$ & 120 & 120 & 40 \\
$\begin{array}{l}\text { Intergroup leading- } \\
\text { by-example }\end{array}$ & 0 & 0 & 0 \\
$\begin{array}{l}\text { Intergroup } \\
\text { transactional leader }\end{array}$ & 120 & 120 & 40 \\
\hline
\end{tabular}

(Subgame perfect) Nash equilibria under risk neutrality.

in own (expected) monetary earnings. Assume she knows that everyone else will contribute 0 for sure. In a classical public goods game, $k$ would also contribute 0 . In a team contest, however, it would be individually rational for $k$ to deviate from zero contribution herself.

Second The strategy that would maximise total monetary welfare across groups would be for all parties to invest nothing and have a $50 \%$ chance of winning. The reason for this is that contributing in the contest only influences winning probabilities without further productive benefit.

Third Under risk neutrality, the equilibrium contribution on group level stays the same for every treatment.

Fourth In the subgame perfect equilibrium of all treatments but the Baseline, either of the following situation emerges: $a$ ) the leader would free ride and contribute zero while the followers fully ship in, providing more than they would in the Baseline treatment. Or $b$ ) the leader delivers as much input by herself, as the group would deliver as a whole in the Baseline treatment.

These four points - and especially the third item - allow us to compare data on the group level across treatments. The first and second point illustrate the difference between our experimental design and classical cooperative games. The fourth point makes apparent the cheap talk nature of the chat, which should not have an influence on players' strategies in the game under standard self-regarding preferences and non-binding communication.

\subsubsection{Alternative Hypotheses}

The leader contributes before followers and her decision is observed by all others in the group. Hence, we expect followers to perceive the leader's contribution as signal or sacrifice and follow her example (cf. Hermalin, 1998; Potters et al., 2001; Meidinger and Villeval, 2002). By contrast, the equilibrium strategies under standard assumptions, as presented before, predict the opposite: Higher leader engagement would cause followers to reduce their spending levels and vice versa. Thus, if the leader's actions are understood as signal 
or sacrifice, contributing zero should not entice followers to contribute more than in the Baseline treatment. We include this as alternative hypothesis.

Accordingly, the leader's contribution serves as reference point for followers. So zero (full) contribution by the leader will at least partially be mimicked by followers, causing them to provide nothing (full) as well, or at least a low (high) amount. In the treatments where the leader can redistribute the prize won (i.e. intergroup leading-by-example and intergroup transactional leader treatment), another aspect comes to play: acting in accordance with the leader's benchmark can be in ones own economic interest. The leader might use her contribution as signal for how followers should behave, rewarding those who do follow and punishing those who do not. This pattern characterises reciprocal behaviour by the leader, rewarding friendly actions and punish hostile actions at own cost. If this is the case, leader's behaviour should also deviate significantly from the benchmark predictions discussed in section 4.4. In a similar way, leaders might be willing to incur costs in order to reduce inequality. ${ }^{11}$ This redistributive motive could induce leaders to share earnings from the contest with the own group. However, if led by inequality aversion, a leader would share the prize with all group members, not just the ones who contributed according to the norm. This is also true for altruistic leaders.

Reuben and Riedl (2013) distinguish between two dimensions of normative rules: efficiency and fairness. If concerned about efficiency, the leader could focus on either of the two: a) Achieving a high level of efficiency for the own group. In this sense, when redistributing the prize she should incentivise contributions to the contest up to the Nash equilibrium (under risk neutrality). b) Maximising the sum of payoffs for all players in the game across groups. If this is the case, she should incentivise low levels of contribution when redistributing.

In a field study, Kosfeld and Rustagi (2015) examine the effect of leaders' intrinsic motivation to execute costly punishment in a public good situation (their leadership style) on performance data from a natural field setting. To this end they compare group performance data of a forest commons management programme in Ethiopia with the behaviour of the respective working group leader in an anonymous, one-shot punishment game. They find that "equality and efficiency driven leaders ... have a significant positive association with the forest management outcome, but the association with anti-social leaders ... is significantly negative."

\subsection{Results}

This section is divided into five parts. First we present general contribution patterns and corresponding treatment differences. The following three subsections are dedicated to the distinct tools, which leaders are endowed with, before examining general individual factors that influence contest spending, amongst which their risk disposition and Social Value Orientation (SVO). In Subsection 4.5.2 we begin by examining the role of leaders' contribution as benchmark for followers' behaviour. Subsequently, Subsection 4.5.3 analyses how leaders in the transactional treatments reallocate the prize and its influence on followers' contribution behaviour. Then Subsection 4.5.4 we study leaders' chats and how this com-

\footnotetext{
${ }^{11}$ Bolton and Ockenfels (2000); Fehr and Schmidt (1999) present models of self-centred inequality aversion.
} 
munication channel pans out for the between group contest. At the close, Subsection 4.5.5 examines the role of risk tolerance, social value orientation and other individual factors.

We apply non-parametric methods for hypotheses testing: Mann-Whitney U tests (MWU) (Mann and Whitney, 1947) for independent sample tests and Wilcoxon signedrank test (Wilcoxon, 1945) for paired tests. Furthermore we use the Kruskal-Wallis test (KW test) (Kruskal and Wallis, 1952) and Dunn's test (Dunn, 1964) with a false discovery rate (FDR) adjustment by Benjamini and Hochberg (1995) for tests involving three or more groups. We use a nonparametric test for trend developed by Cuzick (1985). Unless specified differently, we use data on paired group level (eight players) as independent observation and apply two-sided tests.

\subsubsection{Contest expenditures}

Figure 4.1 provides an overview of contest contributions between treatments. The dashed horizontal line at 120 represents the Nash equilibrium benchmark as reference. In all treatments we observe strong overcontribution with groups contributing almost three times the risk neutral equilibrium prediction (Wilcoxon test: H0: group contr. $=120, \mathrm{H} 1$ : group contr. $\neq 120, \mathrm{~N}=45 . \mathrm{P}=0.000$. Higher rank sum than expected). The results from a KW test indicate that there exists substantial heterogeneity between the treatments (KW test: $\mathrm{N}=45, \mathrm{P}=0.023$ ). Furthermore, a Dunn's pairwise comparison finds significant difference between the Baseline and Ingroup trans treatment, furthermore between the Intergroup lbe treatment with all but the Baseline. ${ }^{12}$

Result 1 Without between group communication, leaders prompt an increase in contest expenditures. Allowing for communication between group leaders cushions this effect and results in a contest expenditure level which is comparable to the baseline.

Figure 4.2 depicts the contribution to the contest over the periods per treatment. For reference purposes, the symmetric Nash equilibrium is indicated at a contribution level of 40. In both Intergroup treatments there exists a significant time trend over the course of the game. While there is a positive trend for the Intergroup trans treatment (Cuzick test: $\mathrm{N}=9, \mathrm{z}=1.80, \mathrm{P}=0.072)$, Intergroup lbe displays a decreasing contribution level over time (Cuzick test: $\mathrm{N}=9, \mathrm{z}=-2.30, \mathrm{P}=0.022$ ). While still displaying some degree of overcontribution, the latter treatment comes closest to the symmetric Nash equilibrium, especially in the last two thirds of the game. To understand the difference between the two Intergroup treatments, we examine leaders' reallocation patterns in Subsection 4.5.3 and find that transactional leaders tend to incentivise high contribution levels by allocating a bigger share of the prize to those followers that shipped in more resources to the contest. Without this incentive mechanism, communicating leaders seem to guide the group towards a less pernicious contribution behaviour.

\footnotetext{
${ }^{12}$ Comparing average group contribution between the Baseline treatment and the ingroup treatments, we observe a significantly higher contribution level for the latter treatments (MWU test: $\mathrm{N}=54, \mathrm{P}=0.019$. Higher rank sum than expected for ingroup treatments). Group contribution of the intergroup treatments, however - being lower than in the ingroup treatment (MWU test: $\mathrm{N}=72, \mathrm{P}=0.013$. Higher rank sum than expected for intergroup treatments) - is at the same level with the Baseline treatment (MWU test: N $=54, \mathrm{P}=0.956)$. This effect is driven in particular by the Intergroup lbe treatment, with an average group contribution level that lies even below the level of the Baseline treatment (MWU test: $\mathrm{N}=36, \mathrm{P}=0.094$. Higher rank sum than expected for the Baseline treatment).
} 


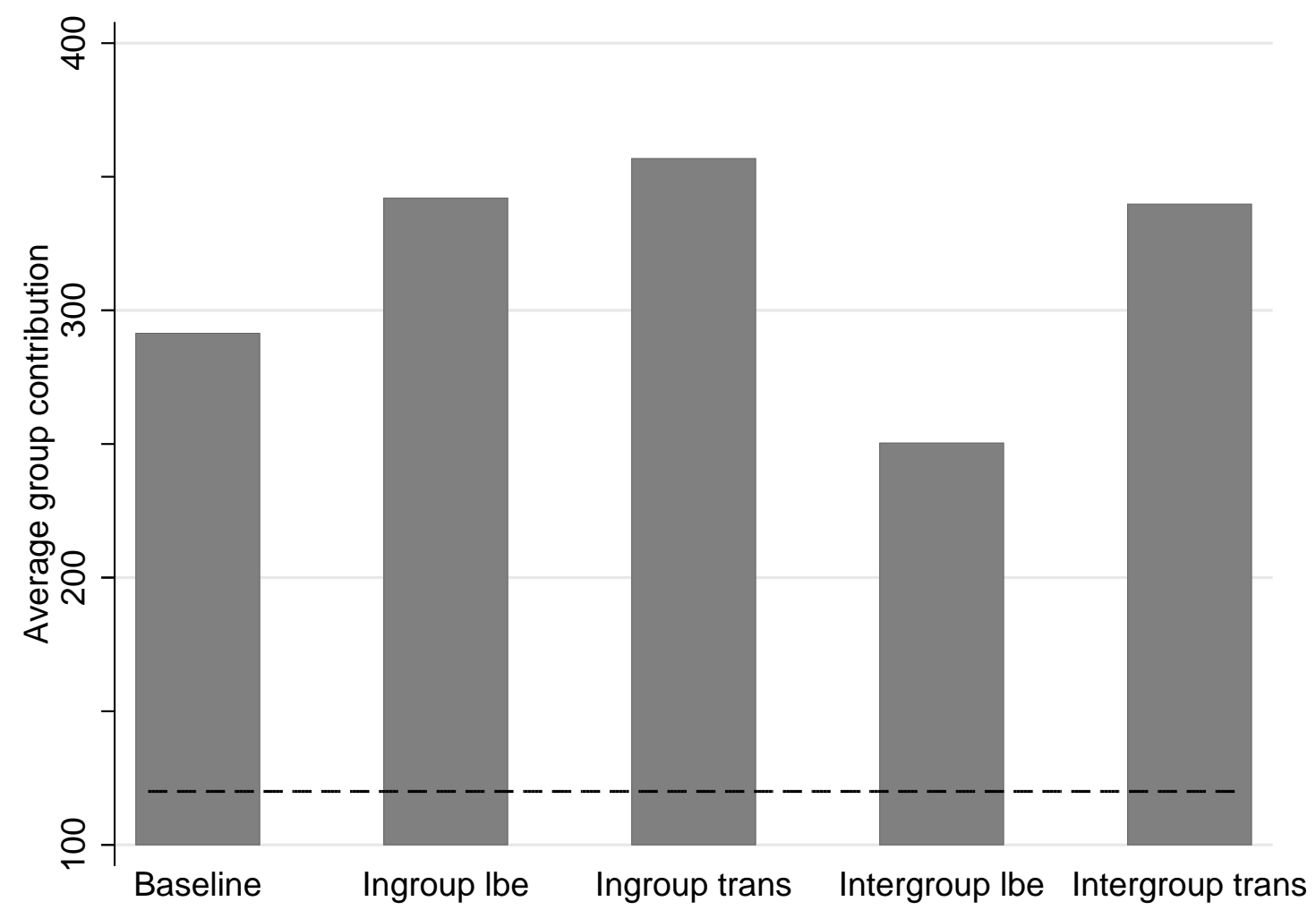

Figure 4.1: Contribution to the Contest

Looking at spending levels in period 1 in Figure 4.2, we can see the on-impact effect between the treatments, which provides a further cue as to whether treatment differences in contribution exist from the get-go or if they evolve over time (and also Figure 4.3). Except for the Intergroup lbe treatment, which displays a significantly lower round-one contribution, other treatments seem to start out on a fairly similar level (MWU test: $\mathrm{N}=$ $45, \mathrm{P}=0.007$. Lower rank sum than expected for Intergroup lbe treatment. $\mathrm{KW}$ test: $\mathrm{N}$ $=45, \mathrm{P}=0.074$. Dunn's test: $\mathrm{H} 0$ rejected for each pairwise comparison iff Intergroup lbe treatment involved).

\subsubsection{The Effect of Leaders' Contribution}

While Figure 4.3 might give the impression that leaders contribute slightly more than followers in the Ingroup lbe and Intergroup trans treatments, statistical tests fail to confirm this relationship (Wilcoxon test Ingroup lbe treatment: $\mathrm{N}=18, \mathrm{P}=0.143$. MWU test Intergroup trans treatment: $\mathrm{N}=18, \mathrm{P}=0.248)$. Still, leaders seem to have no escalating effect on the group contest in round 1. If anything, they would appear to appease contest spendings.

We investigate the overall influence of the leader's contribution as benchmark for the followers in Figure 4.4. This jittered scatterplot depicts followers' contribution on the $\mathrm{y}$-axis as a function of leaders' contribution on the x-axis. The thin line depicts the $45^{\circ}$ line where a follower contributes the same as the leader and the thick line is the fitted line for 


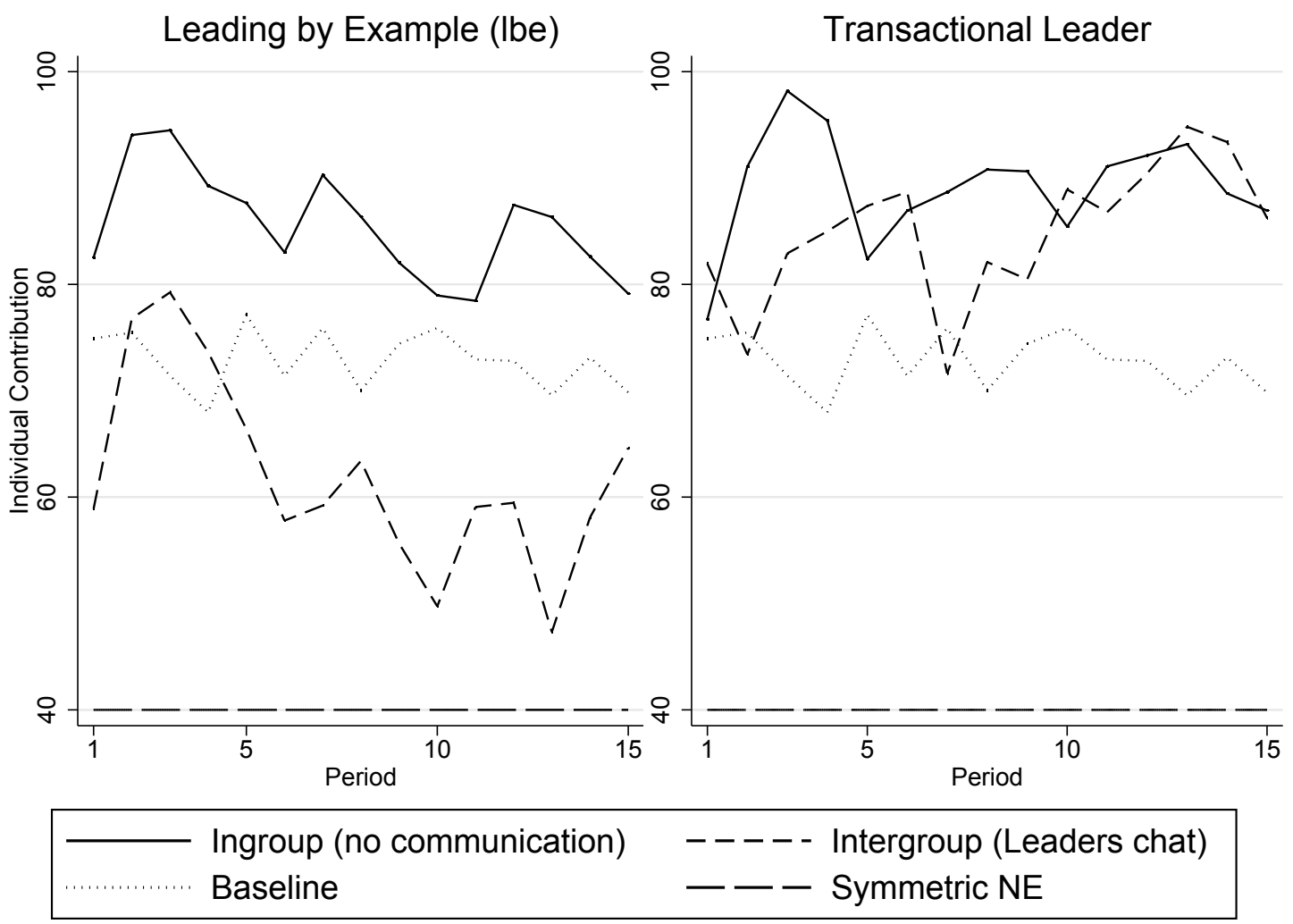

Figure 4.2: Contribution to the Contest over the Periods

the observations in the scatter plot. ${ }^{13}$ All fitted lines have a positive slope, which means that a higher contribution by the leader is paralleled by more follower contributions across all treatments. This observation contradicts the standard Nash equilibrium benchmark prediction in which subjects own contest expenditures negatively depends on (the belief of) other group members' spending level.

The relationship between contribution levels of followers and leaders is significantly positive for all treatments. ${ }^{14}$ Most interestingly, though, the intercept of Intergroup lbe is significantly lower than the others, comparing OLS regression coefficients with treatment intercept and slope dummies (see Regression (6) in Appendix 4.F). Hence, there exists a lower degree of relationship between leaders' and followers' behaviour in this particular treatment. Accordingly, this contributes to explaining the significantly lower spending level in the Intergroup lbe treatment. ${ }^{15}$ A related result is showcased when analysing how followers react to high leader contribution levels (80 and higher) using both Dunn's and MWU test. Followers in the Intergroup lbe treatment contribute less than their counterparts in other treatments after observing a high leader contribution (MWU test: $\mathrm{N}=661, \mathrm{P}=$ 0.000. Lower rank sum than expected for Intergroup lbe treatment. $\mathrm{KW}$ test: $\mathrm{N}=661, \mathrm{P}=$ 0.000. Dunn's test: H0 systematically rejected for each pairwise comparison iff Intergroup lbe treatment involved).

\footnotetext{
${ }^{13}$ Fitted by OLS regression using group level data and clustered standard errors on the group level.

${ }^{14}$ Clustered Tobit regression, both when analysed per treatment and with pooled data. This is robust for using OLS regression.

${ }^{15}$ This is only true if leaders do not contribute more in this treatment, which we can rule out.
} 


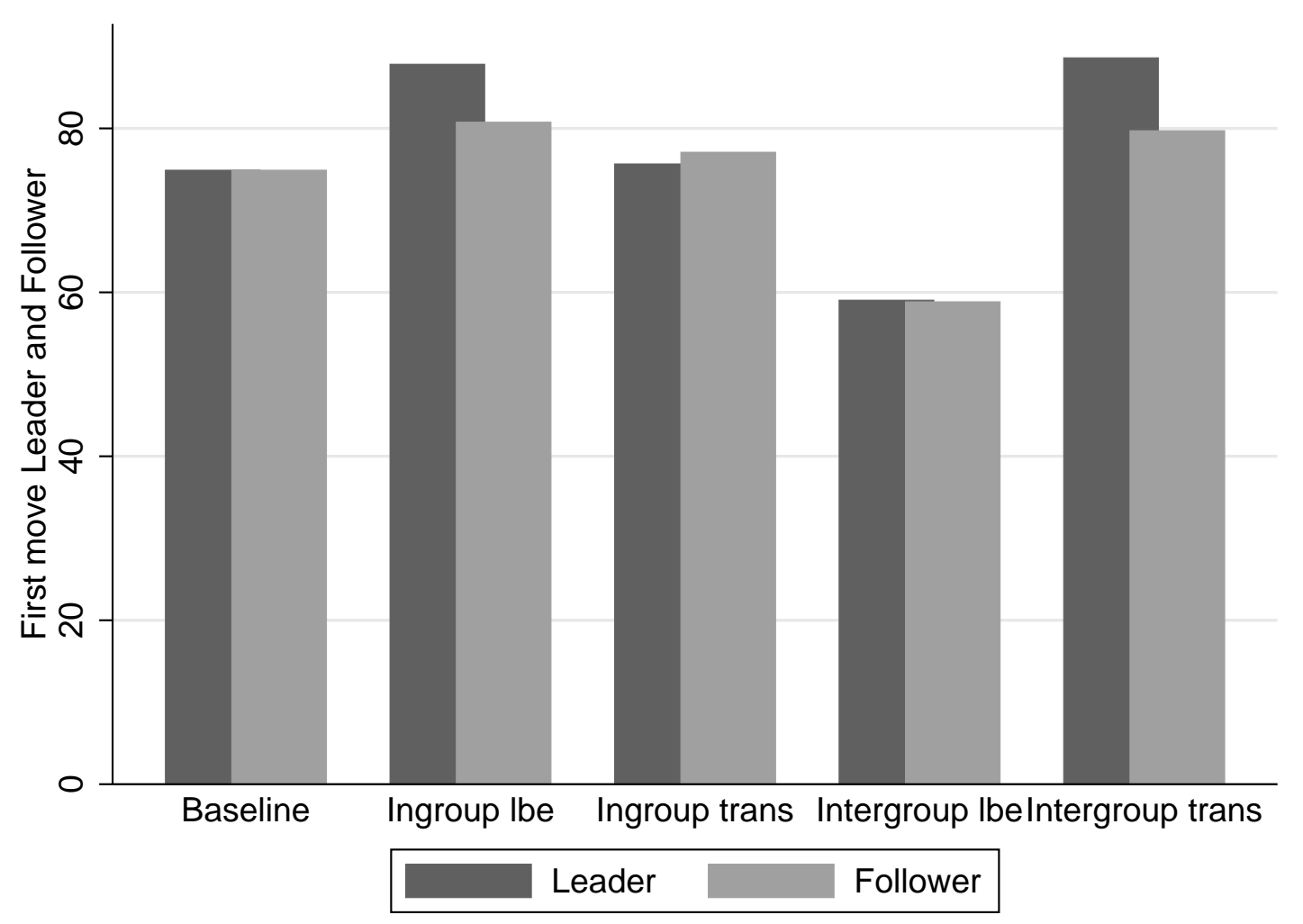

Figure 4.3: Contribution to the Contest First Round

Result 2 Leaders' contribution in round 1 is not significantly different from overall followers' contributions. Over the course of the game, however, there exists a strong positive correlation between leaders' and followers' contribution.

\subsubsection{Transactional Leadership: Prize Allocation and Followers' Reac- tion}

In the transactional treatments there exists another channel of communication between leaders and followers: The redistribution of the prize. If this instrument is used to mitigate the conflict, resources would need to be distributed towards those followers that adhere to low contribution levels. Using a density-distribution sunflower plot (Dupont and Plummer, 2003), Figure 4.5 depicts the relationship between the prize received from the leader and a player's relative contribution to the leader in a given period. This can explain leaders' pattern of redistribution contingent on followers' spending level. Circles represent individual observations, light sunflowers are accumulations of entries within a bin of $8.571,{ }^{16}$ where each petal stands for one observation, dark sunflowers constitute a further aggregation, with a petal for each 23 observations, using the same bin size. We add two reference lines: 1) a horizontal line at 480 , which represents an equal redistribution of the prize among all group members and 2) a vertical line at 0 , where a follower contributes at the same level as her leader does.

\footnotetext{
${ }^{16}$ For our x-axis [-120,120], this creates exactly 28 bin ranges. See Dupont and Plummer (2003) for details on the determination of bin sizes.
} 


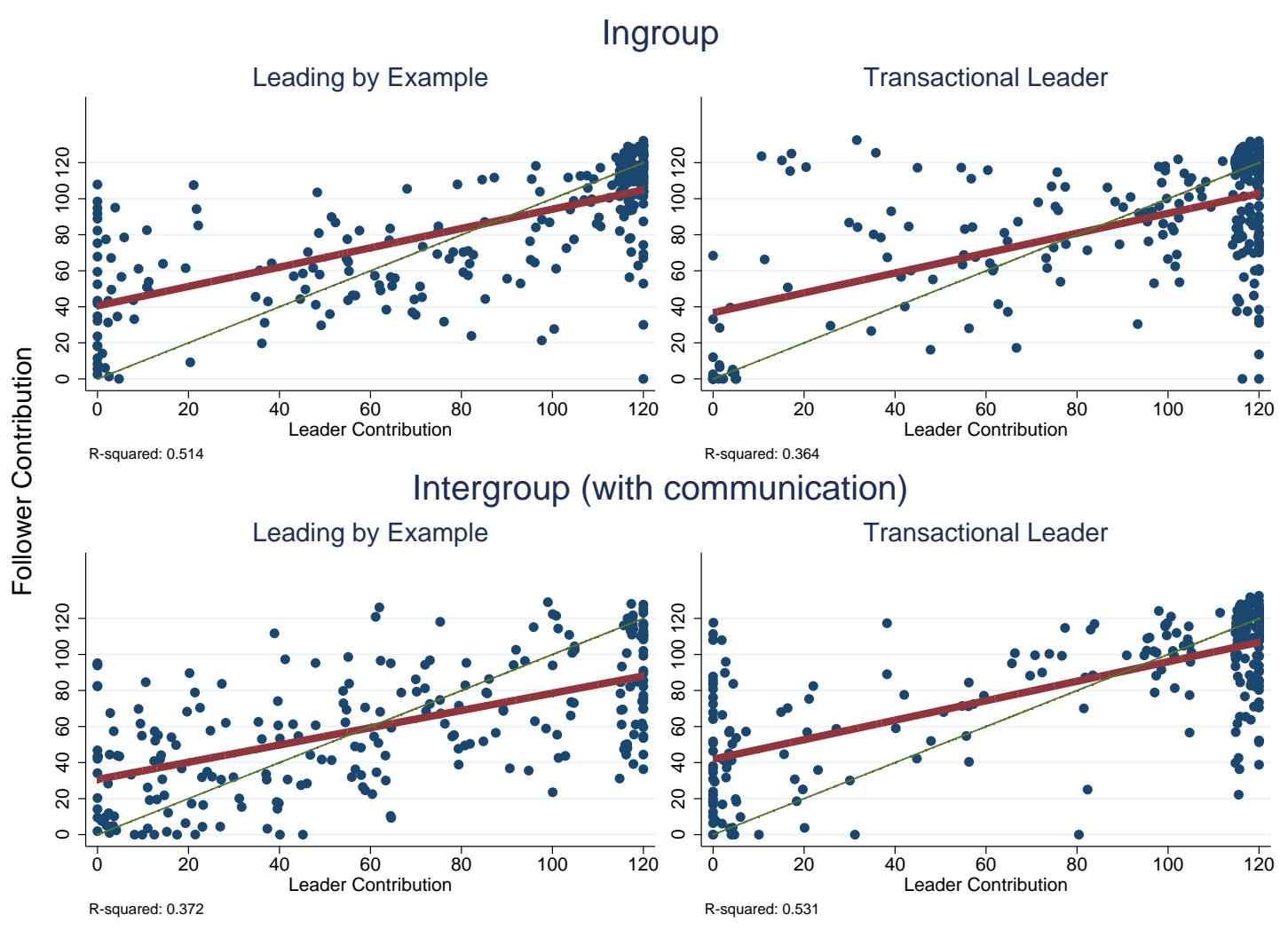

Figure 4.4: Influence of Leader's Contribution on Followers

In Figure 4.5 two dominant strategical patterns are highlighted: First, followers tend to contribute at the same level of the leader, which is illustrated by the high density of observations along a relative contribution of 0 . Second, leaders reallocate an equal share of the prize, which can be seen by the accumulation of observations on the horizontal line of 480. This creates a cross, establishing four domains. The north-western and north-eastern domains contain only a few observations. This means that leaders tend to not reallocate more than the equal share, even to those that contribute more than proportionally. By contrast, it is in the south-western domain where by far the most observations off the aforementioned imaginary cross wind up. This area represents the situation where leaders reallocate less than the equal share to followers with a negative relative contribution. Furthermore, for an extremely low level of relative contribution (-120), we observe a high clustering on zero redistribution. This means that followers who fall far below their leader's benchmark come away empty-handed.

Result 3 In transactional treatments, there exist two dominant strategical patterns: 1) Followers contribute at the same level of the leader and 2) leaders reallocate an equal share of the prize, 480. Furthermore, they tend to reallocate less to those who contribute less than the leader.

In a next step, we investigate the reverse relationship: how is a follower's willingness to contribute (relative to the leader) related to the leader's prize reallocation in the previous period. For this analysis we focus on groups in the transactional treatments that have won 


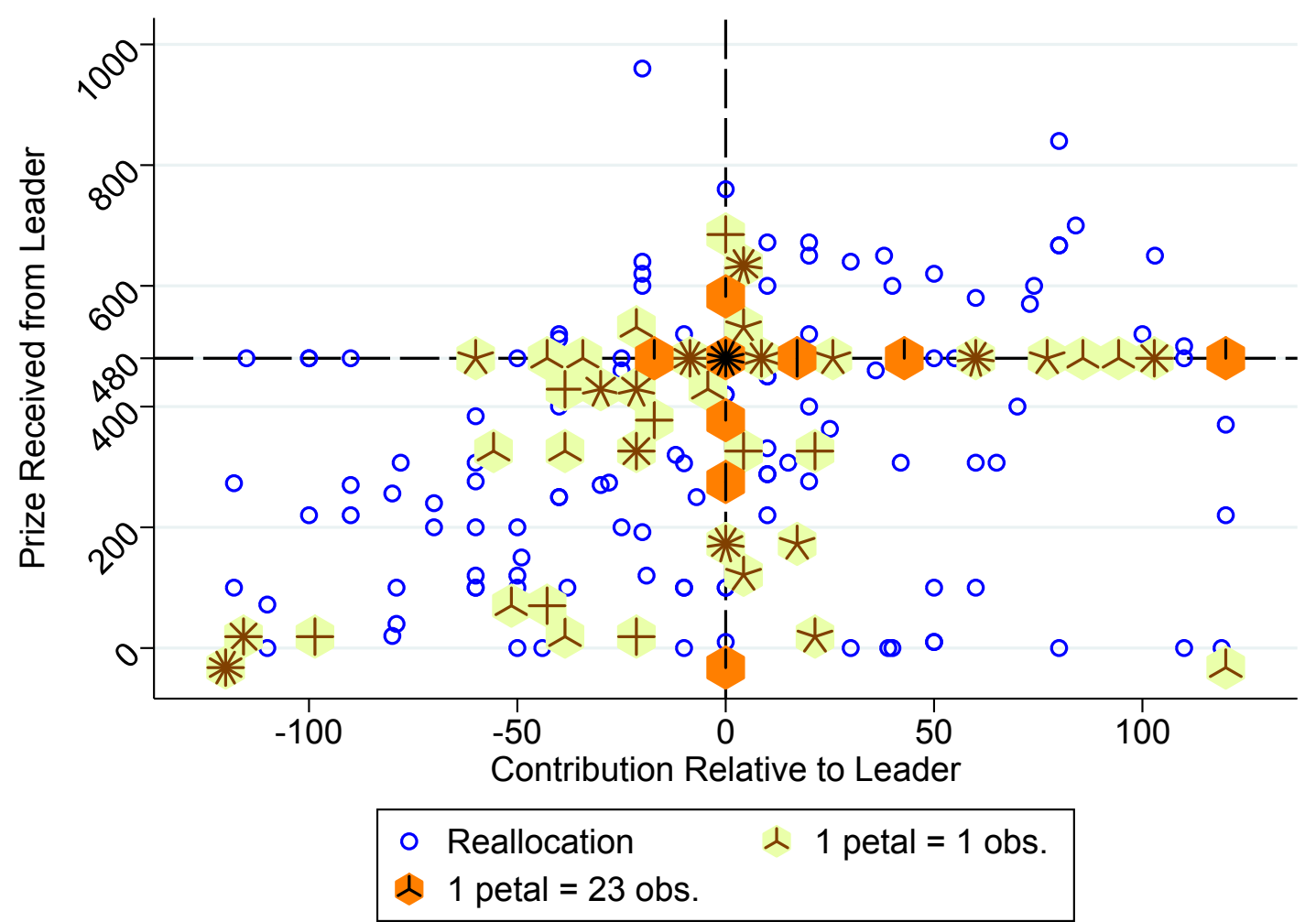

Figure 4.5: Reallocation of Prize by Transactional Leaders

in the previous period. ${ }^{17}$ Similar to the graph above, Figure 4.6 uses a density-distribution sunflower plot. It illustrates the relationship between a follower's relative contribution and the prize received from the leader in the previous period. We also use the same reference lines as before.

We observe a very similar pattern again: Contribute on the same level as the leader and a redistribution of the equal share of 480 tokens. These dominant behaviour patterns serve as boundary for creating four domains in the graph, as in the earlier analysis. The south-eastern domain remains nearly empty, and if there are entries, they lie very close to the delimiters. Accordingly, subjects who receive more than the equal split of the prize tend to not contribute less than the leader in the subsequent period. The vast majority of observations off the cross fall into the south-western domain: Followers who have received less than the equal share in the preceding period, tend to display a lower contribution than the leader. The two northern domains display a few entries, any behaviour off the cross does not seem to be very widespread here.

Result 4 Next to the dominant strategy to mimic the leader's level of contribution, followers have a strong tendency to contribute less than the leader if they have received less than the equal share of the prize in the round before.

\footnotetext{
${ }^{17}$ For groups that have lost in the period before, there is no prize to reallocate. Also, this part only includes data from 14 periods, dropping period 1 contribution data.
} 


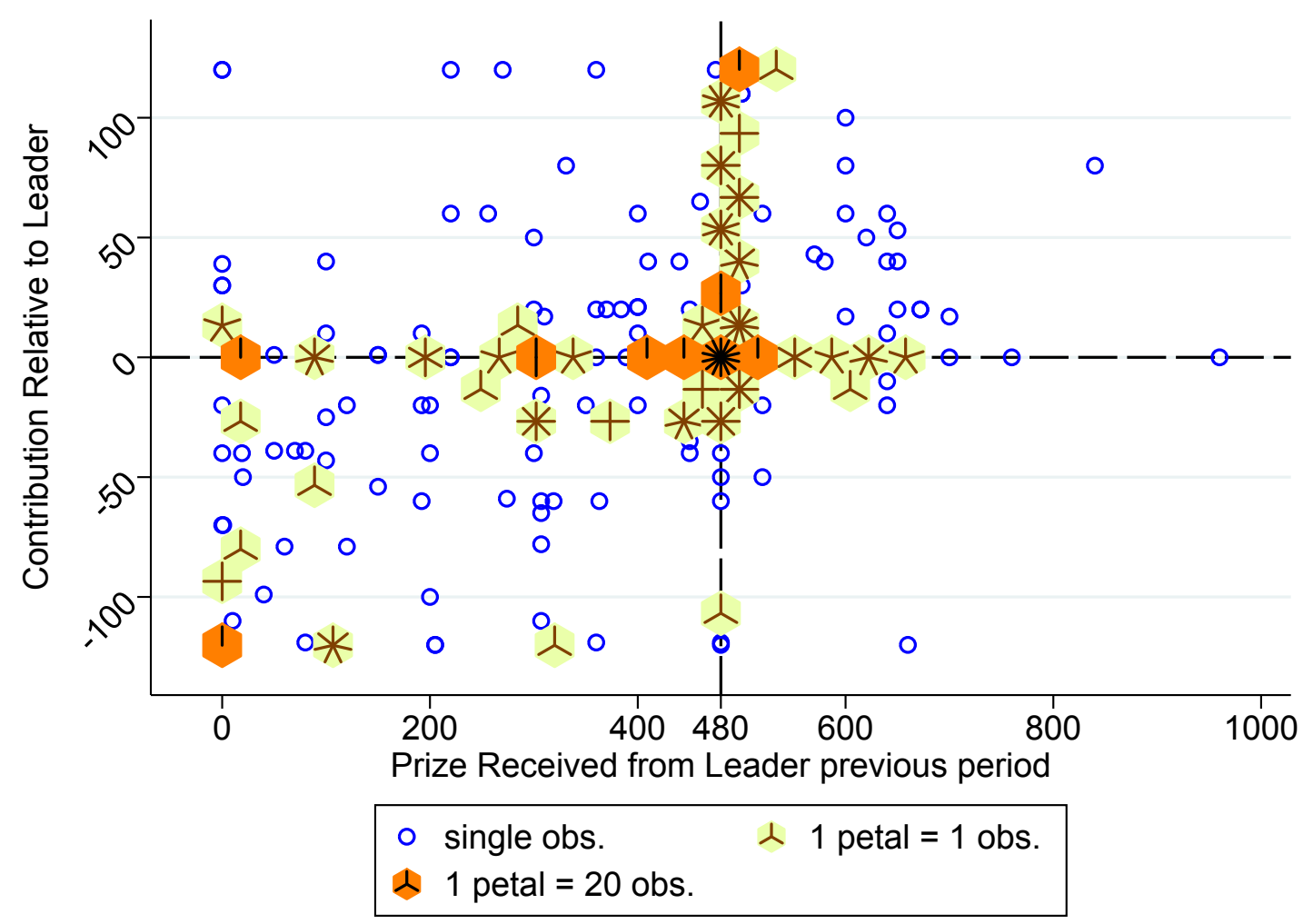

Figure 4.6: Followers' Relative Contribution in Relation to the Prize they Received from the Leader in the Previous Period

\subsubsection{Intergroup Leadership: The chat contents}

Prior to deciding on her contribution level, each leader in the intergroup treatments has the opportunity to communicate with the leader of the competing group via a chat window for 30 seconds each period. These conversations have been documented by the software and categorised by a research assistant who is not involved with this project in any other way. The assistant was not informed about the research question or about the hypotheses of this study. She read the entire chat history of all groups and sorted the messages according to categories, provided by us.

For the following analysis we include data from leaders of the intergroup treatments only. Using a Tobit regression with limits at 0 and 120, respectively, we regress their contribution level on the number of messages sent in a given period, which fall into one of the categories, as discussed below. ${ }^{18}$ Furthermore, we use lagged values for own contribution and a lagged group win term as controls. Table 4.3 contains the regression results for the Intergroup lbe treatment in Regression (1) and for Intergroup trans in Regression (2). The last column in Table 4.3 indicates whether a particular factor is significantly different between the two treatments. For this, we use interaction terms to determine treatment differences (Find the corresponding regression in Table 4.7 in Appendix 4.F).

\footnotetext{
${ }^{18}$ We allow for messages to fall into multiple categories at a time, if applicable. Results using OLS stay qualitatively the same.
} 


\begin{tabular}{|c|c|c|c|}
\hline VARIABLES & $\begin{array}{l}\quad(2) \\
\text { Contribution } \\
\text { Intergroup lbe }\end{array}$ & $\begin{array}{c}(3) \\
\text { Contribution } \\
\text { Intergroup trans }\end{array}$ & $\begin{array}{l}\text { Difference } \\
\text { Significant }\end{array}$ \\
\hline Low contribution & $\begin{array}{c}-16.842^{* * *} \\
(4.12)\end{array}$ & $\begin{array}{l}-50.888^{* * *} \\
(11.51)\end{array}$ & $* *$ \\
\hline Medium contribution & $\begin{array}{c}2.603 \\
(6.01)\end{array}$ & $\begin{array}{l}-1.085 \\
(22.59)\end{array}$ & \\
\hline High contribution & $\begin{array}{l}29.281^{\text {*** }} \\
(7.05)\end{array}$ & $\begin{array}{l}39.901^{* *} \\
(16.06)\end{array}$ & \\
\hline Alternate & $\begin{array}{l}-3.677 \\
(14.52)\end{array}$ & $\begin{array}{c}-32.090^{* *} \\
(15.94)\end{array}$ & \\
\hline Bonding & $\begin{array}{l}18.944^{* * *} \\
(4.17)\end{array}$ & $\begin{array}{r}5.177 \\
(6.57)\end{array}$ & $* * *$ \\
\hline Small talk & $\begin{array}{l}24.844^{* * *} \\
(9.06)\end{array}$ & $\begin{array}{r}9.622 \\
(10.12)\end{array}$ & \\
\hline Understanding & $\begin{array}{c}1.134 \\
(14.60)\end{array}$ & $\begin{array}{l}39.568 \\
(24.26)\end{array}$ & \\
\hline Efficiency & $\begin{array}{c}-1.641 \\
(5.38)\end{array}$ & $\begin{array}{l}-4.291 \\
(12.19)\end{array}$ & \\
\hline Followers' behaviour & $\begin{array}{r}9.357 \\
(5.70)\end{array}$ & $\begin{array}{l}22.223^{*} \\
(11.58)\end{array}$ & \\
\hline $\begin{array}{l}\text { Give much to } \\
\text { followers }\end{array}$ & & $\begin{array}{l}76.646^{*} \\
(42.35)\end{array}$ & \\
\hline $\begin{array}{l}\text { Give little to } \\
\text { followers }\end{array}$ & & $\begin{array}{c}-32.768 \\
(19.87)\end{array}$ & \\
\hline Other & $\begin{array}{c}5.869 \\
(5.71)\end{array}$ & $\begin{array}{c}3.882 \\
(6.22)\end{array}$ & \\
\hline $\begin{array}{l}\text { Contribution } \\
\text { previous period }\end{array}$ & $\begin{array}{l}0.398^{* * *} \\
(0.09)\end{array}$ & $\begin{array}{l}0.781^{\text {*** }} \\
(0.16)\end{array}$ & \\
\hline $\begin{array}{l}\text { Group won previous } \\
\text { period }\end{array}$ & $\begin{array}{c}-6.299 \\
(7.05)\end{array}$ & $\begin{array}{c}-72.439^{* * *} \\
(16.14)\end{array}$ & $* * *$ \\
\hline Constant & $\begin{array}{l}37.586^{* * *} \\
(8.96)\end{array}$ & $\begin{array}{l}84.932^{* * *} \\
(19.41)\end{array}$ & ** \\
\hline $\mathrm{N}$ & 224 & 252 & \\
\hline Pseudo R-squared & 0.064 & 0.078 & \\
\hline
\end{tabular}

Table 4.3: Leader Contribution as Function of Chat Contents 
First of all, after discussing a low contribution level (e.g. between 0 - 40 points) / high contribution level (e.g. between 80 - 120 points), leaders do exhibit a lower / higher spending level. While the effect of low contribution messages is even more pronounced in the transactional treatment, there is no significant difference between the treatments when it comes to high contribution messages. As expected, discussing a medium level of contest spending has neither a lowering nor increasing effect in this regard. Furthermore, transactional leaders who manage to reach across the aisle by coordinating on taking alternating turns manage to alleviate the between-group contest. This result is not robust in Regression (1), however. Somewhat surprisingly, bonding or small talk messages incite a higher spending level in Regression (1). By creating an emotional tie with the other group representative, we would have expected a degree of mitigation towards the intergroup contest. Furthermore, while bonding messages indeed feature an escalating character towards leaders in the Intergroup lbe treatment, this effect appears to be non-existent in the Intergroup trans treatment.

General conversation on the followers' behaviour constitutes another subject matter with escalating influence on transactional leaders' contribution decisions. Concerning the reallocation of the prize, leaders who articulate their intention to allocate open-handedly towards followers, are also the ones who spend more resources to the contest and vice-versa. Conversations including concerns for efficiency, by contrast, have no descriptive power for the leaders' subsequent contribution decision, while this could have been expected to have an abating effect on contest expenditures. Equally, discussing comprehensive understanding questions about the experiment structure has no descriptive power.

Apart from the chat categories, this analysis identifies a twofold of other treatment differences between the two Intergroup treatments. First, there is a stark difference in how leaders' contribution decisions depend on whether they have won in the previous round. While a transactional leader whose group won the preceding period drastically reduces her contributions, this is not the case for leaders in the Intergroup lbe treatment. This could have to do with the fact that alternating seems to work a lot better in the Intergroup trans treatment. Second, the difference in the constant identifies the treatment effects discussed in Subsection 4.5.1.

Figure 4.7 depicts the prevalence of chat categories per treatment. "Low contribution" messages, which have negative influence on spending levels, are being sent more frequently in the Intergroup lbe treatment. Adding to this image, all message categories that have a positive bearing on contribution levels - such as "Bonding" or "Small talk" - are less commonly used in the Intergroup lbe treatment. This can deliver an explanation for the stark difference in contest spending between these two treatments: Leaders structurally chat about different topics, namely sending more messages with an abating and less with an escalating character in the Intergroup lbe treatment.

Result 5 Leaders that coordinate on taking turns manage to reduce contest expenditures significantly. Moreover, the prevalence of subject matters structurally differs between the treatments favouring more mitigating messages in the Intergroup lbe and more escalating messages in the Intergroup trans treatment. This contributes at explaining the strong treatment difference in contest spending. 


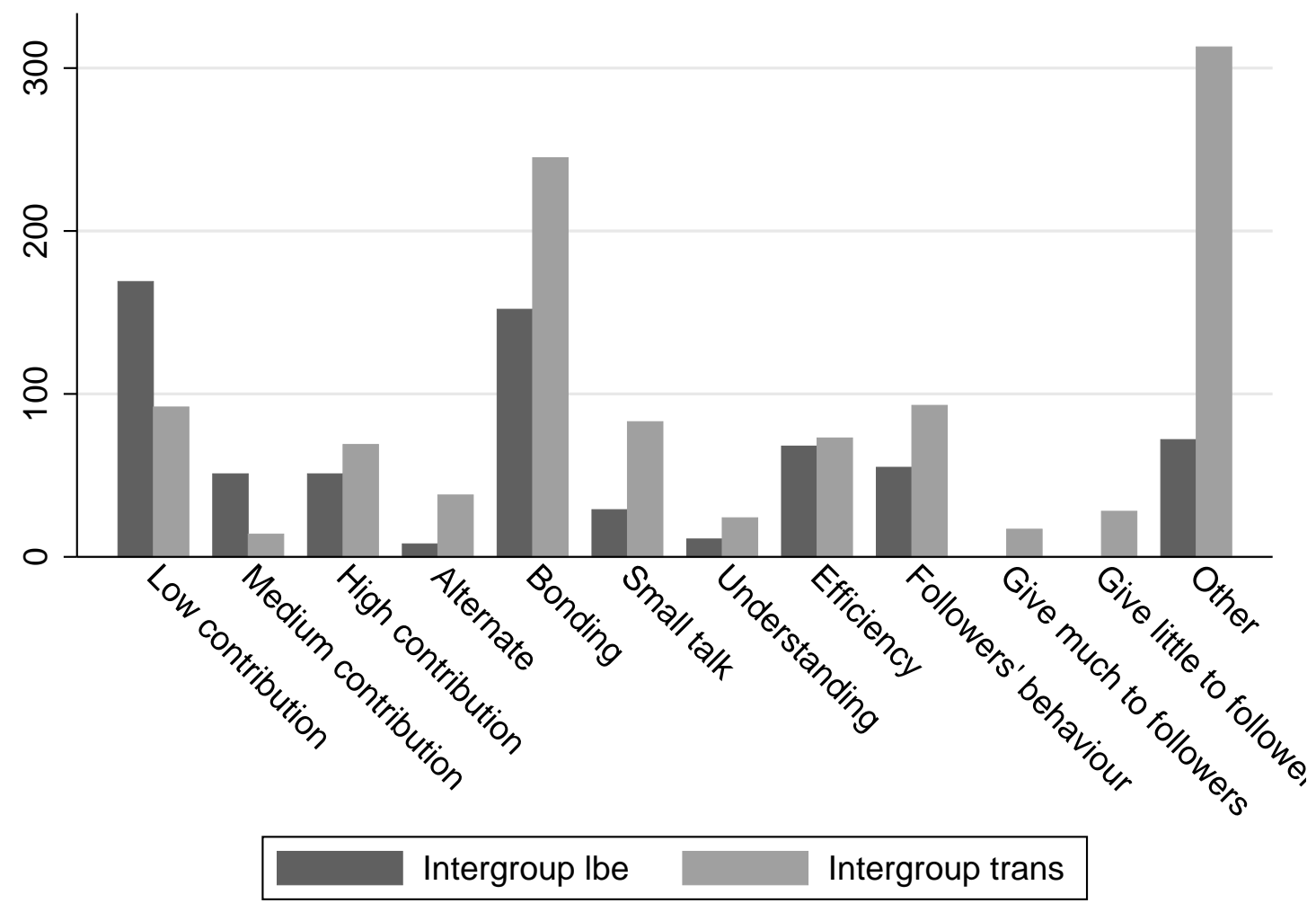

Figure 4.7: Prevalence of Chat Messages per Treatment

\subsubsection{Risk Aversion and Social Value Orientation}

In this subsection we investigate what personal factors can explain individual spending behaviour beyond treatment effects. We hypothesise that risk preferences and Social Value Orientation (SVO) can have a bearing on the willingness to ship in resources for the between group contest. Theory suggests that more risk-averse players should display a lower level of contest spending, which is reflected in our alternative hypotheses in Subsection 4.4.1.

We regress individual contribution, aggregated over the total number of rounds, on a number of factors, as displayed in Table 4.4. ${ }^{19}$ The average number of lottery tickets bought by teammates (Mean Group Contribute) positively influences own contribution levels. Given that there exists some degree of overcontribution in all treatments, first order conditions under self-oriented preferences would predict this factor to be negative, as players would fade out own contribution if (they believe that) their teammates provide more input. There is no evidence for an Age or gender (Female) effect. There is not much variation in the age of our participant body, as it is almost exclusively comprised of university students. Concerning the factor Female, however, literature suggests a lower level in women's competitiveness (e.g. McDonald et al., 2012; Vugt et al., 2007), which would imply less contest spending for female participants.

\footnotetext{
${ }^{19}$ Both models' (Regressions (4) and (5)) variance inflation factors (VIF's) reject the possibility of a potential multicollinearity problem. Still, multicollinearity of the factors would only increase the standard errors of the coefficients if they are collinear. Even then, the coefficients as such would be unaffected.
} 


\begin{tabular}{|c|c|c|}
\hline VARIABLES & $\begin{array}{c}(4) \\
\text { Contribute }\end{array}$ & $\begin{array}{c}(5) \\
\text { Contribute }\end{array}$ \\
\hline Mean Group & $0.229^{* * *}$ & $0.226^{* * *}$ \\
\hline Contribute & $(0.01)$ & $(0.01)$ \\
\hline Age & $\begin{array}{r}0.480 \\
(0.33)\end{array}$ & $\begin{array}{r}0.361 \\
(0.34)\end{array}$ \\
\hline Female & $\begin{array}{c}-1.303 \\
(1.78)\end{array}$ & $\begin{array}{c}-0.049 \\
(1.96)\end{array}$ \\
\hline People known in Lab & $\begin{array}{c}0.268 \\
(0.19)\end{array}$ & $\begin{array}{c}0.383^{*} \\
(0.20)\end{array}$ \\
\hline Friends in Lab & $\begin{array}{c}2.588^{*} \\
(1.36)\end{array}$ & $\begin{array}{c}2.291^{*} \\
(1.38)\end{array}$ \\
\hline $\begin{array}{l}\text { Own Norm for } \\
\text { Contribution }\end{array}$ & $\begin{array}{l}0.145^{* * *} \\
(0.03)\end{array}$ & $\begin{array}{l}0.129^{* * *} \\
(0.03)\end{array}$ \\
\hline $\begin{array}{l}\text { Central Planner's } \\
\text { Norm }\end{array}$ & $\begin{array}{c}0.040 \\
(0.03)\end{array}$ & $\begin{array}{c}0.044 \\
(0.03)\end{array}$ \\
\hline $\begin{array}{l}\text { Riskiness of Gamble } \\
\text { Choice }\end{array}$ & $\begin{array}{l}0.592^{* *} \\
(0.28)\end{array}$ & $\begin{array}{c}0.414 \\
(0.29)\end{array}$ \\
\hline SVO angle & $\begin{array}{r}-0.035 \\
(0.07)\end{array}$ & $\begin{array}{r}-0.042 \\
(0.07) \\
\end{array}$ \\
\hline \multicolumn{3}{|c|}{ Readiness to accept risk in the context of } \\
\hline _General & & $\begin{array}{r}0.666 \\
(0.45)\end{array}$ \\
\hline$\ldots$ Car & & $\begin{array}{c}-0.399 \\
(0.30)\end{array}$ \\
\hline Financial & & $\begin{array}{r}0.071 \\
(0.40)\end{array}$ \\
\hline _Leisure & & $\begin{array}{c}-0.795^{* *} \\
(0.40)\end{array}$ \\
\hline Professional & & $\begin{array}{c}0.837^{\text {** }} \\
(0.39)\end{array}$ \\
\hline _Health & & $\begin{array}{r}0.145 \\
(0.29)\end{array}$ \\
\hline $\begin{array}{l}\text { Towards } \\
\text { Strangers }\end{array}$ & & $\begin{array}{r}0.037 \\
(0.30)\end{array}$ \\
\hline Reciprocity & & \\
\hline $\begin{array}{c}\text { Return } \\
\text { Favour }\end{array}$ & & $\begin{array}{c}-1.311 \\
(1.15)\end{array}$ \\
\hline Revenge & & -1.026 \\
\hline Wrong & & $(0.69)$ \\
\hline Difficult & & $1.876^{* * *}$ \\
\hline Position & & $(0.70)$ \\
\hline Kindness & & $\begin{array}{c}-0.351 \\
(0.78)\end{array}$ \\
\hline -Towards & & -0.132 \\
\hline Insult & & $(0.56)$ \\
\hline _Help & & $\begin{array}{r}0.170 \\
(0.78)\end{array}$ \\
\hline Constant & $\begin{array}{c}-24.003^{* * *} \\
(8.43)\end{array}$ & $\begin{array}{c}-16.019 \\
(11.86)\end{array}$ \\
\hline $\mathrm{N}$ & 360 & 360 \\
\hline R-squared & 0.743 & 0.759 \\
\hline
\end{tabular}

Table 4.4: Risk Aversion and Social Value Orientation Components 
Both the number of people that subjects mention to know in the lab (People known in Lab) and the number of friends that participate in the same session (Friends in Lab) have a positive influence on contest expenditures. ${ }^{20}$ If anything, we would have expected these factors to be negative, as a higher familiarity with other subjects in the lab should increase social identity across groups and hence reduce rivalry.

In the questionnaire, subjects were asked the following two questions: "How many lottery tickets should another player of your group have bought?" (Own Norm) and "Taking the perspective of a benevolent central planner, what do you think should have been the optimal amount of individual lottery tickets bought?" (Central Planner's Norm). ${ }^{21}$ This captures if subjects make a distinction between what they want other group members to contribute, on the one hand, and what the overall socially beneficial spending level would be, on the other hand. In point of fact, subjects seem to recognise the detrimental impact of contest spending on overall social welfare, as subjects specify a significantly lower benchmark for the latter item (Averages: Own Norm: 97.17 Central Planner's Norm: 89.35. Wilcoxon test: $\mathrm{N}=360 . \mathrm{P}=0.000$. Higher positive and lower negative rank sum than expected). While subjects who indicate a greater personal contribution norm administer a higher spending level, this is not the case for the Central Planner's Norm, which has no bearing on contribution levels.

Subjects who select a more risky gamble option in Part 1 of the experiment (Riskiness of Gamble Choice) display a higher willingness to contribute to the between group contest, which confirms our hypothesis mentioned before. By contrast, implied individual SVO values ( $S V O$ angle), determined by reallocation choices in Part 2 of the experiment, do not exhibit explanatory power towards subjects' spending behaviour.

In Regression (5) we add data from the questionnaire concerning risk disposition (as in Dohmen et al., 2005) and reciprocity (from the German Socio-Economic Panel (SOEP)). Dohmen et al. (2005) argue that individual attitudes towards risk vary substantially between contexts. Our results complement this line of reasoning, as the regressors of the different aspects in question display a considerable degree of heterogeneity. While subjects who indicate to be more accepting towards risk in leisure related affairs display a lower spending level, participants expressing a higher risk tolerance in professional matters engage in the contest game more aggressively. Even though the other risk questionnaire items in Regression (4) are not significantly different from zero individually, there is no common trend amongst them. Note also that the gamble choice does not seem to have explanatory power when risk questionnaire items can capture this behavioural aspect.

The factors of the SOEP reciprocity items exhibit a comparable degree of heterogeneity with only Reciprocity Difficult Position item significantly positive. ${ }^{22}$ Hence, subjects who identify more with this negative reciprocity statement display a more competitive spending behaviour. Overall, players' risk attitudes or Social Value Orientation do not play a major role for their contribution decisions.

\footnotetext{
${ }^{20}$ There is a curiously low level of correlation between the two factors of corr $=0.118, \mathrm{~N}=360$.

${ }^{21}$ Both factors have a moderate correlation level of corr $=0.522, \mathrm{~N}=360$.

${ }^{22}$ On a seven step scale, subjects indicated how much the following statement applies to them personally: "If somebody puts me in a difficult position, I will do the same to him/her".
} 


\subsection{Conclusion}

This study provides the first (experimental) investigation on the role of leaders in a team contest. More specifically, we present an experimental investigation examining whether a leader can help coordinate groups towards a more efficient play in a two-party competition for a local public good. We explore, if having the institution of a central authority entrusted with setting a benchmark or with pecuniary say, could mitigate wasteful contest spending and lead to a de-escalation.

By contrast, our results substantiate a considerably pessimist view overall: Most leadership types actually prompt an escalation of the contest and leaders tend to incentivise their teammates to ship in resources to the competition. While the establishment of intergroup leadership through free form text communication between leaders of competing groups can contribute at abating the rat race, general spending levels do not constitute a significant improvement from the baseline level. Leaders who manage to coordinate through the chat on taking turns at shipping in resources are most successful in guiding their groups towards more efficient play.

In contrast to the set of risk-neutral subgame perfect equilibria, outlined in Section 4.4, we find followers' contribution level to be depending positively on the leader's spending level. This confirms our alternative hypothesis in Subsection 4.4.1, that a leader's spending pattern serves as benchmark / signal for the followers of her group.

\section{Appendix 4.A Measuring Risk Aversion}

Prior to the team contest we take an individual risk preference measure. To this end we use an extended version of the method designed by Eckel and Grossman (2002). Players are confronted with a gamble choice as in Dave, Eckel, Johnson, and Rojas (2010). They opt for one out of 11 gambles as presented in Table 4.5. ${ }^{23}$ Each gamble has a 50:50 chance to either receive a low or a high payoff, respectively. While for Gamble 1 both payoffs are identical (representing the safe option), the alternatives gradually become more risky towards Gamble 11. At the same time, expected returns gradually increase from Gamble 1 to Gamble 9, with Gambles 9, 10 and 11 having an identical expected return. The gamble choice is designed such that risk averse players would choose a Gamble 1-8, a risk neutral player would go for Gamble 9 and a risk seeking player would opt for Gambles 10 or 11.

This gamble choice method allows to elicit risk preferences in one step that is easy to understand and easy to implement. Furthermore, it allows for a parameter estimation giving an interval for the player's constant relative risk aversion (CRRA) of the form $u(x)=x^{1-r}$ with $x$ being the wealth and $r$ the coefficient of relative risk aversion (where $r<0$ is risk seeking, $r=0$ risk neutral and $r>0$ risk averse). Dave et al. (2010) compare this method with other, more complex elicitation methods and find that it delivers a less noisy estimate for risk preferences.

\footnotetext{
${ }^{23}$ The gambles were called "Option" in the experiment.
} 
Table 4.5: Gamble choices

\begin{tabular}{lrrrrr}
\hline & $\begin{array}{l}\text { Low } \\
\text { Payoff }\end{array}$ & $\begin{array}{l}\text { High } \\
\text { Payoff }\end{array}$ & $\begin{array}{l}\text { Expected } \\
\text { Return }\end{array}$ & $\begin{array}{l}\text { Standard } \\
\text { Deviation }\end{array}$ & \multicolumn{2}{l}{$\begin{array}{l}\text { Implied CRRA } \\
\text { Range }\end{array}$} \\
\hline Option 1 & 28 & 28 & 28 & 0 & $0.99<\mathrm{r}$ \\
Option 2 & 26 & 32 & 29 & 3 & $0.99<\mathrm{r}$ \\
Option 3 & 24 & 36 & 30 & 6 & $0.99<\mathrm{r}$ \\
Option 4 & 22 & 40 & 31 & 9 & $0.99<\mathrm{r}$ \\
Option 5 & 20 & 44 & 32 & 12 & $0.78<\mathrm{r} \leq 0.99$ \\
Option 6 & 18 & 48 & 33 & 15 & $0.64<\mathrm{r} \leq 0.78$ \\
Option 7 & 16 & 52 & 34 & 18 & $0.54<\mathrm{r} \leq 0.64$ \\
Option 8 & 14 & 56 & 35 & 21 & $0.46<\mathrm{r} \leq 0.54$ \\
Option 9 & 12 & 60 & 36 & 24 & $0 \leq \mathrm{r} \leq 0.46$ \\
Option 10 & 7 & 65 & 36 & 29 & $\mathrm{r}<0$ \\
Option 11 & 2 & 70 & 36 & 34 & $\mathrm{r}<0$ \\
\hline
\end{tabular}

\section{Appendix 4.B Measuring Social Value Orientation}

We take measures of individual social preferences. For this we make use of the SVO slider measure by Murphy et al. (2011). ${ }^{24}$ Individuals set 15 sliders determining how to allocate tokens between themselves and another player, some of which are represented in Figure 4.8. This provides us with a measure for the most commonplace social orientations (for example altruistic, prosocial, individualistic, and competitive) and their relative weighing for the player.

The SVO slider measure constitutes a simplification and adjustment of the circle test employed by Brandts et al. (2009); Sonnemans et al. (2006); Van Lange, De Bruin, Otten, and Joireman (1997). It has demonstrated reliable psychometric properties, yields scores for individuals at the ratio level and is quick and easy to implement (cf. Murphy and Ackermann, 2014).

\section{Appendix 4.C Instructions}

The instructions consisted of three parts. Subjects found Part 1 with general information and introductions for the risk aversion measure ${ }^{25}$ at their place when entering the laboratory. Once everyone was finished with this part of the experiment, the following set of instructions were distributed, which outlined the measurement of individual social value orientation. ${ }^{26}$ After this part, subjects received instructions for the main part of the experiment, which differed somewhat between the treatments, as outlined below. Paragraphs beginning with a treatment name in square brackets were only given to subjects of that particular treatment.

\footnotetext{
${ }^{24}$ Crosetto et al. (2012) provides a helpful tool for implementation.

${ }^{25}$ Find details in Appendix 4.A

${ }^{26}$ see Appendix 4.B
} 

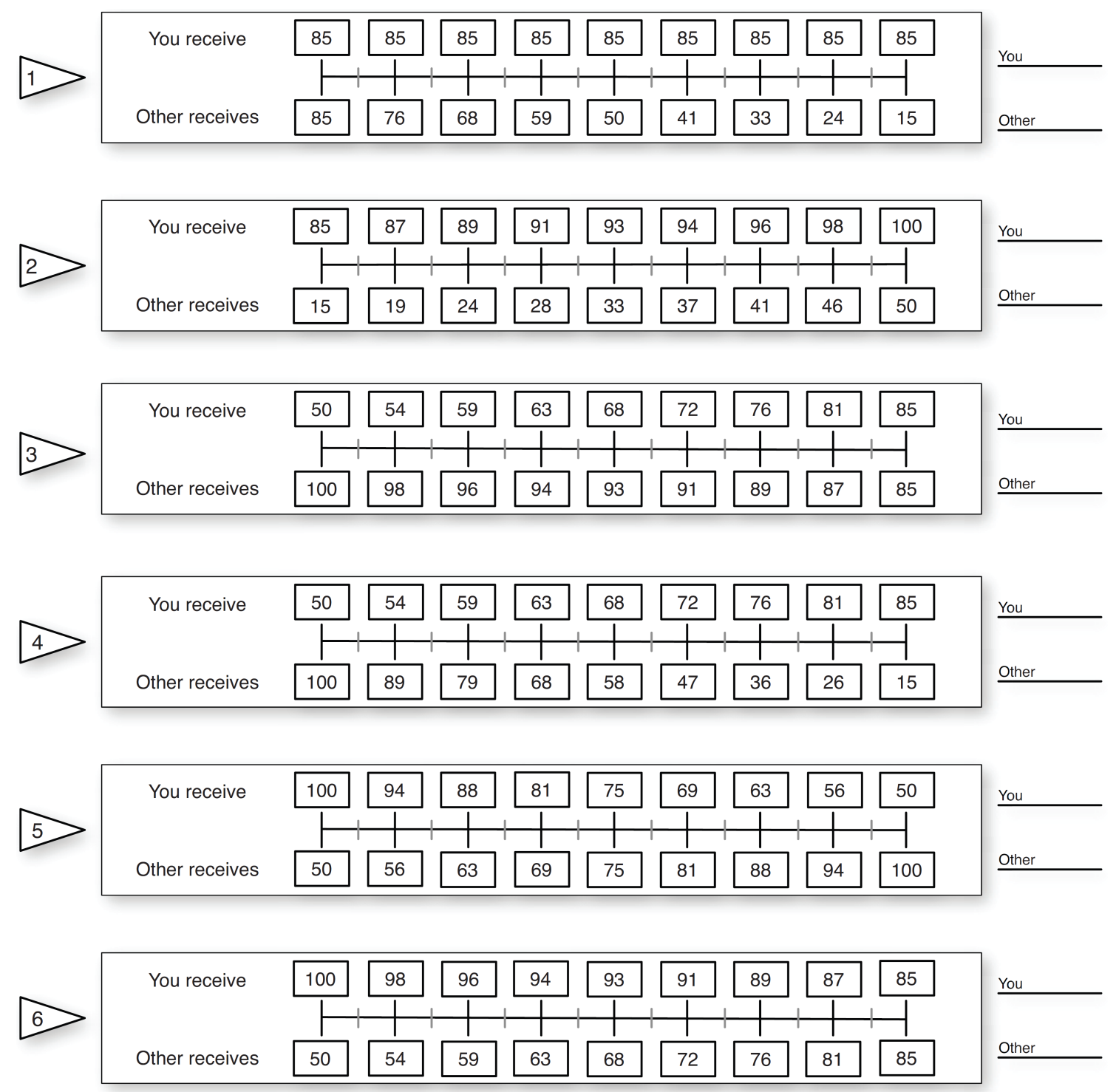

Figure 4.8: Examples for the slider questions as seen by the subjects to measure Social Value Orientation.

\section{General Instructions}

Welcome and thank you for participating in this experiment. In the experiment you can earn money with the decisions you make. Please read these instructions carefully. If you have any questions, please raise your hand and one of the experimenters will come to your cubicle to answer your question.

Talking or using mobile phones or any other electronic devices is strictly prohibited. Mobile phones and other electronic devices should be switched off. If you are found violating these rules, you will both forfeit any earnings from this experiment, and may be excluded from future experiments as well. 
This is an experiment about decision making. The instructions are simple and if you follow them carefully you can earn a considerable amount of money which will be paid to you privately and in cash at the end of the experiment. The amount of money you earn will depend on your decisions, on other participants' decisions and on random events. You will never be asked to reveal your identity to anyone during the course of the experiment. Your name will never be associated with any of your decisions.

During the experiment you can earn points (the experimental money unit), which will be converted into cash at the end of the experiment, using an exchange rate of

$$
40 \text { points }=10 \text { cent. }
$$

Thus, the more points you earn, the more cash you will receive at the end of the session.

This experiment consists of three parts. The following instructions explain Part 1. After finishing that part, you will receive instructions for Part 2 and after the end of Part 2 you will receive instructions for Part 3. None of your (or anyone else's) decisions for one part are affecting your (or anyone else's) earnings in the other parts.

All of your choices are completely confidential. You will learn your results of Part 1 and Part 2 after Part 3 has finished. Points earned in each of the three Parts will be added up to determine your total earnings.

\section{Instructions Part 1}

This is an individual decision task and your choice will only affect you. You will be presented with six payoff options, of which you will have to choose one. Each option is associated with a low and a high payoff and both the high and low payoff are equally likely. At the end, after Part 3 the computer will randomly pick either the low or the high payoff of the option you chose.

\section{Instructions Part 2}

In this task you will be randomly paired with one other person in this room. You will make a series of decisions about allocating points between you and this other person.

One of your decisions will be picked randomly and you receive what you allocated to yourself and the other person receives what you allocated to her in this decision. Note that any of your decisions is equally likely to be chosen. Therefore you should treat each decision as if it is the one that counts.

One other person in the room will make such decision towards you. This is not the person you are randomly paired with.

\section{Instructions Part 3}

In Part 3, all participants are assigned to teams of four and your team will be randomly 
matched with another team. None of you will learn the identities of own team members or other team members. Part 3 will consist of 15 periods, and in each period you and the other participants can obtain a prize in the following way:

At the beginning of each period you will receive an endowment of 120 points. Then you can use none, parts or all of these points to buy lottery tickets for your team. Each lottery ticket costs 1 point. Any of your points not spent on lottery tickets will be accumulated in your private point balance. Likewise, each of your team members receives 120 points which they may use to buy lottery tickets for your team. Similarly, each member of the other team will receive 120 points and may buy tickets for their team in exactly the same way.

[Ingroup leading-by-example $\mathcal{E}$ Ingroup transactional leader] In your and the other group, one participant - member 1 - makes her / his decision before the others. Own team members will see, how many tickets this participant bought, before they make their decisions.

[Intergroup leading-by-example $\&$ Intergroup transactional leader] In your and the other group, one participant - member 1 - has been randomly selected to be able to communicate with one participant of the other group in private, via a chat window. This communication possibility will automatically expire after 45 seconds. Unless you are member 1 , neither you nor any other participant will ever learn the contents of this communication. After that chat window has been closed, member 1 makes her / his decision. Own team members will see, how many tickets this participant bought, before they make their decisions.

After everybody has made the decision, a lottery will determine whether your team, or the team you are matched with, wins. The likelihood that a team wins depends in a proportional way on the total number of tickets, the team bought and on the total number of tickets, the other team bought. That is, if you and your team members bought in total $X$ tickets, and the team members of the other team bought in total $Y$ tickets, the likelihood that your team wins is $\frac{X}{X+Y}$ and the likelihood that the other team wins is $\frac{Y}{X+Y}$. Hence, the more tickets your (the other) team has, the higher is your (the other) team's chance of winning.

Examples: If your team and the other team have bought the same amount of tickets then each team is equally likely to win. If your team has bought three times as many tickets as the other team, then your team is three times more likely to win than the other team. If only one of the teams has bought tickets, then this team wins for sure. If neither your team nor the other team has bought any tickets, then each team is equally likely to win.

[Baseline, Ingroup leading-by-example $\mathcal{E}$ Intergroup leading-by-example] The winning team will receive a prize of 1,920 points in total, which will be split equally among group members. This delivers 480 points for each player of the winning group.

[Ingroup transactional leader $\& 3$ Intergroup transactional leader] The winning team will receive a prize of 1,920 points in total and member 1 will determine how the prize will be split among the group members. The losing team will receive nothing.

Summary: In Part 3, your earnings in each period are determined as follows:

The points you earn in each period accumulate and your earnings in Part 3 will be the 


\section{Winning team:}

Your Endowment $(=120)$

- Your tickets bought (between 0 and 120)

[Baseline, Ingroup leading-by-example $\&$ Intergroup leading-by-example]

+ Prize (480)

[Ingroup transactional leader \& Intergroup transactional leader]

$+\quad$ Share of the prize allocated by member 1 (between 0 and 1,920)

$=$ Your earnings

\section{Losing team:}

Your Endowment $(=120)$

- Your tickets bought (between 0 and 120)

$=$ Your earnings

total point earning from all 15 periods.

This part starts with a trial period in which you will be asked to answer some questions in order to check your understanding and to give you the opportunity to get acquainted with the setup. Points earned in this trial period will not be paid out.

\section{Appendix 4.D Risk Neutral Equilibrium}

Player $l$ maximises expected profit $\pi_{l}$ by setting own contribution $v_{l}=\left(v_{i}\right)_{i \in K \cup M}$. Investment of players $k \in K$ of own group $K$ is labelled $\sum_{k \in K} v_{k}$, while players $m \in M$ in the other disjoint group $M$ invest $\sum_{m \in M} v_{m}$. Individual prize for winning a round is $z$. Solve individual optimisation problem for any period $t$, time indices are omitted.

$$
\pi_{l}\left(\left(v_{i}\right)_{i \in K \cup M}\right)=\frac{v_{l}+\sum_{k \in K \backslash\{l\}} v_{k}}{v_{l}+\sum_{k \in K \backslash\{l\}} v_{k}+\sum_{m \in M} v_{m}} \cdot z-v_{l}
$$

Deriving with respect to $v_{l}$ delivers the best response function for any player $l$ of group $K$ :

$$
\frac{\partial \pi_{l}\left(\left(v_{i}\right)_{i \in K \cup M}\right)}{\partial v_{l}}=0 \quad \Leftrightarrow \quad v_{l}=\sqrt{\sum_{m \in M} v_{m} \cdot z}-\sum_{m \in M} v_{m}-\sum_{k \in K \backslash\{l\}} v_{k}
$$

Checking the second order condition confirms that we find a maximum:

$$
\frac{\partial^{2} \pi_{l}}{\partial v_{l}^{2}}=\frac{-2 \sum_{m \in M} v_{m} \cdot z}{\left(\sum_{k \in K} v_{k}+\sum_{m \in M} v_{m}\right)^{3}}<0
$$

Using the first order condition of group $M$, we find a multiplicity of equilibria, characterised by $\sum_{m \in M} v_{m}=\frac{z}{4}$ and $\sum_{k \in K} v_{k}=\frac{z}{4}$. If we assume symmetry in own group: 
$v_{l}=\frac{z}{16}$.

\section{Appendix 4.E Risk Aversion}

In this analysis we use techniques presented in Abbink et al. (2010); Katz et al. (1990). Let every agent maximise her individual concave utility function $u(\cdot)$, being identical for all players. For brevity, let $X=\sum_{k \in K} v_{k}$ and $Y=\sum_{m \in M} v_{m}$.

$$
\frac{X}{X+Y} u\left(z+E-v_{i}\right)+\frac{Y}{X+Y} u\left(E-v_{i}\right)
$$

As before, $z$ is the individual prize to win, $E$ is the individual endowment and $v_{i}$ is a player's own contribution. Differentiating (4.E.1) with respect to $v_{i}$ and setting equal to zero:

$$
\frac{Y}{X+Y}\left(u\left(z+E-v_{i}\right)-u\left(E-v_{i}\right)\right)=X u^{\prime}\left(z+E-v_{i}\right)+Y u^{\prime}\left(E-v_{i}\right)
$$

For symmetric equilibria $X=Y$, so

$$
\frac{u\left(z+E-v_{i}\right)-u\left(E-v_{i}\right)}{u^{\prime}\left(z+E-v_{i}\right)+u^{\prime}\left(E-v_{i}\right)}=2 X
$$

CARA Under constant absolute risk aversion (i.e. exponential utility), let $u\left(\pi_{i}\right)=$ $-e^{-\alpha \pi_{i}}$, with $\alpha$ being the measure of risk aversion. Set in to (4.E.3):

$$
\frac{-e^{-\alpha\left(z+E-v_{i}\right)}+e^{-\alpha\left(E-v_{i}\right)}}{\alpha e^{-\alpha\left(z+E-v_{i}\right)}+\alpha e^{-\alpha\left(E-v_{i}\right)}}=2 X
$$

We divide both numerator and denominator by $e^{-\alpha\left(E-v_{i}\right)}$ and rearrange:

$$
X=\frac{1}{2 \alpha} \cdot \frac{1-e^{-\alpha z}}{1+e^{-\alpha z}}
$$

As shown in Abbink et al. (2010), $X=\frac{z}{4}$ if $\lim _{\alpha \rightarrow 0}$, which is the risk-neutral equilibrium. Deriving with respect to $\alpha$ delivers the slope of the function:

$$
\frac{\partial X}{\partial \alpha}=\frac{z e^{-\alpha z}\left(2 \alpha+2 \alpha e^{-\alpha z}\right)-\left(1-e^{-\alpha z}\right)\left(2+2 e^{-\alpha z}-2 \alpha z e^{-\alpha z}\right)}{4 \alpha\left(1+e^{\alpha z}\right)^{2}},
$$

which simplifies to:

$$
\frac{\partial X}{\partial \alpha}=\frac{e^{-2 \alpha z}+2 \alpha z e^{-\alpha z}-1}{2 \alpha\left(1+e^{\alpha z}\right)^{2}}
$$

Abbink et al. (2010) show that the slope is negative for all $\alpha>0$ and $z>0$. This means that departing from the risk neutral equilibrium at $\alpha=0$ towards a higher level of risk aversion, equilibrium group contribution decreases. To illustrate, Figure 4.9 depicts equilibrium group contributions for specific $\alpha$-values and $z=480$. 


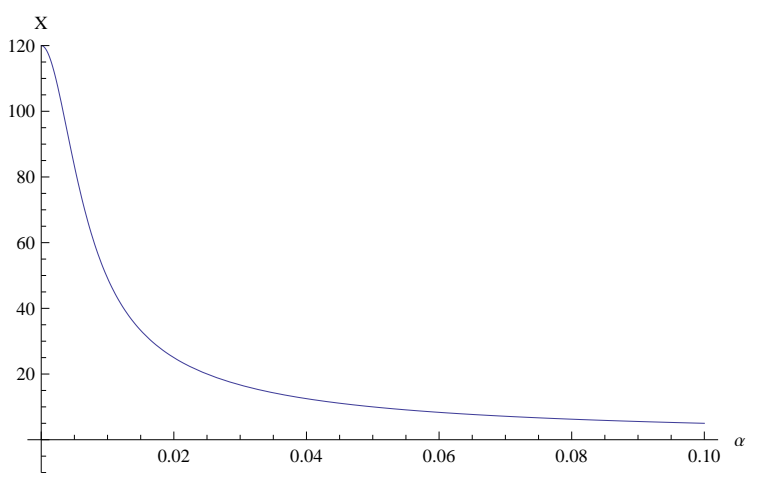

Figure 4.9: Equilibrium Contributions per contest group under CARA

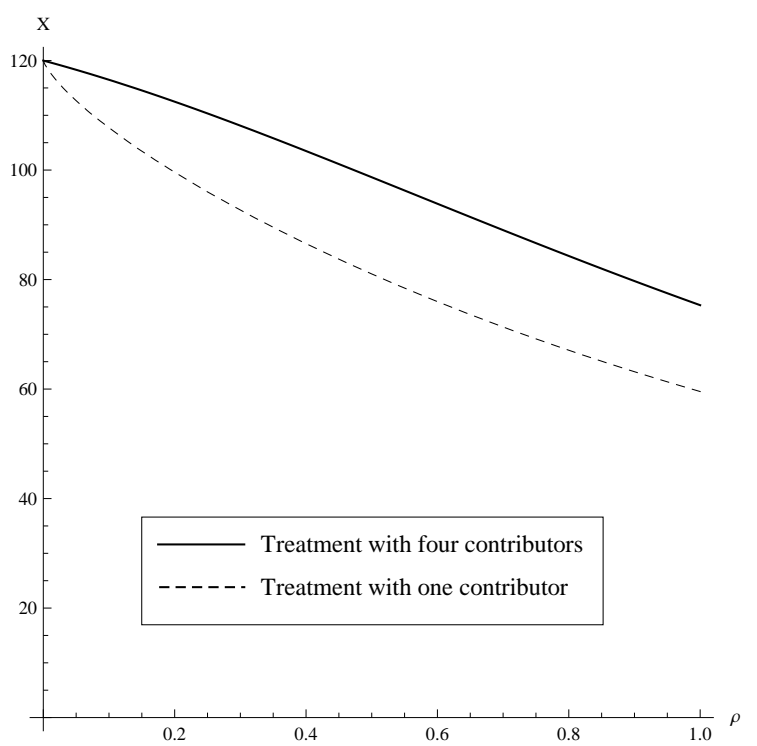

Figure 4.10: Equilibrium Contributions per contest group under CRRA

CRRA We consider constant relative risk aversion, specified as $u\left(\pi_{i}\right)=\frac{\pi^{1-\rho}}{1-\rho}$, with $\rho$ being the risk parameter. Set in to (4.E.3):

$$
\frac{1}{1-\rho} \cdot \frac{\left(z+E-v_{i}\right)^{1-\rho}-\left(E-v_{i}\right)^{1-\rho}}{\left(z+E-v_{i}\right)^{-\rho}-\left(E-v_{i}\right)^{-\rho}}=2 X
$$

Consider Figure 4.10 to see that contribution for the contest decreases with risk aversion, under the assumption of symmetric behaviour $\left(v_{i}=\frac{X}{4}\right)$ and the parameters of the game $(z=480, E=120)$. Treatments with three contributors behave fairly similar to groups of four contributors. 


\section{Appendix 4.F Regression Tables}

(6)

Follower Contribute

VARIABLES

\begin{tabular}{lc}
\hline Leader contribute & $0.536^{* * *}$ \\
& $(0.04)$ \\
Slope Ingroup trans & 0.015 \\
& $(0.05)$ \\
Slope Intergroup lbe & -0.058 \\
& $(0.05)$ \\
Slope Intergroup & 0.005 \\
trans & $(0.05)$ \\
Intercept Ingroup & -3.842 \\
trans & $(5.32)$ \\
Intercept Intergroup & $-9.935^{* *}$ \\
lbe & $(4.59)$ \\
Intercept Intergroup & 1.324 \\
trans & $(4.63)$ \\
Constant & $40.577^{* * *}$ \\
& $(3.45)$ \\
\hline $\mathrm{N}$ & 1052 \\
$\mathrm{R}$-squared & 0.492 \\
\hline p $<0.10, * * \mathrm{p}<0.05, * * * \mathrm{p}<0.01$ \\
Standard errors in parentheses.
\end{tabular}

Standard errors in parentheses.

Table 4.6: Comparing Slopes and Intercepts 
(7)

Follower Contribute

VARIABLES

\begin{tabular}{|c|c|}
\hline Low contribution & $\begin{array}{c}-18.105^{* * *} \\
(5.69)\end{array}$ \\
\hline $\begin{array}{l}\text { Low contribution } \mathrm{x} \\
\text { trans }\end{array}$ & $\begin{array}{c}-23.631^{* *} \\
(9.59)\end{array}$ \\
\hline Medium contribution & $\begin{array}{c}2.239 \\
(8.30)\end{array}$ \\
\hline $\begin{array}{l}\text { Medium contribution } \\
\mathrm{x} \text { trans }\end{array}$ & $\begin{array}{l}-1.368 \\
(17.74)\end{array}$ \\
\hline High contribution & $\begin{array}{l}34.103^{* * *} \\
(9.77)\end{array}$ \\
\hline $\begin{array}{l}\text { High contribution } \mathrm{x} \\
\text { trans }\end{array}$ & $\begin{array}{l}-2.023 \\
(14.66)\end{array}$ \\
\hline Alternate & $\begin{array}{l}-5.340 \\
(20.21)\end{array}$ \\
\hline Alternate $\mathrm{x}$ trans & $\begin{array}{c}-20.431 \\
(22.96)\end{array}$ \\
\hline Bonding & $\begin{array}{l}22.680^{\text {*** }} \\
(5.77)\end{array}$ \\
\hline Bonding $\mathrm{x}$ trans & $\begin{array}{c}-18.952^{* * *} \\
(7.29)\end{array}$ \\
\hline Small talk & $\begin{array}{l}30.178^{* *} \\
(12.58)\end{array}$ \\
\hline Small talk $\mathrm{x}$ trans & $\begin{array}{c}-22.396 \\
(14.34)\end{array}$ \\
\hline Understanding & $\begin{array}{l}-0.170 \\
(20.52)\end{array}$ \\
\hline $\begin{array}{l}\text { Understanding } \mathrm{x} \\
\text { trans }\end{array}$ & $\begin{array}{r}30.727 \\
(26.45)\end{array}$ \\
\hline Efficiency & $\begin{array}{c}-2.215 \\
(7.45)\end{array}$ \\
\hline Efficiency $\mathrm{x}$ trans & $\begin{array}{l}-2.225 \\
(11.23)\end{array}$ \\
\hline Followers' behaviour & $\begin{array}{c}10.773 \\
(7.91)\end{array}$ \\
\hline $\begin{array}{l}\text { Followers' behaviour } \\
\mathrm{x} \text { trans }\end{array}$ & $\begin{array}{r}6.185 \\
(11.13)\end{array}$ \\
\hline $\begin{array}{l}\text { Give much to } \\
\text { followers }\end{array}$ & $\begin{array}{l}58.243^{* *} \\
(29.13)\end{array}$ \\
\hline $\begin{array}{l}\text { Give little to } \\
\text { followers }\end{array}$ & $\begin{array}{c}-28.053^{* *} \\
(13.75)\end{array}$ \\
\hline Other & $\begin{array}{c}6.253 \\
(7.93)\end{array}$ \\
\hline Other $\mathrm{x}$ trans & $\begin{array}{r}-3.337 \\
(9.01)\end{array}$ \\
\hline $\begin{array}{l}\text { Contribution } \\
\text { previous period }\end{array}$ & $\begin{array}{l}0.452^{* * *} \\
(0.12)\end{array}$ \\
\hline $\begin{array}{l}\text { Contribution prev. } \\
\text { period } \mathrm{x} \text { trans }\end{array}$ & $\begin{array}{r}0.177 \\
(0.16)\end{array}$ \\
\hline $\begin{array}{l}\text { Group won previous } \\
\text { period }\end{array}$ & $\begin{array}{r}-7.141 \\
(9.75)\end{array}$ \\
\hline $\begin{array}{l}\text { Group won previous } \\
\text { period } \mathrm{x} \text { trans }\end{array}$ & $\begin{array}{c}-49.368^{\text {*** }} \\
(14.50)\end{array}$ \\
\hline Transactional Leader & $\begin{array}{l}44.590^{* *} \\
(18.18)\end{array}$ \\
\hline Constant & $\begin{array}{l}34.847^{* * *} \\
(12.38)\end{array}$ \\
\hline $\mathrm{N}$ & 476 \\
\hline Pseudo R-squared & 0.073 \\
\hline
\end{tabular}

Table 4.7: Analysis of Chat Contents using Interaction Terms 


\section{Chapter 5}

\section{Conclusion}

In this dissertation I examine group contests for both endogenous and exogenous public goods. Three studies jointly illustrate that participants accede to a pernicious one-upping in order to outdo the competing party. This tendency to over-contribute in (group) contest games complements earlier studies (Sheremeta, 2015; Dechenaux et al., 2012). Taking extant contributions in that field into account I investigate the role of fundamental institutions, which have been characterised as vehicles to promote cooperation towards a more efficient strategy in cooperative games (Williamson, 1985; Ostrom, 1990; Sefton et al., 2007; Fehr and Gächter, 2000). The results of my studies, however, paint a grim picture of the role of these simple institutions - such as rewarding and punishment, free form text communication or wealth redistribution - in group contest games. Unequivocally, players use them to push groupmates to intensify the between-group contest and add insult to injury.

Does this mean that the results of my research substantiate a critical view on the role of institutions in society? Evidently, the tenet of the beneficial character of efficient institutions is deeply rooted in our understanding of a well functioning society (Hobbes, 1651; Locke, 1698). Yet, my results show that instead of steering a group towards efficiency in a deus ex machina fashion, institutions help groups coordinate towards what its members come to perceive as desirable. In point of fact, human history knows plenty of examples for efficiently designed institutions which have propelled an objectionable cause.

Obviously, my results do not shatter the axiom that institutions help overcome coordination problems. Irrespective of its efficiency implications, given that groups carry the desire to raise the spending level in my studies, its members successfully utilise the channels which are at their disposal to achieve this target. Hence, institutions rather influence people to cooperate toward some goal which they come to find desirable. The crucial point of the matter is what determines the group's goal.

In the past chapters I have presented test results and discussions of some of the most prominent hypotheses on the underlying group dynamics in contests for public goods. In Chapter 2 we model a tendering market for a cooperative project to study the role of sunk costs for individual cooperativeness in a public goods game. To this end, there are two types of sunk costs - deliberately accrued expenses and exogenously imposed deductions. Players in the competition treatment enter a group contest for access to a more attractive cooperative project. In the exogenous treatment, by contrast, this decision is superimposed 
onto the participants, such that they do not cast this decision themselves. Although these are mathematically identical, there is some heterogeneity in how participants are influenced by these types of sunk costs. Except for losing teams in the latter treatment, there exists a positive relationship between expenses for the tender and contribution to the cooperative project. In this special case, it is the relatively more wealthy subjects who chip in more resources to the public good.

Furthermore, there exists a detrimental effect for participants' willingness to cooperate in the competition treatment when their team hast lost. As this is not met by a similar markup for the winning groups, we argue that the establishment of a tender for (public) procurement purposes does not convey a signal for their willingness to cooperate. This result casts doubt on whether the institution of a contest for procurement can live up to alternative forms of appropriation.

In Chapter 3 we investigate a team contest for a group prize. Furthermore, we establish two economic environments: One in which two groups compete for a public good and one in which groups face an equilibrium playing mechanism to secure the public good. This way we can isolate the effect of being in a competition with another group. We observe that - while to a different degree - in both environments, players use the institution of reciprocating teammates' actions by the means of rewarding and/or punishing to influence them to chip in additional resources. To this end, we find rewarding to be more successful in spurring a higher contribution level onto other teammates, detrimental efficiency implications abound.

Chapter 4 constitutes the first (experimental) study of its kind, examining different types of leadership in a team contest. We investigate whether the institution of a central authority can help the group coordinate towards de-escalation or if leaders instigate a more aggressive approach.

Our results confirm the latter hypothesis: Most leaders incentivise their followers for spending resources to the contest, which causes an escalation of the two-party competition. While free form text communication between competing leaders can lead to some degree of mitigation, its effect for overall social welfare remain meagre. On a more optimistic note, by using the chat function, some leaders coordinate on taking turns to spend resources, which pans out to be successful at establishing a more efficient play. 


\section{Bibliography}

K. Abbink, J. Brandts, B. Herrmann, and H. Orzen. Intergroup conflict and intra-group punishment in an experimental contest game. American Economic Review, 100(1):420$447,2010$.

G. W. Allport. The Nature of Prejudice. Addison-Wesley, Reading, MA, 1954.

C. Alós-Ferrer and A. B. Ania. Local equilibria in economic games. Economics Letters, 70(2):165 - 173, 2001. ISSN 0165-1765. doi: http://dx.doi.org/10.1016/ S0165-1765(00)00371-2. URL http://www.sciencedirect.com/science/article/

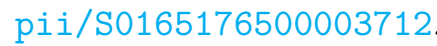

E. Amann and C.-L. Yang. Sophistication and the persistence of cooperation. Journal of Economic Behavior \& Organization, 37(1):91 - 105, 1998. ISSN 0167-2681. doi: http://dx.doi.org/10.1016/S0167-2681(98)00078-X. URL http://www. sciencedirect. $\mathrm{com} / \mathrm{science/article/pii/S016726819800078X.}$

J. Andreoni, W. Harbaugh, and L. Vesterlund. The carrot or the stick: Rewards, punishments, and cooperation. American Economic Review, 93(3):893-902, 2003. doi: 10.1257/000282803322157142. URL http://www. aeaweb.org/articles.php?doi=10. $1257 / 000282803322157142$.

J. D. Angrist and J.-S. Pischke. Mostly harmless econometrics an empiricist's companion. Princeton University Press, Princeton, NJ [etc.], 2009.

E. Arbak and M.-C. Villeval. Voluntary leadership: motivation and influence. Social Choice and Welfare, 40(3):635-662, 2013. ISSN 0176-1714. doi: 10.1007/s00355-011-0626-2. URL http://dx.doi.org/10.1007/s00355-011-0626-2.

H. R. Arkes and C. Blumer. The psychology of sunk cost. Organizational Behavior and Human Decision Processes, 35(1):124 - 140, 1985. ISSN 0749-5978. doi: http: //dx.doi.org/10.1016/0749-5978(85)90049-4. URL http://www.sciencedirect.com/ science/article/pii/0749597885900494.

R. Ashley, S. Ball, and C. Eckel. Motives for giving: A reanalysis of two classic public goods experiments. Southern Economic Journal, 77(1):15-26, 2010.

D. Balliet, L. B. Mulder, and P. A. M. Van Lange. Reward, punishment, and cooperation: A meta-analysis. Psychological Bulletin, 137(4):594 - 615, 2011. ISSN 00332909. URL http://search.ebscohost.com/login.aspx?direct=true\&db=pdh\&AN= 2011-09704-001\&site=ehost-live\&scope=site.

B. Bass. Leadership and Performance Beyond Expectations. Free Press, 1985. ISBN 9780029018101. URL http://books.google.nl/books?id=NCd-QgAACAAJ. 
M. R. Baye and H. C. Hoppe. The strategic equivalence of rent-seeking, innovation, and patent-race games. Games and Economic Behavior, 44(2):217 - 226, 2003. ISSN 0899-8256. doi: http://dx.doi.org/10.1016/S0899-8256(03)00027-7. URL http://www. sciencedirect.com/science/article/pii/S0899825603000277.

Y. Benjamini and Y. Hochberg. Controlling the false discovery rate: a practical and powerful approach to multiple testing. Journal of the Royal Statistical Society. Series B (Methodological), pages 289-300, 1995.

G. E. Bolton and A. Ockenfels. ERC: A theory of equity, reciprocity, and competition. The American Economic Review, 90(1):pp. 166-193, 2000. ISSN 00028282. URL http: //www.jstor.org/stable/117286.

G. Bornstein and M. Ben-Yossef. Cooperation in intergroup and single-group social dilemmas. Journal of Experimental Social Psychology, 30(1):52 - 67, 1994. ISSN 0022-1031. doi: http://dx.doi.org/10.1006/jesp.1994.1003. URL http://www. sciencedirect.com/ science/article/pii/S0022103184710031.

G. Bornstein and U. Gneezy. Price competition between teams. Experimental Economics, 5(1):29-38, 2002. ISSN 1386-4157. doi: 10.1023/A:1016312624038. URL http://dx. doi.org/10.1023/A\%3A1016312624038.

G. Bornstein, T. Kugler, D. V. Budescu, and R. Selten. Repeated price competition between individuals and between teams. Journal of Economic Behavior 83 Organization, 66(3 4):808 - 821, 2008. ISSN 0167-2681. doi: http://dx.doi.org/10.1016/j.jebo.2006.06.004. URL http://www.sciencedirect.com/science/article/pii/S0167268107000042.

S. Bowles. Did warfare among ancestral hunter-gatherers affect the evolution of human social behaviors? Science, 324(5932):1293-1298, 2009.

J. Brandts, A. Riedl, and F. van Winden. Competitive rivalry, social disposition, and subjective well-being: An experiment. Journal of Public Economics, 93(11 - 12):1158 1167, 2009. ISSN 0047-2727. doi: http://dx.doi.org/10.1016/j.jpubeco.2009.07.010. URL http://www.sciencedirect.com/science/article/pii/S0047272709000917.

M. B. Brewer. The role of ethnocentrism in intergroup conflict. In W. G. Austin and S. Worchel, editors, The social psychology of intergroup relations, volume 2. Nelson-Hall Chicago, 1979.

J. M. Burns. Leadership. Harper \& Row, New York, 1978.

R. L. Calvert. Leadership and its basis in problems of social coordination. International Political Science Review / Revue internationale de science politique, 13(1):pp. 7-24, 1992. ISSN 01925121. URL http://www.jstor.org/stable/1601435.

V. Capraro. A model of human cooperation in social dilemmas. PLoS ONE, 8(8):16, 08 2013. doi: 10.1371/journal.pone.0072427. URL http://dx.doi.org/10.1371\% 2Fjournal. pone.0072427.

T. N. Cason, R. M. Sheremeta, and J. Zhang. Communication and efficiency in competitive coordination games. Games and Economic Behavior, 76(1):26 - 43, 2012. ISSN 0899-8256. doi: http://dx.doi.org/10.1016/j.geb.2012.05.001. URL http://www.sciencedirect. $\mathrm{com} / \mathrm{science/article/pii/S0899825612000747.}$ 
J.-K. Choi and S. Bowles. The coevolution of parochial altruism and war. Science, 318(5850):636-640, 2007. ISSN 0036-8075. doi: 10.1126/science.1144237. URL http: //science.sciencemag.org/content/318/5850/636.

W. Conover. Practical nonparametric statistics, 3rd edn wiley. New York: Wiley, 1999.

D. J. Cooper, C. A. Ioannou, and S. Qi. Coordination with endogenous contracts: Incentives, selection, and strategic anticipation. Working Paper, 2015. URL http://myweb.fsu. edu/djcooper/research/selectionandcoordination.pdf. Online; accessed May 31, 2016.

P. Crosetto, O. Weisel, and F. Winter. A flexible z-tree implementation of the social value orientation slider measure (murphy et al. 2011): Manual. Technical report, Jena Economic Research Papers, 2012.

J. Cuzick. A wilcoxon-type test for trend. Statistics in medicine, 4(4):543-547, 1985.

C. Dave, C. Eckel, C. Johnson, and C. Rojas. Eliciting risk preferences: When is simple better? Journal of Risk and Uncertainty, 41(3):219-243, 2010. ISSN 0895-5646. doi: 10.1007/s11166-010-9103-z. URL http://dx.doi.org/10.1007/s11166-010-9103-z.

R. M. Dawes. Social dilemmas. Annual Review of Psychology, 31(1):169-193, 1980. doi: 10. 1146/annurev.ps.31.020180.001125. URL http://www. annualreviews.org/doi/abs/ 10.1146/annurev.ps.31.020180.001125.

D. De Cremer and M. Van Vugt. Intergroup and intragroup aspects of leadership in social dilemmas: A relational model of cooperation. Journal of Experimental Social Psychology, 38(2):126 - 136, 2002. ISSN 0022-1031. doi: 10.1006/jesp.2001.1499. URL http://www. sciencedirect.com/science/article/pii/S0022103101914994.

E. Dechenaux, D. Kovenock, and R. Sheremeta. A survey of experimental research on contests, all-pay auctions and tournaments. All-Pay Auctions and Tournaments (September 28, 2012), 2012.

T. J. Dohmen, A. Falk, D. Huffman, U. Sunde, J. Schupp, and G. G. Wagner. Individual risk attitudes: New evidence from a large, representative, experimentally-validated survey. IZA discussion paper, 2005.

W. Doise. L'articulation psychosociologique et les relations entre groupes. Ed. A. de Boeck, 1976.

O. J. Dunn. Multiple comparisons using rank sums. Technometrics, 6(3):241-252, 1964.

W. D. Dupont and W. D. Plummer. Density distribution sunflower plots. Journal of Statistical Software, 8(3):1-5, 2003.

C. C. Eckel and P. J. Grossman. Sex differences and statistical stereotyping in attitudes toward financial risk. Evolution and Human Behavior, 23(4):281 - 295, 2002. ISSN 1090-5138. doi: http://dx.doi.org/10.1016/S1090-5138(02)00097-1. URL http://www . sciencedirect.com/science/article/pii/s1090513802000971.

A. Egozie. Boeing, Airbus vie to supply replacements for El Al's Boeing 767s, 2015. URL http://www.flightglobal.com/blogs/ariel-view/2015/02/ another-round-fighting-boeing-airbus-el-al-arena/. Online; accessed March 25, 2015 . 
L. Fang. Where have all the lobbyists gone? On paper, the influence-peddling business is drying up. but lobbying money is flooding into Washington, DC, like never before. what's going on? The Nation, 2014. URL http://www.thenation.com/article/178460/ shadow-lobbying-complex. Online; accessed March 18, 2015.

E. Fehr and S. Gächter. Cooperation and punishment in public goods experiments. The American Economic Review, 90(4):980-994, 2000.

E. Fehr and K. M. Schmidt. A theory of fairness, competition, and cooperation. The Quarterly Journal of Economics, 114(3):pp. 817-868, 1999. ISSN 00335533. URL http: //www. jstor.org/stable/2586885.

U. Fischbacher. z-tree: Zurich toolbox for ready-made economic experiments. Experimental Economics, 10(2):171-178, 2007.

M. Fouzder. Legal aid tenders: 'hundreds' of firms will go under. Law Society Gazette, 2015. URL http://www.lawgazette.co.uk/law/ legal-aid-tenders-hundreds-of-firms-will-go-under/5047915.fullarticle. Online; accessed May 31, 2016.

R. H. Frank. If homo economicus could choose his own utility function, would he want one with a conscience? The American Economic Review, 77(4):pp. 593-604, 1987. ISSN 00028282. URL http://www. jstor.org/stable/1814533.

D. Friedman, K. Pommerenke, R. Lukose, G. Milam, and B. Huberman. Searching for the sunk cost fallacy. Experimental Economics, 10(1):79-104, 2007. ISSN 1386-4157. doi: 10.1007/s10683-006-9134-0. URL http://dx.doi.org/10.1007/s10683-006-9134-0.

S. Gächter and B. Herrmann. Reciprocity, culture and human cooperation: previous insights and a new cross-cultural experiment. Philosophical Transactions of the Royal Society B: Biological Sciences, 364(1518):791-806, 2009. doi: 10.1098/rstb.2008.0275. URL http://rstb.royalsocietypublishing.org/content/364/1518/791.abstract.

H. Garland. Throwing good money after bad: The effect of sunk costs on the decision to esculate commitment to an ongoing project. Journal of Applied Psychology, 75(6):728, 1990.

E. L. Glaeser, D. I. Laibson, J. A. Scheinkman, and C. L. Soutter. Measuring trust. The Quarterly Journal of Economics, 115(3):811-846, 2000. ISSN 00335533, 15314650. URL http://www. jstor.org/stable/2586897.

L. Goette, D. Huffman, S. Meier, and M. Sutter. Competition between organizational groups: Its impact on altruistic and antisocial motivations. Management Science, 58(5): 948-960, 2012.

W. H. Greene. Econometric analysis. Pearson, Boston, Mass. [u.a.], 2012.

B. Greiner. The online recruitment system orsee 2.0. A guide for the organization of experiments in economics. University of Cologne, 2004.

A. Gunnthorsdottir, D. Houser, and K. McCabe. Disposition, history and contributions in public goods experiments. Journal of Economic Behavior \& Organization, 62(2):304 - 315, 2007. ISSN 0167-2681. doi: http://dx.doi.org/10.1016/j.jebo.2005.03.008. URL http://www.sciencedirect.com/science/article/pii/S0167268105002532. 
B. E. Hermalin. Toward an economic theory of leadership: Leading by example. The American Economic Review, 88(5):pp. 1188-1206, 1998. ISSN 00028282. URL http: //www.jstor.org/stable/116866.

B. Herrmann and H. Orzen. The appearance of homo rivalis: Social preferences and the nature of rent seeking. CeDEx discussion paper series 2008-10, CeDEx, Nottingham, 2008. URL http://hdl. handle.net/10419/49653.

T. Hobbes. Leviathan; or, the matter, forme and power of a commonwealth, ecclesiasticall and civil. Oxford: Basil Blackwell, 1651.

J. B. V. Huyck, R. C. Battalio, and R. O. Beil. Asset markets as an equilibrium selection mechanism: Coordination failure, game form auctions, and tacit communication. Games and Economic Behavior, 5(3):485 - 504, 1993. ISSN 0899-8256. doi: http://dx.doi.org/10. 1006/game.1993.1026. URL http://www.sciencedirect.com/science/article/pii/ S0899825683710262.

R. Inglehart and Archivo de Estudios Sociales. World values surveys and european values surveys, 1981-1984, 1990-1993, and 1995-1997, 2000.

R. M. Isaac and J. M. Walker. Group size effects in public goods provision: The voluntary contributions mechanism. The Quarterly Journal of Economics, 103(1):pp. 179-199, 1988. ISSN 00335533. URL http://www.jstor.org/stable/1882648.

D. Kahneman and A. Tversky. Prospect theory: An analysis of decision under risk. Econometrica, 47(2):pp. 263-292, 1979. ISSN 00129682. URL http://www. jstor.org/ stable/1914185.

E. Katz, S. Nitzan, and J. Rosenberg. Rent-seeking for pure public goods. Public Choice, 65(1):49-60, 1990. ISSN 0048-5829. doi: 10.1007/BF00139290. URL http://dx.doi. org/10.1007/BF00139290.

K. A. Konrad. Strategy in contests: an introduction. Technical report, Social Science Research Center Berlin (WZB), 2007a. Discussion Papers, Research Unit: Market Processes and Governance.

K. A. Konrad. Strategy in contests: an introduction. Technical report, Social Science Research Center Berlin (WZB), 2007b. Discussion Papers, Research Unit: Market Processes and Governance.

K. A. Konrad. Strategy and dynamics in contests. Oxford University Press, 2009.

K. A. Konrad and F. Morath. Evolutionarily stable in-group favoritism and out-group spite in intergroup conflict. Journal of Theoretical Biology, 306(0):61-67, 2012.

M. Kosfeld and D. Rustagi. Leader punishment and cooperation in groups: Experimental field evidence from commons management in ethiopia. The American Economic Review, 105(2):747-783, 2015.

W. H. Kruskal and W. A. Wallis. Use of ranks in one-criterion variance analysis. Journal of the American statistical Association, 47(260):583-621, 1952.

W. Leininger. Contests over Public Goods: Evolutionary Stability and the Free-Rider Problem. CESifo, 2002. 
J. Locke. Two Treatises of Government: In the Former, The False Principles, and Foundation of Sir Robert Filmer, and His Followers, Are Detected and Overthrown. The Latter Is an Essay Concerning The True Original, Extent, and End of Civil Government. Awnsham Churchill, 3rd ed edition, 1698.

L. Lu and M. Argyle. Happiness and cooperation. Personality and Individual Differences, 12(10):1019 - 1030, 1991. ISSN 0191-8869. doi: http://dx.doi.org/10.1016/ 0191-8869(91)90032-7. URL http://www. sciencedirect.com/science/article/pii/ 0191886991900327.

H. B. Mann and D. R. Whitney. On a test of whether one of two random variables is stochastically larger than the other. The Annals of Mathematical Statistics, 18(1):50-60, 1947.

J. H. Manson, R. W. Wrangham, J. L. Boone, B. Chapais, R. I. M. Dunbar, C. R. Ember, W. Irons, L. F. Marchant, W. C. McGrew, T. Nishida, J. D. Paterson, E. A. Smith, C. B. Stanford, and C. M. Worthman. Intergroup aggression in chimpanzees and humans [and comments and replies]. Current Anthropology, 32(4):369-390, 1991. ISSN 00113204, 15375382. URL http://www.jstor.org/stable/2743814.

M. M. McDonald, C. D. Navarrete, and M. Van Vugt. Evolution and the psychology of intergroup conflict: the male warrior hypothesis. Philosophical Transactions of the Royal Society of London B: Biological Sciences, 367(1589):670-679, 2012. ISSN 0962-8436. doi: 10.1098/rstb.2011.0301. URL http://rstb.royalsocietypublishing.org/content/ $367 / 1589 / 670$.

C. Meidinger and M.-C. Villeval. Leadership in Teams: Signaling or Reciprocating?, Dec. 2002. URL http://halshs.archives-ouvertes.fr/halshs-00178474. Working Paper du GATE 2002-13.

J. Morgan, H. Orzen, M. Sefton, and D. Sisak. Strategic and natural risk in entrepreneurship: An experimental study. Journal of Economics \& Management Strategy, forthcoming.

E. Moxnes and E. van der Heijden. The effect of leadership in a public bad experiment. The Journal of Conflict Resolution, 47(6):pp. 773-795, 2003. ISSN 00220027. URL http://www.jstor.org/stable/3176260.

R. O. Murphy and K. A. Ackermann. Social value orientation: Theoretical and measurement issues in the study of social preferences. Personality and Social Psychology Review, 18(1): 13-41, 2014. doi: 10.1177/1088868313501745. URL http://psr . sagepub.com/content/ 18/1/13.abstract.

R. O. Murphy, K. A. Ackermann, and M. J. Handgraaf. Measuring social value orientation. Judgment and Decision Making, 6(8):771-781, 2011.

W. K. Newey and K. D. West. A simple, positive semi-definite, heteroskedasticity and autocorrelation consistent covariance matrix. Econometrica, 55(3):703-708, 1987.

D. Nosenzo and F. Tufano. Entry or exit? the effect of voluntary participation on cooperation. CeDEx Discussion Paper Series, 2015. ISSN 1749 - 3293. URL http://www.nottingham.ac.uk/cedex/documents/papers/ cedex-discussion-paper-2015-04.pdf. 
T. Offerman and J. Potters. Does auctioning of entry licences induce collusion? an experimental study. The Review of Economic Studies, 73(3):769-791, 2006.

R. O'Gorman, J. Henrich, and M. Van Vugt. Constraining free riding in public goods games: designated solitary punishers can sustain human cooperation. Proceedings of the Royal Society B: Biological Sciences, 276(1655):323-329, 2009.

A. Öncüler and R. Croson. Rent-seeking for a risky rent: A model and experimental investigation. Journal of Theoretical Politics, 17(4):403-429, 2005. doi: 10.1177/ 0951629805056895. URL http://jtp.sagepub.com/content/17/4/403. abstract.

J. Orbell and R. M. Dawes. A "cognitive miser" theory of cooperators advantage. American Political Science Review, 85:515-528, 6 1991. ISSN 1537-5943. doi: 10.2307/1963172. URL http://journals. cambridge.org/article_S0003055400178700.

J. M. Orbell and R. M. Dawes. Social welfare, cooperators' advantage, and the option of not playing the game. American Sociological Review, 58(6):pp. 787-800, 1993. ISSN 00031224. URL http://www. jstor.org/stable/2095951.

E. Ostrom. Governing the commons: The evolution of institutions for collective action. Cambridge university press, 1990.

T. F. Pettigrew. The ultimate attribution error: Extending allport's cognitive analysis of prejudice. Personality and Social Psychology Bulletin, 5(4):461-476, 1979.

T. L. Pittinsky and S. Simon. Intergroup leadership. The Leadership Quarterly, 18(6):586 - 605, 2007. ISSN 1048-9843. doi: http://dx.doi.org/10.1016/j.leaqua.2007.09.005. URL http://www.sciencedirect.com/science/article/pii/S104898430700121X. The Leadership Quarterly Yearly Review of Leadership.

J. Potters, M. Sefton, and L. Vesterlund. Why announce leadership contributions?: An experimental study of the signaling and reciprocity hypotheses. Tilburg University, 2001.

J. Potters, M. Sefton, and L. Vesterlund. Leading-by-example and signaling in voluntary contribution games: an experimental study. Economic Theory, 33(1):pp. 169-182, 2007. ISSN 09382259. URL http://www.jstor.org/stable/27822588.

D. G. Rand, A. Dreber, T. Ellingsen, D. Fudenberg, and M. A. Nowak. Positive interactions promote public cooperation. Science, 325(5945):1272-1275, 2009.

E. Reuben and A. Riedl. Enforcement of contribution norms in public good games with heterogeneous populations. Games and Economic Behavior, 77(1):122 - 137, 2013. ISSN 0899-8256. doi: http://dx.doi.org/10.1016/j.geb.2012.10.001. URL http://www. sciencedirect.com/science/article/pii/S0899825612001492.

D. Rondeau and J. A. List. Matching and challenge gifts to charity: evidence fromÂălaboratory and natural field experiments. Experimental Economics, 11(3):253-267, 2008. ISSN 1386-4157. doi: 10.1007/s10683-007-9190-0. URL http://dx.doi.org/10.1007/ s10683-007-9190-0.

T. Sasaki, R. Brännström, U. Dieckmann, and K. Sigmund. The take-it-or-leave-it option allows small penalties to overcome social dilemmas. Proceedings of the National Academy of Sciences, 109(4):1165-1169, 2012. 
M. Sefton, R. Shupp, and J. M. Walker. The effect of rewards and sanctions in provision of public goods. Economic Inquiry, 45(4):671-690, 2007.

J. Sell and K. J. Kuipers. A structural social psychological view of gender differences in cooperation. Sex Roles, 61(5):317-324, 2009. ISSN 1573-2762. doi: 10.1007/s11199-009-9597-5. URL http://dx.doi.org/10.1007/s11199-009-9597-5.

R. M. Sheremeta. Overbidding and heterogeneous behavior in contest experiments. Journal of Economic Surveys, 27(3):491-514, 2013. ISSN 1467-6419. doi: 10.1111/joes.12022. URL http://dx.doi.org/10.1111/joes.12022.

R. M. Sheremeta. Behavior in Group Contests: A Review of Experimental Research. Working Papers 15-21, Chapman University, Economic Science Institute, 2015. URL https://ideas.repec.org/p/chu/wpaper/15-21.html.

M. Sherif. Intergroup conflict and cooperation the Robbers cave experiment, volume Rev. ed. University Book Exchange, Norman, OK, 1961.

K. Sigmund, C. Hauert, and M. A. Nowak. Reward and punishment. Proceedings of the National Academy of Sciences, 98(19):10757-10762, 2001.

P. Slovic. Smoking: Risk, perception, and policy. Sage Publications, 2001.

A. Smith, D. D. Raphael, and A. L. Macfie. The Theory of Moral Sentiments, volume 1. Clarendon Press, Oxford [etc.], 1976. ISBN 9780198281894, 0198281897.

J. Sonnemans, F. van Dijk, and F. van Winden. On the dynamics of social ties structures in groups. Journal of Economic Psychology, 27(2):187 - 204, 2006. ISSN 0167-4870. doi: http://dx.doi.org/10.1016/j.joep.2005.08.004. URL http://www. sciencedirect.com/ science/article/pii/S0167487005000899.

C. Spearman. The proof and measurement of association between two things. The American journal of psychology, 15(1):72-101, 1904.

B. M. Staw. The escalation of commitment to a course of action. Academy of Management Review, 6(4):577-587, 1981. doi: 10.5465/AMR.1981.4285694. URL http://amr.aom. org/content/6/4/577. abstract.

W. G. Stephan. Intergroup relations. In L. Gardner and A. Elliot, editors, Handbook of social psychology. New York : Random House, 3rd ed edition, 1985.

J. H. Stock and M. W. Watson. Introduction to econometrics, volume 3rd ed., global ed. of The Pearson series in economics. Pearson Education, Boston, MA [etc.], 2012.

J. Stockard, A. J. C. van de Kragt, and P. J. Dodge. Gender roles and behavior in social dilemmas: Are there sex differences in cooperation and in its justification? Social Psychology Quarterly, 51(2):154-163, 1988. ISSN 01902725. URL http://www. jstor. org/stable/2786837.

S. T. Stub. Boeing, Airbus in dogfight over El Al. The Wall Street Journal, 2012. URL http: //www.wsj.com/articles/SB10001424052702303665904577452612947594688. Online; accessed March 25, 2015. 
M. Sutter and C. Strassmair. Communication, cooperation and collusion in team tournaments - an experimental study. Games and Economic Behavior, 66(1):506 525, 2009. ISSN 0899-8256. doi: http://dx.doi.org/10.1016/j.geb.2008.02.014. URL http://www.sciencedirect.com/science/article/pii/S089982560800081X.

H. Tajfel and J. C. Turner. An integrative theory of intergroup conflict. The social psychology of intergroup relations, 33(47):74, 1979.

H. Tajfel, M. G. Billig, R. P. Bundy, and C. Flament. Social categorization and intergroup behaviour. European Journal of Social Psychology, 1(2):149-178, 1971. ISSN 1099-0992. doi: 10.1002/ejsp.2420010202. URL http://dx.doi.org/10.1002/ejsp. 2420010202.

H. E. Tajfel. Differentiation between social groups: Studies in the social psychology of intergroup relations. Academic Press, 1978.

J. H. Tan and F. Bolle. Team competition and the public goods game. Economics Letters, 96(1):133 - 139, 2007. ISSN 0165-1765. doi: 10.1016/j.econlet.2006.12.031. URL http://www.sciencedirect.com/science/article/pii/s0165176506004447.

J. A. Thurber. Corruption and scandal in washington: Have lobbying and ethics reform made a difference? In Conference on Political Corruption in America at Loyola Marymount University's Institute for Leadership Studies, page 7, 2009.

J. A. Thurber. The contemporary presidency: Changing the way washington works? assessing president obama's battle with lobbyists. Presidential Studies Quarterly, 41 (2):358-374, 2011. ISSN 1741-5705. doi: 10.1111/j.1741-5705.2011.03858.x. URL http: //dx.doi.org/10.1111/j.1741-5705.2011.03858.x.

J. Tooby and L. Cosmides. The evolution of war and its cognitive foundations. Institute for evolutionary studies technical report, 88(1):1-15, 1988.

G. Tullock. Efficient rent seeking. In J. Buchanan, R. Tollison, and G. Tullock, editors, Toward a Theory of the Rent-Seeking Society, pages 97 - 112. Texas A \& M University Press, 1980.

E. van der Heijden, J. Potters, and M. Sefton. Hierarchy and opportunism in teams. Journal of Economic Behavior \& Organization, 69(1):39 - 50, 2009. ISSN 0167-2681. doi: 10.1016/j.jebo.2008.09.007. URL http://www.sciencedirect.com/science/article/ pii/S0167268108001844.

P. A. Van Lange, E. De Bruin, W. Otten, and J. A. Joireman. Development of prosocial, individualistic, and competitive orientations: theory and preliminary evidence. Journal of personality and social psychology, 73(4):733, 1997.

L. Vesterlund, L. Babcock, and L. Weingart. Breaking the glass ceiling with "no": Gender differences in declining requests for non-promotable tasks. Unpublished manuscript, Carnegie Mellon University, 2014.

M. V. Vugt, D. D. Cremer, and D. P. Janssen. Gender differences in cooperation and competition: The male-warrior hypothesis. Psychological Science, 18(1):19-23, 2007. doi: 10.1111/j.1467-9280.2007.01842.x. URL http://pss . sagepub.com/content/18/1/19. abstract. 
J. Vyrastekova and D. van Soest. Centralized common-pool management and local community participation. Land Economics, 79(4):pp. 500-514, 2003. ISSN 00237639. URL http://www. jstor.org/stable/3147296.

G. Whyte. Escalating commitment in individual and group decision making: A prospect theory approach. Organizational Behavior and Human Decision Processes, 54(3):430 - 455, 1993. ISSN 0749-5978. doi: http://dx.doi.org/10.1006/obhd.1993.1018. URL http://www.sciencedirect.com/science/article/pii/S0749597883710186.

F. Wilcoxon. Individual comparisons by ranking methods. Biometrics Bulletin, 1(6):pp. 80-83, 1945. ISSN 00994987. URL http://www.jstor.org/stable/3001968.

O. E. Williamson. The economic institutions of capitalism. Free Press, 1985. 


\section{Valorization}

In the Valorization Addendum I discuss the societal and economic opportunities which can be derived from the implications of my research. This is in accordance with Article 23 of the "Regulation governing the attainment of doctoral degrees" at Maastricht University. Knowledge valorization refers to the "process of creating value from knowledge, by making knowledge suitable and / or available for social (and / or economic) use and by making knowledge suitable for translation into competitive products, services, processes and new commercial activities" (adapted definition based on the National Valorization Committee 2011:8). This Chaper is structured as follows: First I discuss what valorization means for research in general and how this concept has guided my approach towards this study. In the following three sections I describe the societal and economic implications which directly relate to the respective chapter. In the final section I will bring together the threads and provide some outlook for future research.

\section{General}

In my understanding of knowledge valorization, the term is akin to 'innovation'. Innovation is crucial to the continuing success of any organisation in the broadest sense - from small and medium sized enterprises to whole economies. Innovation means converting inventions to reality by applying them to a product or process. An invention alone is not considered an innovation; the invention has to be used (or at least be usable) in practice.

In this dissertation I use experiments to understand if and how simple institutions which we use every day - help groups coordinate in a competitive environment. The broader implications of my results can be applied to discussions surrounding political interference of lobby groups and detrimental dynamics in socio-political conflicts. Of course, policy recommendations based on my results (and to some extend the results themselves) should be taken with some caution, keeping in mind that they have been generated from moderate sized student samples in a laboratory setting. There is a certain degree of ambiguity as to whether the interventions in this kind of experiments can be generalised.

\section{Chapter 2}

In Chapter 2 we study individual willingness to cooperate in a public good game after an initial team contest phase in an experimental study. While subjects in the treatment 
setup make a conscious decision on how much to invest in the contest, this decision is exogenously imposed on subjects in the control setup. As such, both groups of subjects incur sunk costs and enter the public good game with different wealth levels. Our results indicate that the way these sunk costs have been accrued matters especially for groups on the losing side of the contest: Given the same level of sunk costs, contributions to the public good are lower for groups which failed to be successful in the preceding between-group contest. Furthermore, this detrimental effect is more pronounced for subjects playing a contest with deliberate contributions before.

Insights from this chapter can be of interest for the design of tendering processes for commercial covenants. Especially if both candidates dispose of comparable productivity levels, the harm to the losing party is not met by an analogous positive burst of the winning party. From an overall social welfare perspective, devising a method of arbitration which avoids a between group contest would be favourable.

\section{Chapter 3}

In Chapter 3 we set up an experimental study to analyse behaviour in a team contest when allowing to punish or to reward other group members. A team contest entails both public good characteristics within the teams as well as a contest across teams. Moreover, we compare two types of contest environment: One in which two groups compete for a prize and another one in which we switch off the between-group element of the team contest. Unlike what experimental studies in isolated public goods games indicate, we find that reward giving, as opposed to punishing, induces higher contributions to the group project. Furthermore, expenditures on rewarding other co-players are significantly higher than those for punishing. This is particularly pronounced for the between-group contest.

The primary application of this study is twofold: First, there is scope for operationalisation in the context of socio-economic conflict or between-country struggles for a natural resource. Second, in a corporate context, commercial tenders are of widespread use for the procurement of public projects, like major or medium-sized construction ventures. In fact, public procurement represents more than $10 \%$ of EU GDP as of 2007 (source: Bovis, Christopher H. (2007). EU Public Procurement Law. Elgar European Law Series. Edward Elgar Publishing. ISBN 978-1-84720-947-4). Given the starkly contrasting nature of these two fields of application, policy recommendations, based on insights gained in this chapter, would fundamentally differ with respect to which goal is considered achievable. While in the former scenario, a de-escalation of conflict expenditures would be desirable, firms in the latter scenario might wish to increase engagement into the procurement tender.

\section{Chapter 4}

In Chapter 4 we present an experiment designed to examine whether the existence of a leader can curtail over-contribution and improve group welfare in a team contest. Furthermore, we compare different levels of leader authority and the effect of communication between leaders of competing groups with respect to conflict potential and social welfare. Our results indicate that contest expenditures in treatments with a leader are higher, unless 
there is communication. Moreover, leaders with authority fan the flames of between group competition by allocating a relatively larger share of the prize to subjects that have delivered more input to the competition. When allowing for communication between leaders of competing groups, those who manage to agree on taking turns for delivering input to the contest, exert a mitigating effect on spending levels.

Valorization opportunities of this study relate closely to the applications outlined in the previous section. The hierarchical nature of the group setup in this experiment has potential for a closer resemblance to group structures which are characterised by having a superordinate leader. Examples for this are most businesses, political parties or sports teams. In a competitive scenario, a proper understanding of the role of managers in a firm or commanders in a military platoon, can be of utmost importance for a smooth functioning of the group as a whole.

\section{Conclusion and Outlook}

Competitive situations are ubiquitous in society. From international conflicts for resources to the daily competition for clients, a finite amount of wealth (and attention) has to be allotted between stakeholders. This happens on various layers of society and with different degrees of hostility. Using the controlled environment of laboratory experiments, I investigate the role of fundamental institutions in situations where groups compete for a prize of fixed or endogenous size.

Globally there exists a total military budget of $\$ 1,676$ billion in 2015 (source: Stockholm International Peace Research Institute (SIPRI) Military Expenditure Database), which is equivalent to 2.3 per cent of global gross domestic product (GDP). This enormous sum of money is not spent to care for the older or to educate the younger generation, but in order to be adequately equipped to face outside (or inside) challenges to the national interest. Insights contributing to a better understanding of group dynamics in a competitive environment can serve to reduce this sum and in the process give fiscal room for welfare enhancing public expenditures instead.

In this context, my research has shown that in a competitive environment, groups oftentimes do not use interaction mechanisms to coordinate towards a more efficient outcome. Instead, participants incentivise their teammates to pursue a more aggressive strategy to outdo the opposing group, beyond a financially prudent level of appropriation. This is in contrast with established findings on how interaction mechanisms pan out in cooperative environments. Hence, policy recommendations can substantially differ, depending on the economic environment under consideration. 



\section{Biography}

Florian Andreas Heine was born on 20 July 1986 in Berlin-Friedrichshain, Germany. After graduating from Theodor-Heuss-Gymnasium Pforzheim in 2006 with the degree Abitur, he served in the Special Operations Division (now Rapid Forces Division) of the German Army, from which he was honourably discharged at the end of his service.

In 2007 Florian started studying economics at the University of Mannheim, Germany. From 2009 - 2010 he was a visiting student at the Université catholique de Louvain, Belgium, and graduated with the degree of Bachelor of Science in Economics at the University of Mannheim in 2010. From 2010 - 2012 he completed the Master's programme in Economic and Financial Research at Maastricht University School of Business and Economics.

Florian became a PhD candidate at the Department of Economics, Maastricht University, in 2012. As part of his graduate training he spent several months as a visiting $\mathrm{PhD}$ student at the University of Nottingham School of Economics in 2015. The results of his work as a doctoral student are collected in this dissertation. He has presented his research at various international conferences and seminars, including the Annual conference of GfeW (Gießen, September 2016; Passau, September 2014), TIBER Symposium (Tilburg, August 2016), LEE Research Seminar Series (Prague, March 2016), RES PhD Meeting (London, January 2016), Thurgau Experimental Economics Meeting (Stein am Rhein, April 2014) and Italian Doctoral Workshop in Applied Economics (Turin, December 2013).

Florian will further his academic career as Assistant Professor at the Department of Public Governance, Tilburg School of Economics and Management. 